\title{
THESIS
}

\section{COMPARATIVE ASSESSMENT OF TRANSPORTATION SUSTAINABILITY RATING SYSTEMS}

\author{
Submitted by \\ Oluwatobi Temitope Oluwalaiye \\ Department of Construction Management
}

In partial fulfillment of the requirements

For the Degree of Master of Science

Colorado State University

Fort Collins, Colorado

Fall 2018

Master's Committee:

Advisor: Mehmet E. Ozbek

Svetlana Olbina

Rebecca A. Atadero 
Copyright by Oluwatobi Oluwalaiye 2018

All Rights Reserved 


\begin{abstract}
COMPARATIVE ASSESSMENT OF TRANSPORTATION SUSTAINABILITY RATING SYSTEMS.
\end{abstract}

The construction industry contributes a significant amount of greenhouse gas emissions to the environment. This highlights the need for this industry to implement sustainable practices to mitigate its negative effects. In the transportation sector of the construction industry, several transportation sustainability rating systems (TSRS) have been developed to measure and promote sustainability. However, studies show that these TSRS have not been developed within a consistent "sustainability scope". This raises the question of the consistency of these TSRS in measuring sustainability of transportation projects. This study assessed three prominent TSRS to determine how each measure sustainability with respect to the triple bottom line. The TSRS that are in the scope of this study are: ENVISION - a third-party rating system, INVEST - a self-assessed rating system and, GreenLITES - an in-house developed self-assessed rating system.

The results show that these three rating systems assess and reward sustainability practices differently. Additionally, results suggest that it may be easier for a project to get awarded in GreenLITES compared to the other two TSRS. Notwithstanding all the above, a consistency was noted in all three rating systems in the Quality of Life/Social performance of projects. This study helps inform stakeholders in the transportation industry on how transportation projects perform when run through each of these rating systems. This will help stakeholders make informed decisions with respect to choosing one (or more) TSRS to assess their projects with and evaluating the results obtained from such TSRS. 


\section{ACKNOWLEDGEMENTS}

I owe my profound gratitude, respect, honor, and appreciation to my advisor, Dr. Mehmet E. Ozbek, for being kind, welcoming, cooperative, practical, and supportive. I find myself exceptionally fortunate to have an advisor like him. I thank him for always being there when I needed his guidance and making me utilize my capabilities in the best possible way. His unrelenting effort to see me succeed has brought me this far. He has given me soft landing with basic foundation in the field of research. I will forever appreciate his role in my life's journey. I would also like to thank Dr. Svetlana Olbina and Br. Rebecca Atadero, my committee members, for taking out time to walk with and support me on this journey.

I am exceptionally grateful to Mr. Paul Krekeler of the New York State Department of Transportation for being a good resource and for helping me achieve the purpose of this study. I also want to thank Ms. Connie Hill of the Federal Highway Administration for taking out time to review my ratings. I am also grateful to all the Envision Sustainability Professionals I chatted with during this research.

My appreciation goes to my mums - Mrs. Oluwalaiye and Mrs. Oke for their unflinching support and encouragement while I completed this work. I am also grateful to Professor Omole, who's never ending support strengthened me in my pursuit of a MS degree. My profoung gratitude goes to my fathers and siblings for their moral, financial, and spiritual support at all times. I appreciate the love. To my amazing husband, Oluwatobi Oke, and daughter, Tirenioluwa Oke, thanks so much for your encouragement, understanding, faith, support, and prayers. You both are amazing, and I love you! 
Special thanks to my colleagues in the CM department, you made the graduate school journey interesting. I am especially grateful to Jared and his family for being a great support system to me in my first semester at CSU. Many thanks to the professors of the CM department, Dr. Elliot, Dr. Strong, Dr. Killingsworth, Dr. Glick, Dr. Nobe, you have helped to form me into the professional that I am now. My story will never be complete without you

Finally, to the Lord Most High, the Lover of my soul, the Almighty God eternal whose special grace, mercy, love, and favor has brought me this far. My success shall sing praise to thee and not be silent. Therefore, I shall return to Him all the glory, honor, dominion, adoration, and praise. Amen. 


\section{DEDICATION}

To God Most High, in whom I live, move and have my being

To my daughter, Tirenioluwa Oke, may your path and your light shine bright every day. 


\section{TABLE OF CONTENTS}

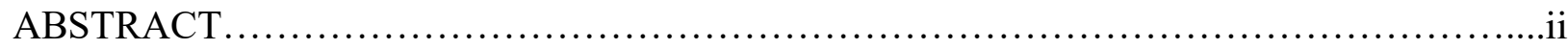

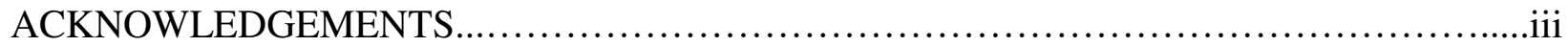

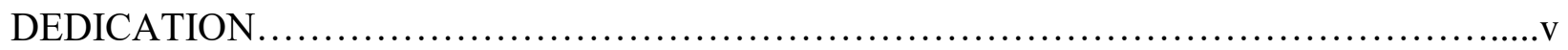

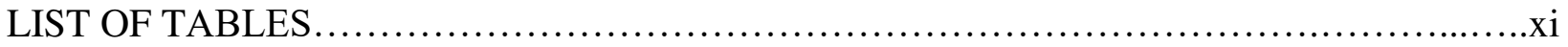

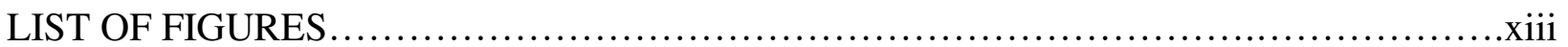

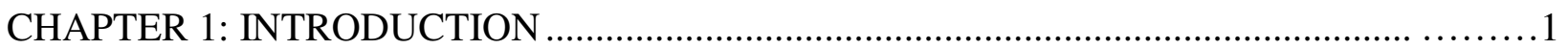

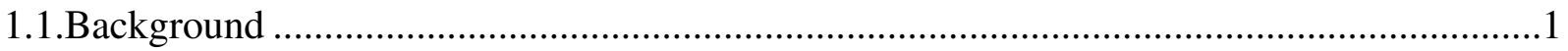

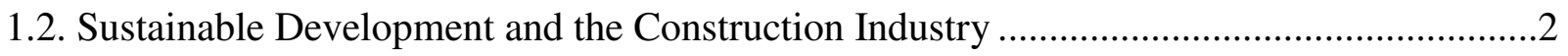

1.3. Sustainable Development in the Transportation Sector ..........................................................

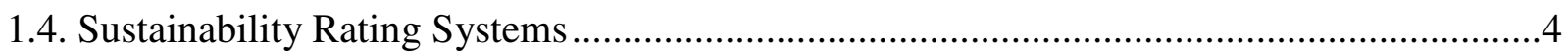

1.5. Transportation Sustainability Rating Systems (TSRS) ……...............................................5

1.6. Problem Statement and Research Need ........................................................................

1.7. Research Objective, Questions and Contribution ..............................................................

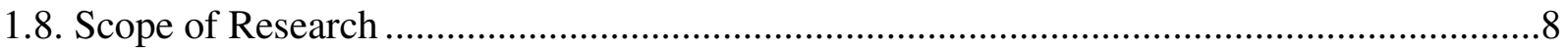

CHAPTER 2: LITERATURE REVIEW ..................................................

2.1. Background on Sustainability Rating Systems ………….................................................

2.2. Transportation Sustainability Rating Systems Investigated in this Research .....................11

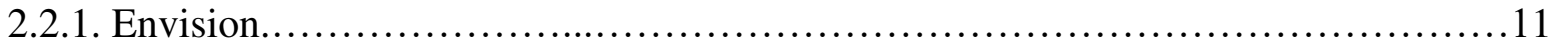

2.2.1.1 Envision Categories......................................................................................13

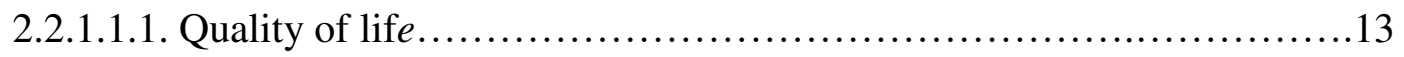

2.2.1.1.2. Leadership ......................................................... 14 
2.2.1.1.3. Resource Allocation ............................................... 16

2.2.1.1.4. Natural World ................................................. 17

2.2.1.1.5. Climate and Risk .................................................19

2.2.1.2. Application of the Envision rating system ..................................20

2.2.1.2.1. Self-Assessment Checklist ............................................20

2.2.1.2.2. Guidance Manual/Online Scoring Module ............................21

2.2.1.2.3. Verification/Awards Program ........................................21

2.2.1.3. Credits Levels of Achievement ..........................................22

2.2.1.4. Weighting in the Envision Rating System..................................22

2.2.2. Invest - Infrastructure Voluntary Evaluation Sustainability Tool...................24

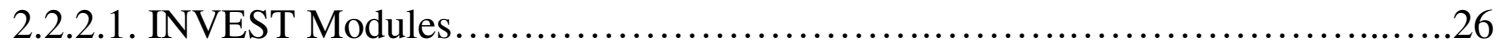

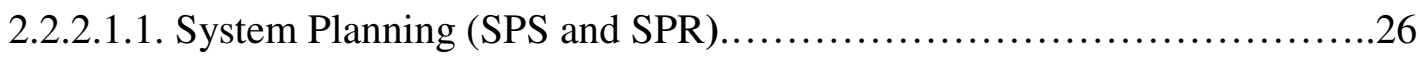

2.2.2.1.2. Project Development .............................................27

2.2.2.1.2.1. Project Development Criteria..............................28

2.2.2.1.2.2. Project Development Scorecards..........................28

2.2.2.1.2.3. Application of the Project Development Module..................29

2.2.2.1.2.4. Levels of Achievement....................................30

2.2.2.1.3. Operations and Maintenance Module...................................30

2.2.3. GreenLITES-Green Leadership in Transportation and Environmental Sustainability.31

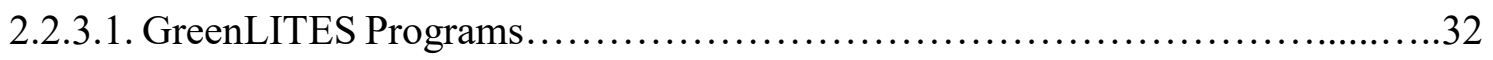

2.2.3.1.1. GreenLITES Project Design Program.....................................32

2.2.3.1.1.1. Sustainable Sites........................................... 33

2.2 .3 .1 .1 .2$. Water Quality............................................... 


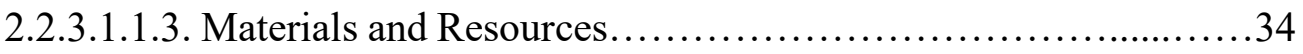

2.2.3.1.1.4. Energy and Atmosphere.......................................34

2.2.3.1.1.5. Innovation/Unlisted..................................... 34

2.2.3.1.2. Application of the Project Design Program...............................35

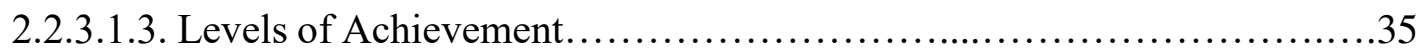

2.2.3.1.4. Weighting in the Project Design Program...............................35

2.2.3.2. GreenLITES Operations Certification Program..............................37

2.2.3.3. GreenLITES Planning Program..............................................38

2.3. Comparative Assessment of the Transportation Sustainability Rating Systems.............38

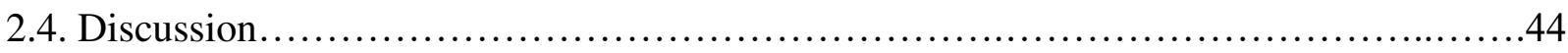

2.5. Summary of Transportation Sustainability Rating Systems Utilized in This Study........47

2.6. Previous Studies on Comparative Assessment of Transportation Sustainability Rating

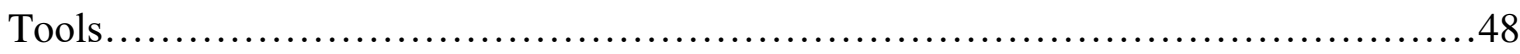

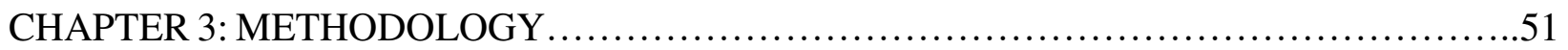

3.1. Carrying out a Literature Review................................................ 51

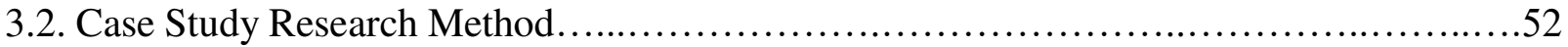

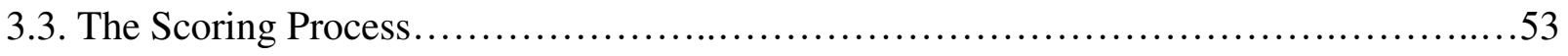

3.4. Description of Projects Analyzed in Study ..............................................5

3.4.1. D262883 F. A. Project - Route 28, Old Forge to Hamilton County Line,

Herkimer County, New York..................................................55

3.4.2. D263387 F. A. Project - I390, I490, and Lyell Avenue Interchange

Improvements, Phase 2, City of Rochester, Town of Gates..........................56

3.4.3. D263411 F. A. Project - Route 146 (Hamburg Street) Safety Improvements 
(1.5 miles, roundabout, new waterline and sewer system), Town of Rotterdam .56

3.4.4. D263477 F. A. Project - NYS Route 231 Safety Improvements at Northern

State Parkway Interchange in the Town of Huntington.

3.4.5. D263572 F. A. Project - Highway Reconstruction on Route 5S (1 Mile) in the

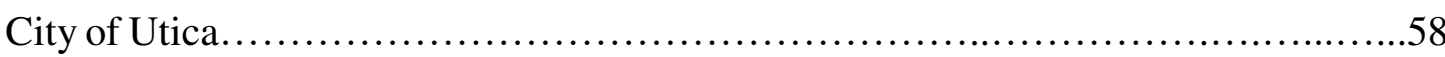

3.5. Addressing the Triple Bottom Line...........................................59

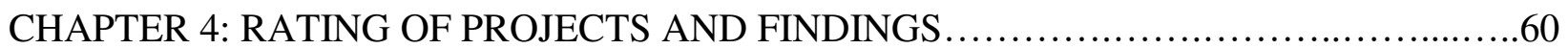

4.1. Rating the Projects.......................................................6

4.2. D262883 F. A. Project - Route 28, Old Forge to Hamilton County Line, Herkimer

County, New York........................................................61

4.2.1 Envision Rating for Project D262883 ..............................63

4.2.2. INVEST Rating for Project D262883............................68

4.2.3. GreenLITES Rating for Project D262883 ..........................70

4.3. D263387 F. A. Project - I390, I490, and Lyell Avenue Interchange Improvements,

Phase 2, City of Rochester, Town of Gates................................ 73

4.3.1. Envision Rating for Project D263387..............................75

4.3.2. INVEST Rating for Project D263387 ............................ 79

4.3.3. GreenLITES Rating for Project D263387.........................80

4.4. D263411 F. A. Project - Route 146 (Hamburg Street) Safety Improvements

(1.5 miles, roundabout, new waterline and sewer system), Town of Rotterdam...................82

4.4.1 Envision Rating for D263411 ............................................ 84

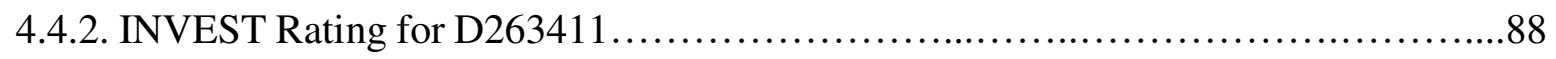

4.4.3. GreenLITES Rating for D263411 ................................... 89 
4.5. D263477 F. A. Project - NYS Route 231 Safety Improvements at Northern State

Parkway Interchange in the Town of Huntington..................................91

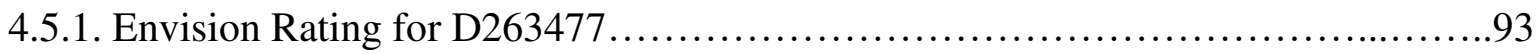

4.5.2. INVEST Rating for D263477......................................... 97

4.5.3. GreenLITES Rating for Project D263477................................98

4.6. D263572 F. A. Project - Highway Reconstruction on Route 5S (1 Mile) in the City

of Utica...................................................................... 100

4.6.1. Envision Rating for Project D263572 .................................. 102

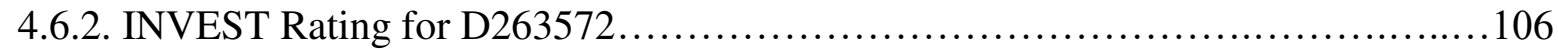

4.6.3. GreenLITES Rating for D263572 .................................. 107

4.7. Comparison of Rating Systems across the Projects............................... 109

4.8. Discussion of Results...................................................... 110

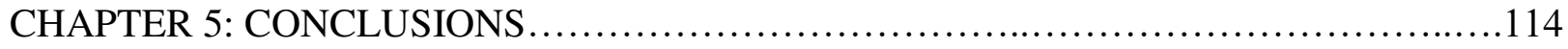

5.1. Summary of Research................................................... 114

5.2. Summary of Results gotten from Ratings.,.................................. 115

5.3. Concluding Remarks....................................................... 116

5.4. Future Research...................................................... 117

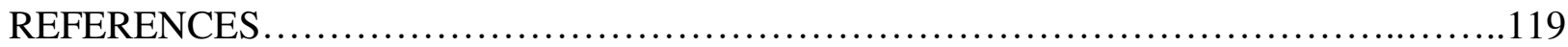




\section{LIST OF TABLES}

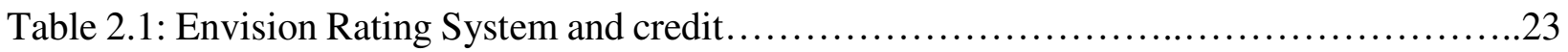

Table 2.2: The Levels of Achievement in the Project Development Module......................30

Table 2.3: GreenLITES Project Design Program and its credits............................... 35

Table 2.4: Legend showing Codes used in tables..........................................

Table 2.5: Project Phases applicable to Rating Systems......................................39

Table 2.6: Points achievable by Credits related to the Environmental Category in each Rating

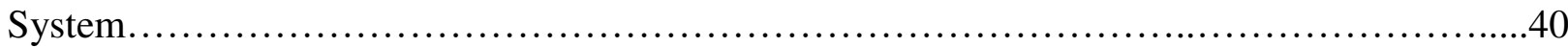

Table 2.7: Points achievable by Credits related to the Quality of Life/Social Category in each

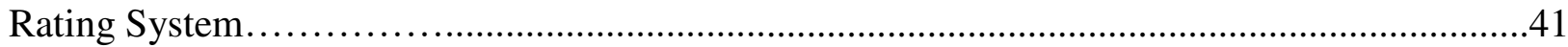

Table 2.8: Points achievable by Credits related to the Material Category in each Rating

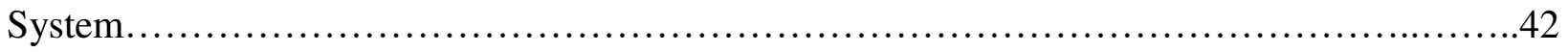

Table 2.9: Points achievable by Credits related to the Energy Category in each Rating

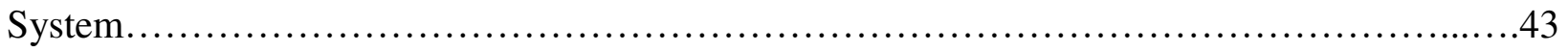

Table 2.10: Points achievable by Credits related to the Water Category in each Rating

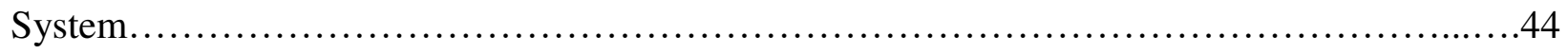

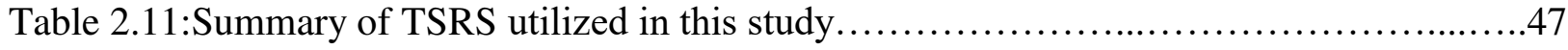

Table 4.1: Project D262883's Normalized Score and Award Level on Each Rating

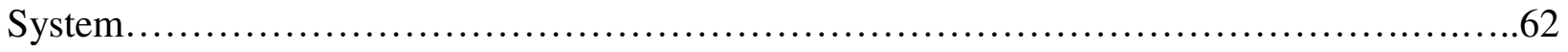

Table 4.2: Envision Credits Applicable to Project D262883..................................64

Table 4.3: Project D263387's Normalized Score and Award Level on Each Rating

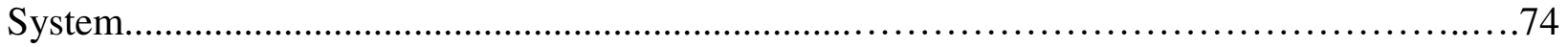


Table 4.4: Envision Credits applicable to Project D263387............................76

Table 4.5: Project D263411's Normalized Score and Award Level on Each Rating Syste........83

Table 4.6: Envision Credits Applicable to Project D263411..............................85

Table 4.7: Project D263477's Normalized Score and Award Level on Each Rating System......92

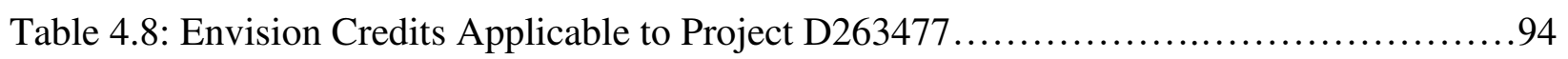

Table 4.9: Project D263572's Normalized Score and Award Level on Each Rating System.....101

Table 4.10: Envision Credits Applicable to Project D263572........................... 102 


\section{LIST OF FIGURES}

Figure 2.1: Fraction of total achievable points covered by each category under the Envision

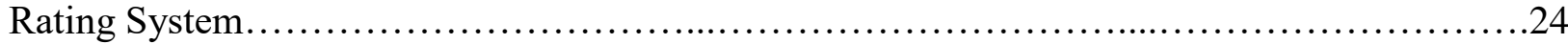

Figure 2.2: Fraction of total achievable points covered by each category under the GreenLITES

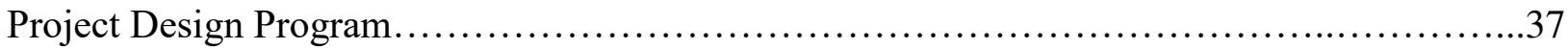

Figure 2.3: Distribution of the Rating Systems' Credits across the Triple Bottom

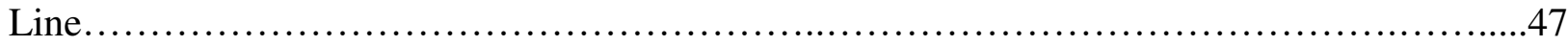

Figure 4.1. Project D262883 points spread across the five categories considered in this study

Figure 4.2. Points achieved in relation to applicable points across each category of Envision rating system for Project D262883.

Figure 4.3. Points achieved in relation to applicable points across the five categories considered in this study for the Envision rating system for Project D262883. .66

Figure 4.4. Points earned in relation to achievable points across the five categories considered in this study for the INVEST rating system for Project D262883. .69

Figure 4.5. Points achieved in relation to applicable points across each category in GreenLITES rating system for Project D262883. .71

Figure 4.6. Points scored in relation to achievable points across the five categories considered in this study for the GreenLITES rating system for Project D262883.

Figure 4.7. Project D263387 points spread across the five categories considered in this

study. 
Figure 4.8. Points achieved in relation to applicable points across each category of Envision rating system for Project D263387................................................... 78

Figure 4.9. Points achieved in relation to applicable points across the five categories considered in this study for the Envision rating system for Project D263387 .........................78

Figure 4.10. Points earned in relation to achievable points across the five categories considered in this study for the INVEST rating system for Project D263387 .........................80 Figure 4.11. Points achieved in relation to applicable points across each category in GreenLITES

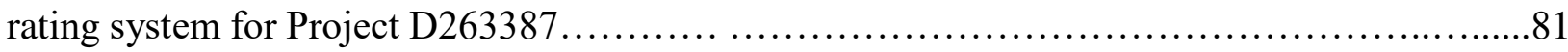
Figure 4.12. Points scored in relation to achievable points across the five categories considered in this study for the GreenLITES rating system for Project D263387

Figure 4.13. Project D263411 points spread across the five categories considered in this study

Figure 4.14. Points achieved in relation to applicable points across each category of Envision rating system for D263411

Figure 4.15. Points achieved in relation to applicable points across the five categories considered in this study for the Envision rating system for D263411....... .88

Figure 4.16. Points earned in relation to achievable points across the five categories considered in this study for the INVEST rating system for D263411 Figure 4.17. Points achieved in relation to applicable points across each category in GreenLITES rating system for D263411 .90 Figure 4.18. Points scored in relation to achievable points across the five categories considered in this study for the GreenLITES rating system for D263411 
Figure 4.19. Project D263477 points spread across the five categories considered in this study. .93

Figure 4.20. Points achieved in relation to applicable points across each category of Envision rating system for D263477. .96

Figure 4.21. Points achieved in relation to applicable points across the five categories considered in this study for the Envision rating system for D263477.

Figure 4.22. Points earned in relation to achievable points across the five categories considered in this study for the INVEST rating system for D263477. .98 Figure 4.23. Points achieved in relation to applicable points across each category in GreenLITES rating system for D263477

Figure 4.24. Points scored in relation to achievable points across the five categories considered in this study for the GreenLITES rating system for D263477. 100

Figure 4.25. Project D263572 points spread across the five considered in this study Figure 4.26. Points achieved in relation to applicable points across each category of Envision rating system for D263572 105 Figure 4.27. Points achieved in relation to applicable points across the five categories considered in this study for the Envision rating system for D263572.

Figure 4.28. Points earned in relation to achievable points across the five categories considered in this study for the INVEST rating system for D263572. 107 Figure 4.29. Points achieved in relation to applicable points across each category in GreenLITES rating system for D263572 108 Figure 4.30. Points scored in relation to achievable points across the five categories considered in this study for the GreenLITES rating system for D263572.... .109 
Figure 4.31. Comparison of Rating Systems across the Projects...........................110 


\section{CHAPTER 1: INTRODUCTION}

\subsection{Background}

The growing pressures and challenges of the earth's environment have created in humans an awareness of the urgency of sustainable development (Wang \& Li, 2006). Sustainable Development is a concept that was formally introduced in 1987 in the report of the World Commission on Environment and Development, Our Common Future (Kates, Parris, \& Leiserowitz, 2005). It is defined as "the ability to meet the needs of the present without compromising the ability of the future generation to meet their own needs" ((UN, 1987), Page 41). Although the sustainable development concept was formally introduced in 1987, the origin of this concept can be traced to early times (Du Pisani, 2006). The early medieval civilizations encountered sustainability issues like deforestation, salinization and loss of soil productiveness (Du Pisani, 2006). Several authors such as Plato, Strabo and Columella discussed several environmental degradations that had occurred because of human activities (Du Pisani, 2006). The need to preserve the "everlasting youth" of the earth through sustainable practices was also discussed by them (Du Pisani, 2006). Consequently, actions were taken that served as a foundation for sustainable development.

In 1972, "the Stockholm conference", a United Nations conference on the human

environment served as the first of its kind on international environmental issues. It was a milestone in the creation of global environmental policies (UN-DESA, 2015) and the outcome of the conference was the development of a framework for environmental action (UNEP, 2015). In 1973, a worldwide consensus on the regulation of pollution originating from ships was created. By 1974, the convention on the protection of aquatic environment had been employed by every Baltic 
coast (Burns, 2012). In 1985, the "Responsive Care" was established by the International council of Chemical Association. The RIO declaration which aimed at reducing unsustainable consumption patterns was published in 1992 (Burns, 2012). The Intergovernmental Panel on Climate Change had acknowledged in its fourth assessment report that most of the detected rise in the average temperature worldwide since the mid- $20^{\text {th }}$ century is connected to the perceived surge in greenhouse gas $(\mathrm{GHG})$ emissions. The report also anticipated a temperature increase between 2 and 6 degrees Celsius if GHG emissions keep growing (Nauclér \& Enkvist, 2009). The year 1997 therefore saw the establishment of the Kyoto Protocol, which was a modification to the UN convention held in 1994 on the change in climate. One hundred and seventy (170) countries excluding the United States of America signed and ratified the protocol. This marked the first attempt to regulate greenhouse gas emissions globally (Yudelson, 2008).

\subsection{Sustainable Development and the Construction Industry}

The construction industry, according to Yudelson (Yudelson, 2008) contributes 30\% of greenhouse gas emissions and as such, the industry needs to implement sustainable development practices to mitigate its environmental, social and economic effect (Simpson, 2013). Adopting sustainable development practices in the construction industry holds a lot of promise for both the industry and the world at large. Green buildings are said to reduce energy consumption by $30 \%$, save water by $30-50 \%$, diminish carbon emissions by $35 \%$ and provide a construction waste reduction of $50-90 \%$ (Yudelson, 2008). Whereas, buildings which do not apply sustainable practices will produce $30 \%$ of all greenhouse gas emissions, $45-60 \%$ of waste outputs to landfill, consume $30 \%$ of all raw material, yield $70 \%$ of all electricity consumption, give off $31 \%$ of all solid waste and will use up $12 \%$ of all fresh water (Yudelson, 2008). An additional advantage of 
adopting sustainable development practices in the construction industry is the improvement in air quality for occupants of green buildings (Simpson, 2013).

\subsection{Sustainable Development in the Transportation Sector}

Implementing sustainable developments practices in the construction industry, should not only be limited to buildings but should also be applied in other sectors of the industry such as the transportation sector. In recent years, the request for easy mobility of people, merchandise and services has risen (Simpson, 2013) and as such, transport infrastructure functions as a fundamental and essential support system for social and economic interchange(Caroline M. Clevenger, Ozbek, Simpson, \& Atadero, 2016). The transport sector globally accounts for $28 \%$ of total energy consumption (IPCC, 2015) and contributes 14\% of greenhouse gas emissions (IPCC, 2015). The United States transport sector produces $31 \%$ of the United States total greenhouse gas emissions while road transportation contributes $81 \%$ of the transport sector's total greenhouse gas emission (Simpson, 2013). Since 1990, the Unites States'(US) transport sector has been the fastest-growing source of the United States' total greenhouse gas emission accounting for a net increase of $47 \%$ (Awadallah, Fini, \& Mellat-Parast, 2013).

The subject of sustainable transport has been brought to the fore in all spheres; and a few reasons for this are the countless challenges faced by the modern society such as congestion, security, rising cost, noise, travel delays, air pollutions and so on (Awasthi \& Chauhan, 2011). Sustainable transport is characterized by the provision of safe access to basic services as well as goods while preserving the health of people and the environment, affordability of choice transport mode, solid economic advantage while reducing emissions and waste to a point where it can be absorbed by the environment with ease and equality amongst generations (Caroline M. Clevenger et al., 2016; STC, 2012). With the aim to control the challenges mentioned above, transportation 
professionals have provided several solutions involving the following: Energy efficient vehicles, trip reduction in private vehicle movement, clean fuels, pricing measures such as carbon tax, technology adoption such as intelligent transport system and regulatory policies on passenger and freight transport(Black, 1996; Caroline M. Clevenger et al., 2016).

However, for increased effectiveness of sustainability practices in the transportation sector, it is important that sustainable practices be integrated in the planning, design, construction implementation, operations and maintenance phases of transportation projects (Simpson, 2013).

\subsection{Sustainability Rating Systems}

Sustainable development is a concept that has gained much ground all over the world due to the solutions and benefits it provides to the increasing issues faced by our environment. In the construction industry, policies and regulations worldwide are requesting that sustainable practices be adopted (Berardi, 2012). Sustainability in the construction industry involves considering its development in terms of economic, environmental and social aspects as well as meeting the necessities for practical and useful performance (Berardi, 2012). There is therefore the need to assess the practical and useful performance of construction projects. To achieve this, there has been a wide adoption and endorsement of sustainability rating systems by the construction industry (Simpson, 2013).

Sustainability rating systems are tools that help to guide the assessment of construction projects against a collection of sustainability best practices that cover the three aspects of sustainability - environmental, economic and social (K. Griffiths, Boyle, \& Henning, 2015). In the building sector of the construction industry, several rating systems are available to measure building performance. The United States Green Building Council in the year 2000, unveiled the 
Leadership in Energy and Environmental Design (LEED) green building rating system (Yudelson, 2008), the foremost green building rating system used worldwide. Some other green building rating systems are Living Building Challenge, GBTool, Green Globes and Building Research Establishment's Environmental Assessment Method (BREEAM) (Simpson, 2013). In the transportation sector as well, several rating systems are available to measure project performance. Some of such systems that measure transportation sustainability are Greenroads, ENVISION, Illinois Livable and Sustainable Transportation (I-LAST), Sustainable Transportation Analysis System (STARS), the Infrastructure Voluntary Evaluation Sustainability Tool (INVEST), Green Leadership in Transportation and Environmental Sustainability (GreenLITES), BEST-inHighways, Green Guide for Roads, GreenPaths and GreenPave (Caroline M Clevenger, Ozbek, \& Simpson, 2013; Caroline M. Clevenger et al., 2016; Lineburg, 2016; Simpson, 2013, 2014).

\subsection{Transportation Sustainability Rating Systems (TSRS)}

Transportation Sustainability Rating Systems (TSRS), developed to measure transportation project features and actions against a sustainability standard, can be used to quantify the project's progress against that standard (Veeravigrom, Muench, \& Kosonen, 2015). Some of the TSRS are based solely on self-assessment while others are based on third-party verification and certification (K. Griffiths et al., 2015). TSRS that are third-party verified systems entail a greater level of proof and a more meticulous review process (K. Griffiths et al., 2015). Examples of TSRS that are selfassessed systems are Infrastructure Voluntary Evaluation Sustainability Tool (INVEST), Illinois Livable and Sustainable Transportation (I-LAST) and Green Leadership in Transportation and Environmental Sustainability (GreenLITES). Some examples of third party verified systems are Greenroads, ENVISION and Infrastructure Sustainability (IS). 
However, in recent years, there has been an increase in the development of transportation sustainability rating systems (Veeravigrom et al., 2015). Emerging transportation sustainability rating systems are known to be developed by a consensus of road/infrastructure professionals (Veeravigrom et al., 2015). The recent increase in the development of transportation sustainability rating systems strongly suggests that these systems are viewed as context sensitive and as such, rating systems will be developed to suit different countries, regions and industries (Veeravigrom et al., 2015). These systems have been developed with the intent of enhancing sustainability outcomes in the design and construction of transportation projects (K. A. Griffiths, Boyle, \& Henning, 2017).

Extensive research has been carried out on building sustainability rating systems (Asdrubali, Baldinelli, Bianchi, \& Sambuco, 2015; Fenner \& Ryce, 2008), while there is little research that has been carried out related to transportation/infrastructure sustainability rating systems and their application (K. A. Griffiths et al., 2017). Research carried out on TSRS with respect to application have focused on the application of one tool to a single project or to multiple projects (Anderson \& Muench, 2013; Bosco \& Buckingham, 2013). The comparative research that has been done on TSRS have focused on the content of the tool (Caroline M. Clevenger et al., 2016; Simpson, 2013).

\subsection{Problem Statement and Research Need}

A number of rating systems have been developed to evaluate the sustainability of transportation infrastructure projects. However, studies show that these TSRS have not been developed with a consistent "sustainability scope" ("the breadth of sustainability addressed and the prioritization within") (K. Griffiths et al., 2015; Veeravigrom et al., 2015). Thus, a project, run 
through more than one of these rating systems may be high performing on one rating system and low performing on another. This brings about the question of the consistency of these rating systems in measuring sustainability. Thus, there is the need to evaluate multiple TSRS to determine if a trend or consistency exists in the way the systems measure sustainability in transportation projects.

\subsection{Research Objective, Questions and Contribution}

The purpose of this study is to assess how three prominent transportation sustainability rating systems; ENVISION, INVEST and GreenLITES rate performance of transportation projects with the ultimate goal of determining if a trend or consistency exists in the way these three TSRS measure sustainability. ENVISION is a third-party rating system developed by Zofnass Institute in conjunction with the American Society of Civil Engineers, INVEST is a self-assessed rating system developed by Federal Highway Administration and GreenLITES is a self-assessed rating system developed by the New York State Department of Transportation for internal use. This study hopes to answer the following research questions:

$>$ Is there a trend or consistency in the numbers of points a project gets in each category of each rating system applied to it?

$>$ Is there a trend or consistency in the overall rating a project attains in each rating system applied to it?

This study helps inform stakeholders in the transportation industry (Departments of Transportation, Developers, Contractors and the public) on how transportation projects perform when run through each of these rating systems by providing them with trends or consistencies gotten from the research outcome thus enabling them to make decisions. 


\subsection{Scope of Research}

This study will only focus on three transportation sustainability rating systems ENVISION, INVEST and GreenLITES. ENVISION is a third-party rating system developed by Zofnass Institute in conjunction with the American Society of Civil Engineers, INVEST is a selfassessed rating system developed by Federal Highway Administration and GreenLITES is a selfassessed rating system developed by the New York State Department of Transportation. These rating systems are being used in this study because they provide the parameters (a third-party rating system, a self-assessed rating system and an in-house rating system) needed to achieve the goal of this study. A third-party rating system is one, which requires the presence of a sustainability professional accredited by the rating system on a project team to carry out ratings for a project thus qualifying the project for verification by a professional employed by the rating system and finally certification. A self-assessed rating tool is one which does not require a sustainability professional recognized by the rating system on the project neither does it require third-party verification by the rating system. An in-house rating system is one, which has been developed by a transportation agency or department of transportation for the specific purpose of applying it to the projects carried out by the transportation agency or department.

The projects used in this study are limited to rehabilitation, reconstruction and safety improvement projects from the New York State Department of Transportation only not new construction projects. The projects will be received from only the New York State Department of Transportation because it helps to corroborate the research goal of working with an in-house rating system. The study focuses on five rehabilitation, reconstruction and safety improvement projects only because the New York State Department of Transportation engages more in these types projects than in new projects. 


\section{CHAPTER 2: LITERATURE REVIEW}

\subsection{Background on Sustainability Rating Systems}

Sustainable development is a concept that has gained much ground all over the world due to the solutions and benefits it provides to the increasing issues faced by our environment. The construction industry has continued to see a growing interest in sustainability and its application as a good planning indicator (Simpson, 2013). Policies and regulations worldwide are requesting that sustainable practices be adopted in construction activities (Berardi, 2012). Incorporating sustainable practices into construction activities involves considering its development in terms of economic, environmental and social aspects as well as meeting the necessities for practical and useful performance (Berardi, 2012). There is therefore the need to evaluate the practical and useful performance of construction projects. To achieve this, there has been a wide adoption and endorsement of sustainability rating systems by the construction industry (Simpson, 2013).

Implementing the use of sustainable rating systems to measure the usefulness and efficiency of construction works experienced great growth in the building sector with the development and use rating systems such as the Leadership in Energy and Environmental Design (LEED) green building-rating system (Yudelson, 2008) which was developed in 1993 and is the most commonly used green building rating system. A few others are GBTool, Living Building Challenge, Building Research Establishment's Environmental Assessment Method (BREEAM) and Green Globes (Simpson, 2013). However, the transportation sector of the construction industry saw a slow growth in the development of tools for assessing the input of transportation infrastructure in the building of sustainable communities (McVoy, Nelson, Krekeler, Kolb, \& Gritsavage, 2010; Simpson, 2013). 
Nonetheless, recent years have seen notable increase in the development of transportation sustainability rating systems (Veeravigrom et al., 2015). This has led to the development of prominent transportation sustainability rating systems such as Greenroads, ENVISION, Infrastructure Sustainability (IS), Infrastructure Voluntary Evaluation Sustainability Tool (INVEST), Illinois Livable and Sustainable Transportation (I-LAST) and Green Leadership in Transportation and Environmental Sustainability (GreenLITES). This recent increase in the development of transportation sustainability rating systems suggests that these systems are seen as context sensitive. Thus, transportation sustainability rating systems were developed to suit specific countries, industries and regions while focusing on clearly defined local needs (Hirsch, 2011; Veeravigrom et al., 2015).

However, recent studies show that these TSRS have not been developed with a consistent "sustainability scope" (K. Griffiths et al., 2015; Veeravigrom et al., 2015). Sustainability scope is defined as "the breadth of sustainability addressed and the prioritization within" (Veeravigrom et al., 2015). Given the number of transportation sustainability rating systems that have been developed in the past years, the sustainability scope covered by each of them and their context sensitivity, a recent study was carried out to provide frameworks for selecting transportation sustainability rating systems that are most applicable to different state departments of transportation (Simpson, 2013). Also, another recent study was carried out in New Zealand to analyze how four rating systems (Infrastructure Sustainability (IS); ENVISION; CEEQUAL and Greenroads recognize performance by applying all four rating systems to a New Zealand highway viaduct project (K. Griffiths et al., 2015). Using these studies as groundwork, this research will assess how three rating systems; ENVISION - a third-party rating system and INVEST - a selfassessed rating system and GreenLITES - a self-assessed in-house rating system; rate performance 
of rehabilitation, reconstruction and safety improvement project with the ultimate purpose of determining if a trend or consistency exists in the way TSRS measure sustainability.

\subsection{Transportation Sustainability Rating Systems Investigated in this Research}

\subsubsection{ENVISION}

Envision, an innovative resource for professionals involved in the planning, designing, building and maintenance phases of civil infrastructure, is a holistic rating system used to rate sustainable infrastructure such as bridges, roads, railways, pipelines, water treatment systems, dams, airports, landfills, levees and other civil infrastructure (ISI, 2017a). The Envision rating system was developed through a collaboration between the Institute of Sustainable Infrastructure (ISI) and the Zofnass Program for Sustainable Infrastructure at the Harvard University Graduate School of Design (ASCE, 2017; ZofnassProgram, 2016). The Institute of Sustainable Infrastructure, a not-for-profit research and education organization founded in 2010, is a partnership of three organizations namely the American Council of Engineering Companies (ACEC), the American Society of Civil Engineers (ASCE) and the American Public Works Association (APWA) (ASCE, 2017). Each of these organizations was individually in the process of developing a sustainable infrastructure rating system (ISI, 2017a). However, these organizations saw the necessity for a standardized framework that classifies sustainability best practices (ISI, 2017a). Hence, the three founding organizations of the Institute of Sustainable Infrastructure came together to develop and operate the Envision sustainability rating system (ISI, 2017a).

The Envision rating system is a third-party rating system that provides a holistic and comprehensive framework used to evaluate and rate the economic, community and environmental benefits of infrastructure projects regardless of the size or type of the project (ISI, 2017b). A third- 
party rating system is one which requires the presence of a sustainability professional accredited by the rating system on a project team to carry out ratings for a project thus qualifying the project for verification by a professional employed by the rating system and finally certification. The Envision rating system offers guidance on sustainability best practices to users at no cost functions as a planning and design tool as well as a tool for assessing completed infrastructure projects (ISI, 2017a). The Envision rating tool can be used in the planning and design phases of an infrastructure project (ISI, 2015). The rating tool provides great value to policy makers, environmental organizations, regulators, community groups, constructors, designers, owners and more as it can be utilized by any of the parties involved in the delivery of infrastructure projects (ISI, 2017a). Envision rating system is made up of a wide array of criteria that enable individuals as well as project teams make better choices at every step of the project (ISI, 2017a). Criteria contained in the Envision rating tool are aimed at addressing a project's impact on its immediate environment and community, vital choices made throughout the lifecycle of the project and technical considerations concerning materials as well as processes (ISI, 2017a).

The Envision rating system has a total of 60 performance objectives otherwise known as credits/criteria (ISI, 2015) that address the impacts of the triple bottom line (economic, social and environmental) on sustainability in the planning and design phases of an infrastructure project (ISI, 2017b). The ENVISION rating system modules for the construction, operations and maintenance phases are still under development. These 60 credits are classified under five categories and have total achievable points of 809 . The credits are the sustainability practices being assessed while the points are scores that can be achieved for each credit. The five categories of the Envision rating system are: Quality of Life, Leadership, Resource Allocation, Natural World and Climate and Risk (ISI, 2015). These five categories are further divided into 14 subcategories according to subject 
matter (ISI, 2015). Each credit in the Envision rating tool contains an intent statement as well as metric, achievement level, description, means of advancing to higher achievement levels, evaluation criteria and documentation, sources utilized for Envision and related envision credits (ISI, 2015).

\subsubsection{Envision Categories}

\subsection{Quality of Life}

The Quality of Life Category deals with the impact of a project on its host and surrounding (affected) community, ranging from the health and wellbeing of individual members of the community to the wellbeing of the larger community structure (ISI, 2015). The impact of a project on a community could be social, physical or economic (ISI, 2015). Quality of Life category places emphasis on assessing the alignment of infrastructure projects with community goals, the incorporation of the project into existing community networks and the benefits the community stands to gain from the project in the long term (ISI, 2015). According to this category, a significant part of achieving good quality of life for a project's host and affected community is by considering their community members as important stakeholders and thus incorporating them in the decisionmaking process. Quality of Life category, which focuses on the social characteristics of sustainability (Simpson, 2013) has maximum achievable points of 181 and a total of 13 credits distributed under three subcategories namely: Purpose, Wellbeing and Community (ISI, 2015).

The Purpose subcategory focuses on the impact of a project on functional characteristics of a community, including its development, job creation, growth and overall quality of life improvement (ISI, 2015). This subcategory accounts for 3 of the 13 credits under the Quality of Life category (ISI, 2015). The Wellbeing subcategory places focus on how sustainable 
infrastructure projects address individual health, comfort as well as mobility (ISI, 2015). Attention is given to the physical safety of construction workers and security of residents during construction and operation of infrastructure projects (ISI, 2015). Emphasis is also placed on encouraging the use of alternative modes of transportation as well as integrating the infrastructure project into the community’s larger mobility network (ISI, 2015).

The Wellbeing subcategory accounts for 6 of the 13 credits under the Quality of Life category (ISI, 2015). The Community subcategory addresses a project's ability to improve or maintain its environs using context-sensitive design such as preserving natural features and views or integrating the local character of the community into the project design (ISI, 2015). This category accounts for 3 of the 13 credits under the Quality of Life category (ISI, 2015). The Quality of Life category also has an Innovation credit which rewards exceptional performance beyond the system's expectation (ISI, 2015).

\subsection{Leadership}

Ensuring a successful sustainable project does not just require traditional sustainability actions like reducing water and energy use (ISI, 2015). An essential requirement for the success of sustainable projects is the early collaboration and communication of all parties involved in the project such as the owner, designer, engineers, contractors, necessary government agencies and members of the community that houses the project. Early involvement of all parties to the project helps in idea creations for the project and builds a long-term and holistic understanding of the project and its life cycle (ISI, 2015). The Leadership category encourages and awards the incorporation of collaborative leadership in infrastructure projects as it produces sustainable projects that make effective and positive contributions to the environment around the project (ISI, 
2015). The Leadership category has maximum achievable points of 121 and a total of 10 credits addressed in three subcategories namely: Collaboration, Management and Planning.

The Collaboration subcategory addresses the ability of the project stakeholders to come together to work collectively. The success of sustainable projects is hinged on several factors including the ability to incorporate the inputs of an extensive variety of the project's stakeholders thus creating a synergy of ideas (ISI, 2015). Creating such collaboration calls for a high commitment and leadership level from the project stakeholders as well as innovative methods of managing the collaborative process (ISI, 2015). This subcategory which accounts for 4 of the 10 credits in the Leadership category has maximum achievable point of 60 (ISI, 2015).

The Management subcategory encourages the project team to achieve a holistic and comprehensive understanding of the project as this enables them to be aware of and to seek synergies between systems, within the project or amid the larger infrastructure systems in the community (ISI, 2015). Such holistic and comprehensive understanding of a project helps to achieve innovative ways of managing the project in its entirety, which will result in increased sustainability, reduced cost, protection against future difficulties and expansion of the project useful life (ISI, 2015). The Management subcategory has a total of 31 achievable points and accounts for 2 of 10 credits in the Leadership category (ISI, 2015).

The Planning subcategory focuses on the consideration of the long-term view of a project to help increase its sustainability (ISI, 2015). This includes taking into consideration planning issues that may arise, such as environmental regulations and subsequent growth tendencies of that area, as this will help the project plan against pitfalls while making effective plans for its future (ISI, 2015). This subcategory has a total of 30 achievable points while accounting for 3 of the 10 credits in the Leadership category (ISI, 2015). Like the Quality of Life category, the Leadership 
category also has an Innovation credit which rewards exceptional performance beyond the system's expectation (ISI, 2015).

\subsection{Resource Allocation}

The Resource Allocation category focuses on the assets required to construct and operate infrastructure (ISI, 2015). It addresses the source, character and quantity of these assets as well as their impact on the project's overall sustainability (ISI, 2015). The Resource Allocation category places attention on the sustainable utilization of finite resources such as water, physical materials (those consumed and those that leave the infrastructure project) and energy (ISI, 2015; Simpson, 2013). The three subcategories that make up the Resource Allocation category are Water, Energy and Material (ISI, 2015). This category has a total of 14 credits and maximum achievable points of 182 (ISI, 2015).

Water, as a finite resource has an uncertain future with respect to its availability (ISI, 2015). This uncertainty can be tied to population growth, climate change and increased consumption (ISI, 2015). Hence, a reduction in the consumption of water, especially potable water, is required and the use of alternative sources of water such as storm-water runoff will aid the reduction of potable water consumption (ISI, 2015). The determination of a community's water consumption balance is achieved by monitoring and studying that community's water availability (ISI, 2015). The Water subcategory focuses on protecting the availability of fresh-water, reducing the consumption of potable water and monitoring water systems (ISI, 2015). This subcategory has a total of 3 credits and maximum achievable points of 53 (ISI, 2015).

The Energy subcategory encourages the use of renewable energy as this helps to reduce the consumption of fossil fuels, a finite resource (ISI, 2015). This subcategory also places focus 
on the reduction of overall energy utilized throughout the life of a project (ISI, 2015). The Energy subcategory also encourages commissioning and monitoring energy systems to make certain that the project performs as planned and to maintain the project's proposed efficiency level throughout its life (ISI, 2015). This subcategory has a total of 3 credits and maximum achievable points of 49 (ISI, 2015). The Resource Allocation category also has an Innovation credit which rewards exceptional performance beyond the system's expectation (ISI, 2015).

Cutting down on the total material quantity used in an infrastructure project is of utmost importance as this helps to lower the quantity of extracted and processed natural resources and the energy needed to manufacture and convey the materials (ISI, 2015). However, durability, stability and safety must be considered in minimizing the use of materials (ISI, 2015). Sourcing for materials is also of utmost important as obtaining materials from long distances should be avoided once those materials can be found locally (ISI, 2015). A material's lifecycle, where the material comes from and where it goes to after its useful life, the percentage of reusable or recyclable content and its adaptability and durability are also factors that must be considered in the selection of materials for an infrastructure project (ISI, 2015). The Materials subcategory measures material reduction, sustainable procurement practices, utilization of local and recyclable materials, reduction of material taken offsite, diversion of waste from landfills and the provision of recycling and deconstruction of materials (ISI, 2015). This subcategory accounts for 7 of the 13 credits in the Resource Allocation category and has maximum achievable points of 80 (ISI, 2015).

\subsection{Natural World}

The impact of infrastructure projects on the natural world that surrounds it, which includes species, non-living natural systems and habitats, could be negative or positive (ISI, 2015). Unwanted impacts could be created by the location of a project within a system and the elements 
the project introduces into that system (ISI, 2015). The Natural World category focuses on means through which a project can positively interact with the natural systems around it while understanding and reducing negative impacts on these natural systems (ISI, 2015). The Natural World category has a total of 14 credits and maximum achievable points of 203 divided into three subcategories namely Siting, Land and Water and Biodiversity (ISI, 2015).

When siting an infrastructure project, efforts must be made to avoid direct and indirect impacts on ecological areas such as areas that serve as direct habitat like wetlands, temporary waters or waterbodies and areas of high ecosystem value (ISI, 2015). Areas of hydrologic or geologic value should also be preserved while avoiding the interruption of natural cycles such as the hydrologic cycle (ISI, 2015). The significance or nature of an infrastructure project could make it impossible to avoid sites of environmental value, mitigation efforts should be taken in such instances to diminish the interruption of environmental systems (ISI, 2015). Utilizing previously disturbed or developed land can help achieve such mitigation while stopping further environmental damage to that site and thus improving its value (ISI, 2015). The Siting subcategory addresses the preservation of ecological areas, areas of hydrological values and greenfields (ISI, 2015). With 7 credits, this subcategory has maximum achievable points of 99 (ISI, 2015).

The Land and Water subcategory focuses on the management of stormwater throughout the project life, the reduction of the impact of fertilizers and pesticides on both land and water and the prevention of ground and surface water contamination (ISI, 2015). This subcategory accounts for 3 of the 14 credits under the Natural World category and has maximum achievable points of 48 (ISI, 2015). 
The impact of infrastructure projects on habitats on or near the project site should be minimized thus avoiding habitat fragmentation and promoting habitat connectivity (ISI, 2015). The Biodiversity subcategory addresses the preservation of species biodiversity, restoration of disturbed soil, control of invasive species and maintenance of wetland and surface water functions (ISI, 2015). This subcategory has a total of 4 credits and maximum achievable points of 55 (ISI, 2015). The Natural World category also has an Innovation credit which rewards exceptional performance beyond the system's expectation (ISI, 2015).

\subsection{Climate and Risk}

Minimizing the emissions that contribute to increased risk, both short and long term, as well as ensuring the resilience of infrastructure projects to short-term hazards and the capability of these projects to adapt to modified long-lasting future conditions is what the Climate and Risk category aims to address (ISI, 2015). This category which has a total of 7 credits and maximum achievable points of 122 is divided into two subcategories namely: Resilience and Emissions (ISI, 2015).

The Resilience subcategory focuses on an infrastructure project's ability to resist shortterm risks like fires and flooding as well as the project's ability to adjust to varying long term conditions (ISI, 2015). A good understanding of the types of risk as well as the probability of these risks occurring aids the project team to produce a project design that is informed and anticipates these risks (ISI, 2015). This helps to prepare the project to adapt/adjust to or withstand the risks thus minimizing the vulnerability of the project (ISI, 2015). Decreased vulnerability and increased adaptability makes certain that the project can meet both the present and future needs of the community and guarantees a longer useful life of the project (ISI, 2015). The Resilience subcategory has a total of 5 credits and has maximum achievable points of 82 (ISI, 2015). 
Understanding the impact of dangerous emissions, such as greenhouse gas emission as well as other dangerous pollutants, and reducing their emission during all phases of a project's lifecycle is the objective the Emission subcategory aims to achieve (ISI, 2015). Minimizing both short and long-term risk protects a project from future problems while increasing the project's lifecycle (ISI, 2015). Reduction of greenhouse gas emission decreases environmental risk as well (ISI, 2015). The Emission subcategory achieves its goal with a total of 2 credits and has maximum achievable points of 40 (ISI, 2015).

\subsubsection{Application of the ENVISON rating system}

These following tools contained in the Envision rating system can be used independently or in combination based on the project type or the project phase in which it is being applied (Shivakumar, Pedersen, Wilkins, \& Schuster, 2014). The tools are:

- Self-Assessment/Pre-Assessment Checklist

- Guidance Manual/Online Scoring Module

- Verification/Awards Program

\subsection{Self-Assessment Checklist}

The Self-Assessment Checklist also known as the Pre-Assessment Checklist functions as an educational tool to aid Envision users in becoming familiar with sustainability practices that can be incorporated in infrastructure project designs (ISI, 2017c; Shivakumar et al., 2014). It is a web-based tool that can be used as a guide to make informed sustainability decisions about infrastructure projects and to make comparisons of project alternatives (ISI, 2017c; Shivakumar et al., 2014). The Self-Assessment Checklist is organized as a sequence Yes/No questions which are 
based on the criteria/credits contained in the Envision rating system (ISI, 2017c; Shivakumar et al., 2014) This tool can be used by anyone and it is available to download at no cost (ISI, 2017c).

\subsection{Guidance Manual/Online Scoring Module}

The Online Scoring Module is an in-depth web-based self-assessment tool that consists of a scoring system and a guidance manual to aid the scoring of infrastructure projects (Shivakumar et al., 2014). To use the Online Scoring Module, the project team led by an Envision Sustainability Professional must register the project on the sustainable infrastructure site (Shivakumar et al., 2014). The project is rated under the five categories contained in the Envision rating system. For the project to be verified, some mandatory questions that are contained in the rating system must be answered and documentations must be submitted with the project application to back-up the level of achievement claimed by the project team (Shivakumar et al., 2014; Simpson, 2013). The Online Scoring Module is a tool that should be used by the project team all through the project phase hence, it can be updated as often as required (Shivakumar et al., 2014; Simpson, 2013).

\subsection{Verification/Awards Program}

The Verification/Awards Program involves a third-party verification process that is optional (Shivakumar et al., 2014). The third-party process helps to validate ratings made by the project team and to affirm that a project the evaluation criteria set out by the Envision rating system (ISI, 2017c; Shivakumar et al., 2014). The verification program also determines a project's eligibility for public recognition as well as Envision certification (ISI, 2017c; Shivakumar et al., 2014). However, to be eligible for verifications, initial ratings of the project must be carried out by an Envision accredited sustainability professional (ISI, 2015). The Envision certification/award has four categories namely Platinum (50\% of total applicable points), Gold (40\% of total 
applicable points), Silver (30\% of total applicable points) and Bronze (20\% of total applicable points) (ISI, 2017c; Shivakumar et al., 2014; Simpson, 2013).

\subsubsection{Credit Levels of Achievement}

To better assess performance and encourage improvement in the construction of infrastructure projects, the Envision credits provide multiple achievement levels as identified by the Envision Fact Sheet (ISI, 2017c) and Guidance Manual (ISI, 2015):

- The Improved Level: this level recognizes performance that slightly surpasses regulatory requirements (ISI, 2015).

- The Enhanced Level: the enhanced level of achievement recognizes sustainable practices that conform to Envision principles (ISI, 2017c).

- The Superior Level: this level recognizes sustainable practices that are remarkable (ISI, 2015, 2017c).

- The Conserving Level: the conserving level of achievement awards sustainable practices that achieve "zero negative impact" (ISI, 2015, 2017c).

- The Restorative Level: this level of achievement recognizes and celebrates sustainable practices that restores social and natural systems (ISI, 2015, 2017c). The Restorative level does not apply to all objectives/credits (ISI, 2015).

\subsubsection{Weighting in the Envision Rating System}

Table 2.1 shows how the different categories contained in the Envision rating system are weighted. 
Table 2.1: Envision Rating System and credit

\begin{tabular}{|c|c|c|}
\hline Category & $\begin{array}{l}\text { Sub-Category } \\
\end{array}$ & Available Points \\
\hline \multirow{3}{*}{ Quality of Life } & QL - 1: Purpose & \multirow{3}{*}{ 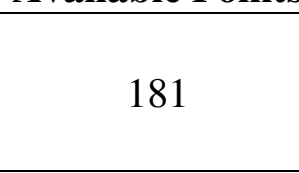 } \\
\hline & QL - 2: Wellbeing & \\
\hline & QL - 3: Community & \\
\hline \multirow{3}{*}{ Leadership } & LD - 1: Collaboration & \multirow{3}{*}{121} \\
\hline & LD - 2: Management & \\
\hline & LD - 3: Planning & \\
\hline \multirow{3}{*}{ Resource Allocation } & RA - 1: Materials & \multirow{3}{*}{182} \\
\hline & RA - 2: Energy & \\
\hline & RA - 3: Water & \\
\hline \multirow{3}{*}{ Natural World } & NW - 1: Siting & \multirow{3}{*}{203} \\
\hline & NW - 2: Land and Water & \\
\hline & NW - 3: Biodiversity & \\
\hline \multirow{2}{*}{ Climate and Risk } & CR - 1: Emissions & \multirow{2}{*}{122} \\
\hline & CR - 2: Resilience & \\
\hline Achievable Points & & 809 \\
\hline
\end{tabular}

As shown in shown in Table 2.1, the Envision rating system places more focus on the Natural World category which has maximum achievable credit of 203 and accounts for $25 \%$ of the total achievable points under the Envision rating tool. The Natural World category is followed closely by the Quality of life and Resource allocation categories which have maximum achievable points of 181 and 182 respectively while each category accounts for $22 \%$ of the total achievable points under the Envision rating tool. The Leadership and Climate and Risk subcategories have maximum achievable points of 121 and 122 respectively with each category accounting for $15 \%$ of the total achievable points under the Envision rating tool. Figure 2.1 shows a pie chart depicting the fraction of total achievable point covered by each category. 


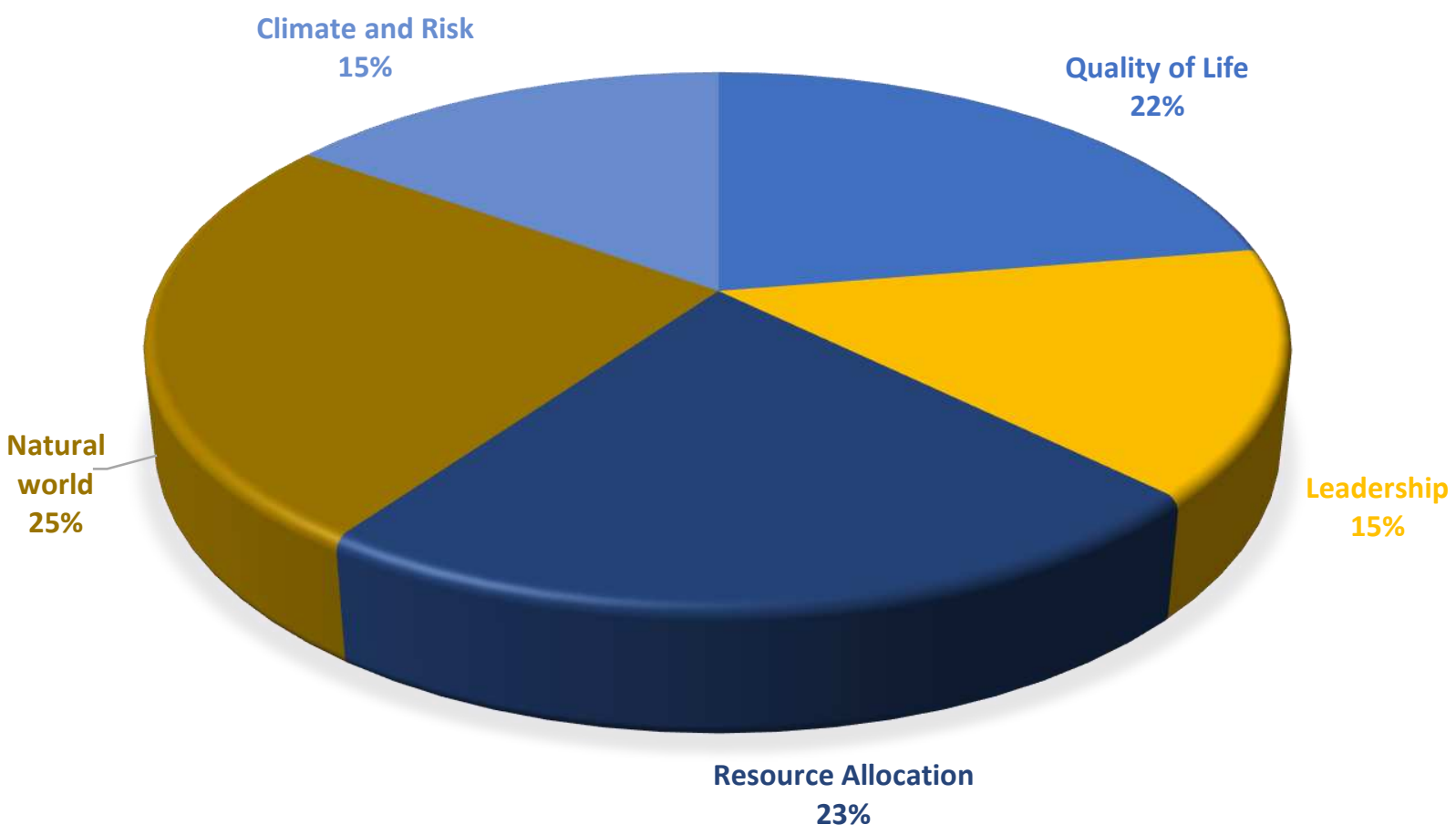

Figure 2.1: Fraction of total achievable points covered by each category under the Envision Rating System.

\subsubsection{INVEST - Infrastructure Voluntary Evaluation Sustainability Tool}

Infrastructure Voluntary Evaluation Sustainability Tool (INVEST) is a self-assessed webbased transportation sustainability rating tool (FHWA, 2017a). A self-assessed rating tool is one which does not require an INVEST recognized sustainability professional on the project neither does it require third-party verification by INVEST. This rating tool was developed by the Federal Highway Administration in conjunction with $\mathrm{CH} 2 \mathrm{M}$ Hill and inputs from American Society of Civil Engineers (ASCE), American Association of State Highway and Transportation Officials (AASHTO), American Council of Engineering Companies (ACEC) and American Public Works Association (APWA) (Brodie et al., 2013; Simpson, 2013). Launched in 2012, this rating tool was developed to assist transportation agencies in achieving their respective sustainability goals 
(Brodie et al., 2013; Simpson, 2013). The INVEST rating tool consist of sustainability best practices known as criteria and it covers the entire lifecycle of transportation projects made up of planning, design, construction and the operations and maintenance phases (FHWA, 2017a).

The INVEST rating system defines sustainability with the principles of triple bottom line and interprets sustainability as a notion that balances all three aspects of the triple bottom line; economic, social and environmental; to achieve transportation sustainability goals (Brodie et al., 2013). The INVEST rating tool can be used to evaluate the sustainability best practices implemented by a project currently under construction (Brodie et al., 2013). It also provides guidance on sustainability best practices that can be applied to a transportation project as well as help the project team set realistic sustainability goals (Brodie et al., 2013). The INVEST rating tool can be used to measure the sustainability of completed transportation projects (Brodie et al., 2013). This rating tool can also be applied to state, regional and local transportation projects (Brodie et al., 2013).

The INVEST rating system comprises of four modules namely: System Planning for States (SPS), System Planning for Regions (SPR), Project Development (PD) and Operations and Management (OM) (FHWA, 2017a; Simpson, 2013). The Systems Planning (SPS and SPR) and the Operation and Maintenance modules are designed to assess agencies' programs while the Project Development module assesses projects from the planning phase through the construction phase (FHWA, 2017a). 


\subsubsection{INVEST Modules}

\subsection{System Planning (SPS and SPR)}

The first phase in the lifecycle of any transportation project is the system planning phase and it involves the analysis and evaluation of a transportation agency's system-wide network (FHWA, 2017c). In this phase, projects aimed at improving capacity, safety, access and operations are identified (FHWA, 2017c). The System Planning for States module was created to meet the needs of local, Tollways and States transportation agencies who own infrastructure, engage in corridor wide planning and landscape-scale (FHWA, 2017c). The System Planning for Regions was developed to meet the needs of Government Councils, Metropolitan Planning Organizations (MPOs) that engage in landscape-scale for metropolitan areas (FHWA, 2017c). The System Planning module places focus on carrying out system-level analysis with the aim of contributing to the general sustainability of the agency as well as individual projects contained in this phase of the lifecycle (FHWA, 2017c).

The System Planning module consists of criteria to self-assess the system-level procedures, processes, practices and planning and programming policies of transportation agencies (FHWA, 2017b). Each System Planning module consists of seventeen (17) criteria merged into one scorecard (FHWA, 2017c). A bonus criterion, Integrated Planning: Bonus, is contained in the System Planning Module and eligibility for this criterion is by scoring a maximum of 45 points on the first, second and third System Planning criteria (FHWA). This bonus is aimed at rewarding agencies that perform integrated planning in their programs (FHWA, 2017c). The criteria included in the System Planning Module are Integrated Planning, Access and Affordability, Safety Planning, Multi-modal Transportation, Freight and good movement, Travel Demand Management, Air Quality, Energy and Fuel, Financial Sustainability, Analysis Method, Transportation Systems 
Management and Operations, Linking Asset Management and Planning, Infrastructure Resiliency and Linking Planning and NEPA (FHWA, 2017c).

The maximum achievable point under the System Planning Module is 240 (FHWA, 2017d). There are four levels of achievement under this module - the Platinum level (60\% of total points possible), the Gold level (50\% of total points possible), the Silver level (40\% of total points possible) and the Bronze level (30\% of total points achievable) (FHWA, 2017d).

\subsection{Project Development}

The second phase in the lifecycle of transportation projects is the Project Development phase (FHWA, 2017f). The Project Development module contains criteria to self-assess specific projects that have been conceptualized and programmed in the System Planning module (FHWA, 2017e, 2017f). The Project Development module can be used from the early planning phase to preliminary and final design phase and to the construction phase (FHWA, 2017e, 2017f). This module can also be used retrospectively to evaluate completed projects (FHWA, 2017g). The criteria contained in this module can be used for analysis of alternatives (FHWA, 2017f). The criteria in the Project Development module have been developed in a way that gives the project owner control over decisions and actions required to meet all the criteria contained in the module (FHWA, 2017f). Meeting all the criteria in this module can be achieved by integrating sustainable elements into the project specifications and plans (FHWA, 2017f).

The Project Development module has a total of 33 criteria that can be used in six fixed scorecards and one custom scorecard (FHWA, 2017f). The scorecards have been created to cater to different project types located in urban and rural locations as all criteria cannot be applicable to all project types (FHWA, 2017f). 


\subsection{Project Development Criteria}

The Project Development module has 33 criteria that incorporate the principles of the triple bottom line thus producing credits that span across the social, economic and environmental aspects

of sustainability. They are split into the Planning and Design criteria and the Construction criteria (FHWA, 2017f). The Planning and Design category has 28 criteria while the Construction category has 5 criteria that cover the three aspects of sustainability - social, economic and environmental (FHWA, 2017f).

\subsection{Project Development Scorecards}

There are seven scorecards under the Project Development Module (FHWA, 2017f):

- Paving - this scorecard is used for projects that are exclusively dedicated to the preservation of pavements and projects that improve safety as well as extend the life of facilities that are already in existence through pavement restoration projects. (Brodie et al., 2013; FHWA, 2017f). This scorecard can be used for paving projects in urban and rural settings (Brodie et al., 2013; FHWA, 2017f).

- Basic Rural - this scorecard can be used for rural projects that are small and do not increase the road capacity such as bridge replacement and rural reconstruction (Brodie et al., 2013; FHWA, 2017f).

- Basic Urban - this scorecard is used for small, urban projects that do not extend road capacity such as replacement of urban bridges and urban road reconstruction (Brodie et al., 2013; FHWA, 2017f). 
- Extended Rural - this scorecard is used for new rural projects such as new road facility and for reconstruction projects that require an expansion of a road or bridge capacity (Brodie et al., 2013; FHWA, 2017f).

- Extended Urban - this scorecard is used for new urban projects like new road facilities and reconstruction projects that require the expansion of a road or bridge capacity (Brodie et al., 2013; FHWA, 2017f).

- Recreational and Scenic Scorecard - this scorecard is used for projects on scenic or recreational roads (FHWA, 2017f).

- Custom - the Custom scorecard is used for projects that do not fit into any of the other scorecards (Brodie et al., 2013; FHWA, 2017f). This scorecard allows users to create a set of criteria unique to the project they are working on (Brodie et al., 2013; FHWA, 2017f). However, the scorecard has 11 mandatory credits that must be included in the score (FHWA, 2017f). This scorecard has no level of achievement attached to it (Brodie et al., 2013; FHWA, 2017f).

\subsection{Application of the Project Development Module}

The Project Development module is a self-assessment tool that contains criteria to assess the development of a specific transportation project in its planning, design and construction phases (FHWA, 2017e). It can be used by any person who has access to project information like the contractor, the architect/designer, project manager, owner and consultants (FHWA, 2017h). The Project Development module can be used to look up sustainability best practices that can be integrated into the project (FHWA, 2017h). 


\subsection{Levels of Achievement}

Table 2.2 show the different levels of achievement in the project development module and the required percentage needed to attain the various levels of achievement. It also shows the number of available points for each scorecard points.

Table 2.2: The Levels of Achievement in the Project Development Module

\begin{tabular}{|c|c|c|c|c|c|c|c|}
\hline Achievement Level & $\begin{array}{c}\text { Percentage } \\
\text { of Total } \\
\text { Point } \\
\text { Possible }\end{array}$ & \multicolumn{6}{|c|}{ Points Required } \\
\hline Score Cards & & Paving & $\begin{array}{l}\text { Urban } \\
\text { Basic }\end{array}$ & $\begin{array}{c}\text { Urban } \\
\text { Extended }\end{array}$ & $\begin{array}{l}\text { Rural } \\
\text { Basic }\end{array}$ & $\begin{array}{c}\text { Rural } \\
\text { Extended }\end{array}$ & $\begin{array}{c}\text { Scenic } \\
\text { and } \\
\text { Recreatio } \\
\text { nal }\end{array}$ \\
\hline $\begin{array}{l}\text { Number of Available } \\
\text { Points }\end{array}$ & & 63 & 136 & 171 & 119 & 153 & 136 \\
\hline Platinum & $60 \%$ & 38 & 82 & 103 & 71 & 92 & 82 \\
\hline Gold & $50 \%$ & 32 & 68 & 86 & 60 & 77 & 68 \\
\hline Silver & $40 \%$ & 25 & 54 & 69 & 48 & 61 & 54 \\
\hline Bronze & $30 \%$ & 19 & 41 & 52 & 36 & 46 & 41 \\
\hline
\end{tabular}

However, these levels of achievement are unofficial and lack any recognition from the FHWA (FHWA, 2017i; Simpson, 2013).

\subsection{Operations and Maintenance Module}

The Operations and Maintenance phase is the third phase in the lifecycle of transportation projects in which already constructed projects are operated and maintained (FHWA, 2017k). Data from Operation and Maintenance is collected, needs for new projects are identified and taken to the System Planning module to bring to completion the lifecycle of the project (FHWA, 2017k). The goal of the Operations and Maintenance module is to carry out system-level operations and maintenance activities in a way that contributes positively to the general sustainability of the road 
network (FHWA, 2017k). The criteria contained in the Operations and Maintenance module were specifically developed for scoring the asset management, internal and systems operation and maintenance activities of a transportation agency (FHWA, 2017k).

The Operations and Maintenance module contain criteria used to self-assess the processes, operations and maintenance policies, practices and procedures of a transportation agency (FHWA, 2017j). Operations and Maintenance module has fourteen modules with maximum achievable point of 210 points (FHWA, 2017k). There are four levels of achievements in this module Platinum (60\% of total points possible), Gold (50\% of total points possible), Silver (40\% of total points possible) and Bronze (30\% of total points possible) (FHWA, 2017k). However, these achievement levels are unofficial as they are not recognized by the FHWA due to an absence of third-party verification (FHWA, 2017k).

Each module in the INVEST rating system has an "Innovative Criteria" that encourages users to incorporate sustainable innovations and utilize emerging technologies that are not included in the INVEST system in their projects (FHWA, 20171).

\subsubsection{GreenLITES - Green Leadership in Transportation and Environmental Sustainability}

The Green Leadership in Transportation and Environmental Sustainability (GreenLITES) is a self-assessed transportation sustainability rating system developed by the New York State Department of Transportation(NYSDOT) (McVoy et al., 2010; NYSDOT, 2017a). It was modelled after Leadership in Energy and Environmental Design (LEED) rating system and the Greenroads rating system (McVoy et al., 2010; NYSDOT, 2017a). GreenLITES was developed in-house, principally; as an internal administration instrument for the NYSDOT to evaluate its performance, acknowledge good practices and detect areas that require improvements (McVoy et 
al., 2010; NYSDOT, 2017a). A transparent, metric-based system, the GreenLITES rating tool integrates the triple bottom line principle and assesses project performance based on environmental, social and economic contributions (McVoy et al., 2010). The GreenLITES rating system advocates for transportation developments that do not impact the environment negatively and causes slight disturbance socially (Simpson, 2013).

The GreenLITES rating system has four programs used to investigate the planning, design, construction and operations and maintenance phases of transportation projects (Simpson, 2013). These programs are the GreenLITES Project Design Program, GreenLITES Maintenance and Operations Plan Spreadsheet, Regional Pilot Sustainability Assessment Program and the GreenLITES Planning Program (McVoy et al., 2010; NYSDOT, 2017a). The programs contain a list of sustainable practices which the GreenLITES recognize and allocate credits to (McVoy et al., 2010). The four programs under the GreenLITES system provide credits for Innovation/Unlisted, however, approval for this credit must be sought from the NYSDOT project review committee (McVoy et al., 2010).

\subsubsection{GreenLITES Programs}

\subsection{GreenLITES Project Design Program}

The GreenLITES Project Design Program began in September, 2008 as a self-assessed program that recognizes transportation project in which sustainable practices are integrated extensively (McVoy et al., 2010). This program is a mandatory tool for us on all NYSDOT projects and is applied to the plans, specifications and estimates of these projects in the design phase (NYSDOT, 2017b; Simpson, 2013). The GreenLITES program utilizes a scorecard which the project team reviews with the aim of selecting sustainable practices that can be integrated into the 
project (McVoy et al., 2010; Simpson, 2013). This program has maximum achievable points of 278 and contains 175 credits (criteria) that are divided into five categories namely Sustainable Sites, Water Quality, Materials and Resources, Energy and Atmosphere and Innovation or Unlisted (McVoy et al., 2010).

\subsection{Sustainable Sites}

Avoiding the use of undeveloped land helps to preserve greenfield and preserves the ecosystem of a community. Locating a site in a manner that avoids wetlands, parklands farmlands and historic sites helps to minimize or avoid negative environmental and social impacts (NYSDOT, 2017c). The Sustainable Sites category has five subcategories namely Alignment Selection, Context Sensitive Solutions, Land Use or Community Planning, Protecting, Enhancing or Restoring Wildlife Habitat and Protecting Plants and Mitigating the Removal of Trees and Plant Communities (NYSDOT, 2017c). This category has 55 credits and maximum achievable points of 81 (NYSDOT, 2017c).

\subsection{Water Quality}

The Water Quality category focuses on stormwater management which involves the use of stormwater retrofitting, stream restorations, wetland protections, stormwater crediting strategies and management practices (NYSDOT, 2017c). This category also focuses on best management practices such as minimizing the project's total impervious surface area, inclusion of grass channels and permeable pavements and so on (NYSDOT, 2017c). The Water Quality category contains two subcategories namely Stormwater Management and Best Management Practices (NYSDOT, 2017c). This category contains 12 credits and maximum achievable points of 20 (NYSDOT, 2017c). 


\subsection{Materials and Resources}

The Materials and Resources category focuses the reuse of materials, the use of local materials, and the use of recycled material as well as the recycling of materials used on the project site, the use of bioengineering techniques for soil treatment and the minimization of hazardous materials on the project (NYSDOT, 2017c). This category has five subcategories namely reuse of Materials, Recycled Content, Local Materials, Bio-engineering Techniques and Hazardous Materials Minimization (NYSDOT, 2017c). The Materials and Resources category has 39 credits and maximum achievable points of 66 (NYSDOT, 2017c).

\subsection{Energy and Atmosphere}

The Energy and Atmosphere category focuses on how well the transportation project will conserve energy after it has been constructed and the impact of this on the atmosphere. This category has maximum achievable points of 104 and 69 credits addressed under five categories namely Improved Traffic Flow, Reduce Electrical Consumption, Reduce Petroleum Consumption, Improve Bicycle and Pedestrian Facilities and Noise Abatement (NYSDOT, 2017c).

\subsection{Innovation/Unlisted}

The Innovation category focuses on the integration of new or improved techniques to deliver more sustainable transportation project (NYSDOT, 2017c). The Unlisted category considers techniques that may have sustainable value but have not been specifically called out in the Project Development Scorecard (NYSDOT, 2017c). However, achieving credit for this category is subject to approval by the transportation project review team (NYSDOT, 2017c). Maximum achievable points for this category is 7 (NYSDOT, 2017c). 


\subsection{Application of the Project Design Program}

The Project Design program is a self-assessment tool that contains criteria to assess the plans, specification and estimates of transportation projects in the design phase (NYSDOT, 2017b; Simpson, 2013). It can be used by the project team as well as stakeholders on the project. The Project Design scorecard can be used to look up sustainability best practices that can be integrated into the project (Simpson, 2013).

\subsection{Levels of Achievement}

There are four levels of achievement that can be attained under the GreenLITES Project Design Program (McVoy et al., 2010). They are GreenLITES Certified (15 - 29 points), GreenLITES Silver (30 - 40 points), GreenLITES Gold (45 - 59 points) and GreenLITES Evergreen (60 points and above) (McVoy et al., 2010; NYSDOT, 2017a).

\subsection{Weighting in the Project Design Program}

Table 2.3 shows how the different categories contained in the Project Design Program are weighted.

Table 2.3: GreenLITES Project Design Program and its credits

\begin{tabular}{|c|c|c|}
\hline Category & Sub-Category & Available Points \\
\hline \multirow{5}{*}{ Sustainable Sites } & S - 1: Alignment Selection & \multirow{5}{*}{ - } \\
\hline & S - 2: Context Sensitive Solution & \\
\hline & S - 3: Land Use/Community Planning & \\
\hline & $\begin{array}{l}\text { S - 4: Protect, Enhance or Restore } \\
\text { Wildlife Habitat }\end{array}$ & \\
\hline & $\begin{array}{l}\text { S - 5: Protect, Plant or Mitigate for } \\
\text { Removal of Trees and Plant } \\
\text { Communities }\end{array}$ & \\
\hline \multirow{2}{*}{ Water Quality } & W - 1: Stormwater Management & \multirow{2}{*}{20} \\
\hline & W - 2: Best Management Practices & \\
\hline \multirow{2}{*}{ Materials and Resources } & M - 1: Reuse of Materials & \multirow{2}{*}{66} \\
\hline & M - 2: Recycled Content & \\
\hline
\end{tabular}




\begin{tabular}{|c|c|c|}
\hline & M - 3: Local Materials & \\
\hline & M - 4: Bio-Engineering Techniques & \\
\hline & $\begin{array}{l}\text { M - 5: Hazardous Material } \\
\text { Minimization }\end{array}$ & \\
\hline \multirow{5}{*}{ Energy and Atmosphere } & E - 1: Improve Traffic Flow & \multirow{5}{*}{104} \\
\hline & E - 2: Reduce Electrical Consumption & \\
\hline & E - 3: Reduce Petroleum Consumption & \\
\hline & $\begin{array}{l}\text { E - 4: Improve Bicycle and Pedestrian } \\
\text { Facilities }\end{array}$ & \\
\hline & E - 5: Noise Abatement & \\
\hline \multirow{3}{*}{ Innovation/Unlisted } & I - 1: Innovation & \multirow{3}{*}{7} \\
\hline & I - 2: Unlisted & \\
\hline & I - 3: NYCDOT Street Design Manual & \\
\hline \multicolumn{2}{|l|}{ Achievable Points } & 278 \\
\hline
\end{tabular}

As shown in shown in Table 2.3, the GreenLITES Project Design Program places more focus on the Energy and Atmosphere category which has maximum achievable credit of 104 and accounts for $37 \%$ of the total achievable points under the GreenLITES Project Design Program. The Energy and Atmosphere category is followed closely by the Sustainable Sites and Materials and Resources categories which have maximum achievable points of 81 and 66 respectively while each category accounts for $29 \%$ and $24 \%$ of the total achievable points under the GreenLITES Project Design Program. The Water Quality and Innovation/Unlisted subcategories have maximum achievable points of 20 and 7 respectively with each category accounting for $7 \%$ and $3 \%$ of the total achievable points under the GreenLITES Project Design Program. Figure 2.2 shows a pie chart depicting the fraction of total achievable point covered by each category. 


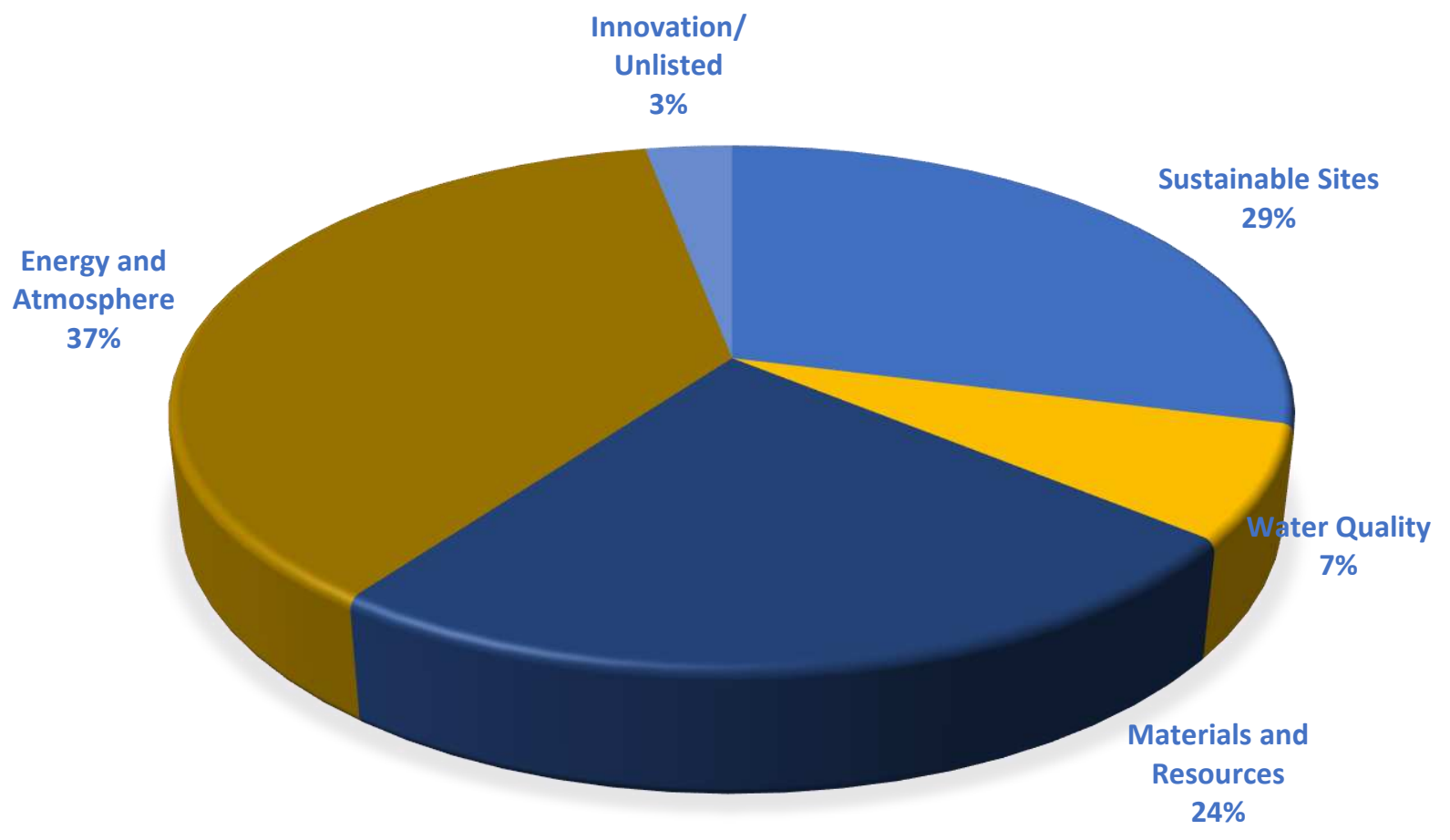

Figure 2.2: Fraction of total achievable points covered by each category under the GreenLITES Project Design Program.

\subsubsection{GreenLITES Operations Certification Program}

Between the years 1995 and 2007, the NYSDOT invested in the construction of new lane miles to its highway system resulting in a yearly addition of $0.06 \%$ of new lane miles (McVoy et al., 2010). It was noted, in that time period, that Vehicular Miles Travelled (VMT) increased yearly by $1.3 \%$ (McVoy et al., 2010). It became clear that road use increased as the highway system was built. This resulted in a decision to place a greater focus on the operation and maintenance of existing highway system rather than investing in new projects (McVoy et al., 2010).

With this new decision in place, the NYSDOT developed the GreenLITES Operations Certification Program in April, 2009 with the aim of operating and maintaining its transportation system in a manner that does not deplete resources but rather enhances it, improves quality of life for its population while contributing positively to the economy (McVoy et al., 2010; NYSDOT, 
2017d). GreenLITES Operations certification are open to Regional Bridge Maintenance Groups as well as Residencies. There are four levels of achievement under this program namely Evergreen, Gold, Silver or Certified (McVoy et al., 2010).

\subsubsection{GreenLITES Planning Program}

The GreenLITES Planning Program was developed with the aim of applying it in the planning phase of new transportation projects to facilitate a more balanced process of making project related decisions (Simpson, 2013). The program encourages the involvement of project stakeholders in the planning phase of a project with the goal of meeting community needs (Simpson, 2013). Promoting the use of the GreenLITES Planning Program at the local level led to the development of a project solicitation tool used by project financiers to appraise and measure the sustainability of proposed transportation projects (NYSDOT, 2017e). The GreenLITES Planning Program can be applied to long-term transportation projects (Simpson, 2013).

\subsection{Comparative Assessment of the Transportation Sustainability Rating Systems}

The three rating systems reviewed in this study hold several similarities as well as differences. The tables below display the similar as well as distinct characteristics possessed by the three rating systems. Table 2.4 shows the legend for codes used in the following tables.

\section{Table 2.4: Legend showing Codes used in tables}

\begin{tabular}{|c|c|}
\hline \multicolumn{2}{|c|}{ LEGEND } \\
\hline$\sqrt{ }$ & Meets Criterion \\
\hline$\times$ & Doesn't meet Criterion \\
\hline$\infty$ & Under Development \\
\hline$\diamond$ & Represented Elsewhere \\
\hline
\end{tabular}


Table 2.5 shows the different phases of construction in which the rating systems are applicable. All three rating systems apply to the Planning and Design phases of construction. The GreenLITES and INVEST rating systems are also applicable to the Construction as well as Operations and Maintenance phases. However, the ENVISION rating system does not apply to the Construction and Operations and Maintenance phases of construction. The ENVISION rating system modules for these phases are still under development as shown in Table 2.5.

Table 2.5: Project Phases applicable to Rating Systems

\begin{tabular}{|l|c|c|c|c|}
\hline \multicolumn{7}{|c|}{ APPLICABLE PROJECT PHASES } \\
\hline \multicolumn{1}{|c|}{ Rating System } & Planning & Design & Construction & $\begin{array}{c}\text { Operations and } \\
\text { Maintenance }\end{array}$ \\
\hline ENVISION & $\sqrt{ }$ & $\sqrt{ }$ & $\infty$ & $\infty$ \\
\hline INVEST & $\sqrt{ }$ & $\sqrt{ }$ & $\sqrt{ }$ & $\sqrt{ }$ \\
\hline GreenLITES & $\sqrt{ }$ & $\sqrt{ }$ & $\sqrt{ }$ & $\sqrt{ }$ \\
\hline
\end{tabular}

The following tables; Tables 2.6 - 2.10, display similarities and differences the three rating systems have as discussed under five categories namely the environment category, the quality of life category, the materials category, the energy category and the water quality category. These categories represent the triple bottom line (environment, social and economic) of sustainability. The tables also show the percentage of each rating system allocated to the different categories. These categories do not represent the entirety of the rating systems as there are other categories which are not common to all three rating systems. The Maximum Achievable Points for Envision, GreenLITES and INVEST are 809, 278 and 171 respectively.

Table 2.6 shows a review of the priority given by each rating system to the Environmental aspect of sustainability. As shown in the table, GreenLITES places more focus on the Environment category than the two other rating systems, with $29 \%$ of its rating being allocated to that category. 
ENVISION and INVEST come behind GreenLITES with $25 \%$ and $21 \%$ respectively. Notwithstanding the percentages allotted to the Environment Category by each rating system, these rating systems address issues that impact the environment at length.

Table 2.6: Points achievable by Credits related to the Environmental Category in each Rating System.

\begin{tabular}{|c|c|c|c|c|c|c|c|c|c|c|c|c|}
\hline \multicolumn{13}{|c|}{ ENVIRONMENT CATEGORY } \\
\hline Rating System & 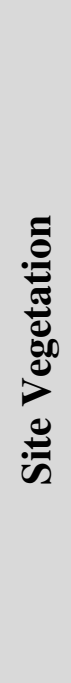 & 象 & 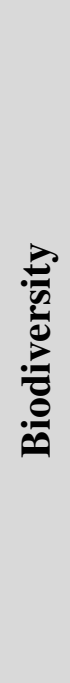 & 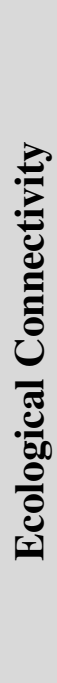 & 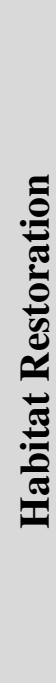 & 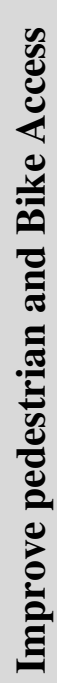 & & 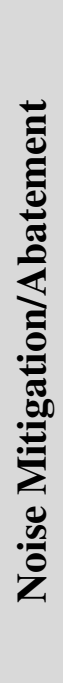 & 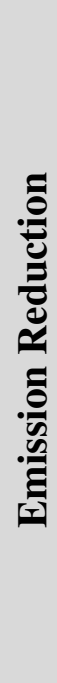 & 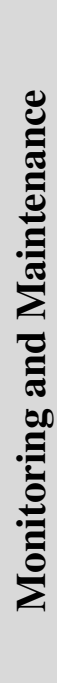 & 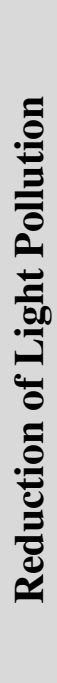 & 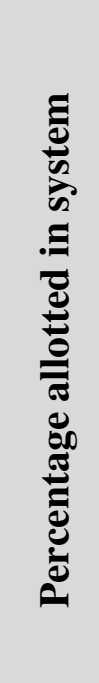 \\
\hline ENVISION & $\diamond$ & 99 & 55 & $\diamond$ & $\diamond$ & $\diamond$ & $\diamond$ & $\diamond$ & $\diamond$ & $\diamond$ & $\diamond$ & $25 \%$ \\
\hline GreenLITES & 14 & 13 & $\diamond$ & $\diamond$ & 19 & $\diamond$ & $x$ & $\diamond$ & $\diamond$ & $\diamond$ & 3 & $29 \%$ \\
\hline INVEST & 6 & $\diamond$ & $\diamond$ & 4 & 7 & 6 & 1 & 7 & 2 & $\diamond$ & 3 & $21 \%$ \\
\hline
\end{tabular}

Table 2.7 deals with the Quality of Life Category, which also defines the Social aspect of sustainability. The ENVISION rating system leads the other rating systems in this category with $22 \%$ of its rating being allotted to the Quality of Life category. The GreenLITES rating system does not have any category dedicated to the Quality of Life/Social category. However, some aspects related the social wellbeing of the community, in which the project is being constructed, are addressed under other categories as shown in the table. The INVEST rating system places little focus on the Quality of Life category with an allocation of $1 \%$ of its rating to this category. 
Table 2.7: Points achievable by Credits related to the Quality of Life/Social Category in each Rating System.

\begin{tabular}{|c|c|c|c|c|c|c|c|c|c|c|c|c|}
\hline \multicolumn{13}{|c|}{ QUALITY OF LIFE/SOCIAL CATEGORY } \\
\hline $\begin{array}{l}\text { Rating } \\
\text { System }\end{array}$ & 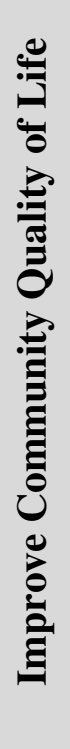 & 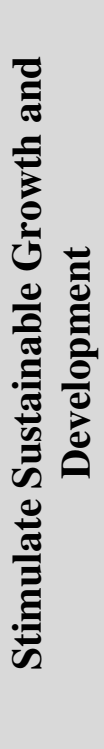 & 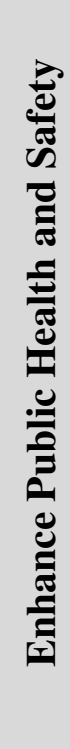 & 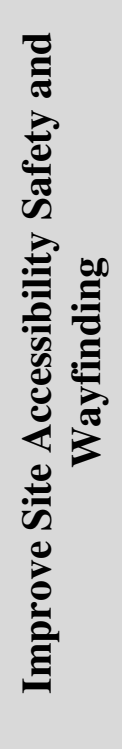 & 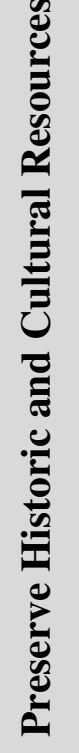 & 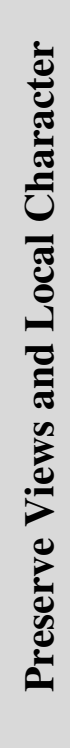 & 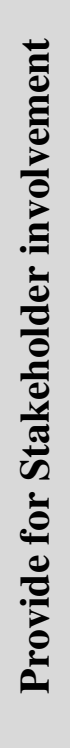 & 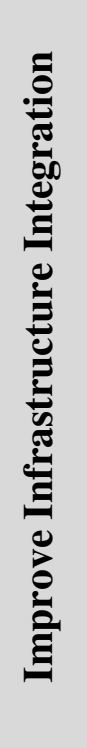 & 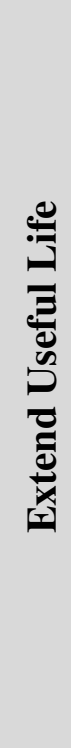 & 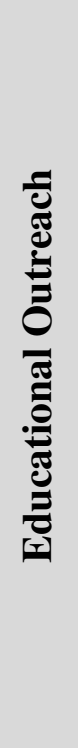 & 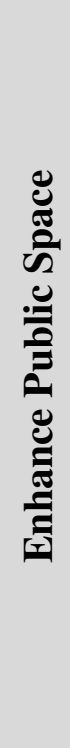 & 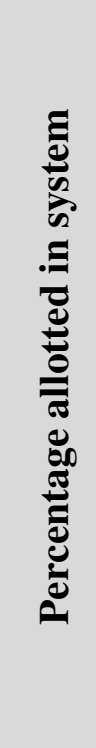 \\
\hline ENVISION & 25 & 16 & 16 & 15 & 16 & 14 & $\diamond$ & $\diamond$ & $\diamond$ & $\diamond$ & 13 & $22 \%$ \\
\hline GreenLITES & $\diamond$ & $\diamond$ & $\diamond$ & $x$ & $\diamond$ & $\diamond$ & $\diamond$ & $x$ & $\diamond$ & $\diamond$ & $\diamond$ & $0 \%$ \\
\hline INVEST & $\diamond$ & $\diamond$ & 10 & $x$ & 3 & $\diamond$ & $\diamond$ & $\diamond$ & $\diamond$ & 2 & 3 & $1 \%$ \\
\hline
\end{tabular}

Table 2.8 addresses the Material Category and the focus placed on this category by each of the rating systems. The GreenLITES rating system tops the list in this category with $24 \%$ of its rating allocated to Materials and its usage. INVEST follows with a percentage of $18 \%$ while ENVISION is behind in this category with a percentage allocation of $10 \%$. 
Table 2.8: Points achievable by Credits related to the Material Category in each Rating System.

\begin{tabular}{|c|c|c|c|c|c|c|c|c|c|}
\hline \multicolumn{10}{|c|}{ MATERIAL CATEGORY } \\
\hline Rating System & 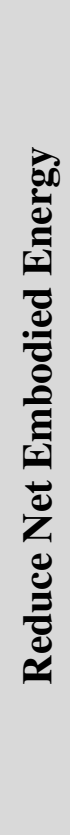 & 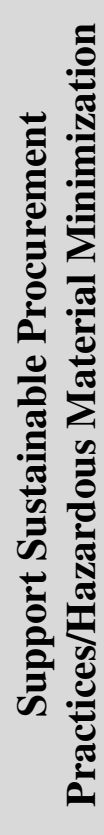 & 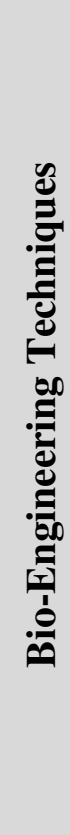 & 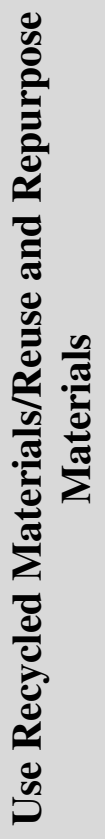 & 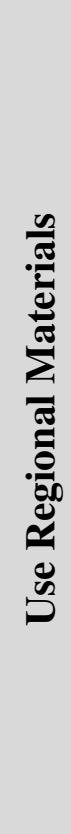 & 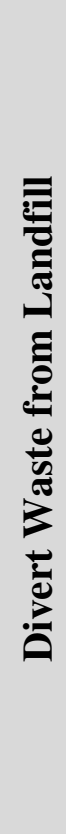 & 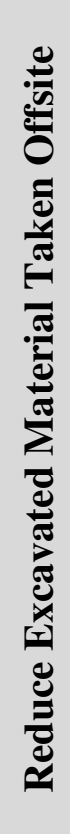 & 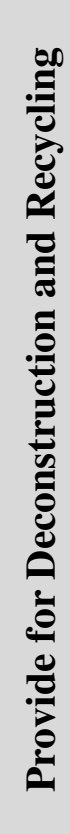 & 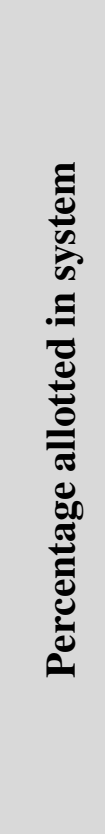 \\
\hline ENVISION & 18 & 9 & $x$ & 14 & 10 & 11 & 6 & 12 & $10 \%$ \\
\hline GreenLITES & $x$ & 6 & 8 & 48 & 4 & $\diamond$ & $\diamond$ & $\diamond$ & $24 \%$ \\
\hline INVEST & 3 & $\diamond$ & $x$ & 22 & $x$ & $\diamond$ & 5 & $\diamond$ & $18 \%$ \\
\hline
\end{tabular}

Table 2.9 places focus on the Energy Category of each rating system. The GreenLITES rating system leads in this category as well with $37 \%$ of its rating allotted to the Energy category. The INVEST rating system allots $13 \%$ of its ratings to the Energy Category. Although the ENVISION rating system has a percentage of $6 \%$ dedicated to the Energy category, some aspects related to Energy and its management are addressed under other categories in the rating system. 
Table 2.9: Points achievable by Credits related to the Energy Category in each Rating System.

\begin{tabular}{|c|c|c|c|c|c|c|c|c|c|}
\hline \multicolumn{10}{|c|}{ ENERGY CATEGORY } \\
\hline Rating System & 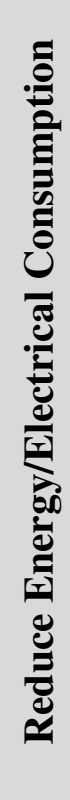 & 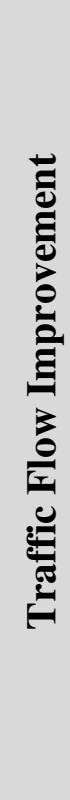 & 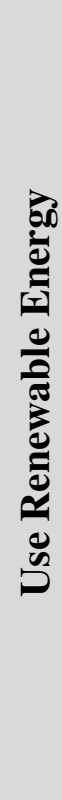 & 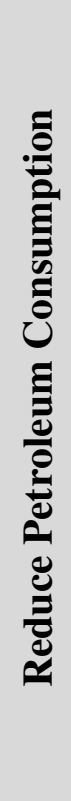 & 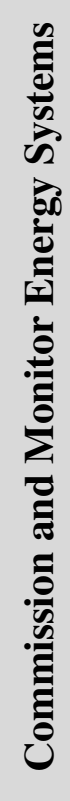 & 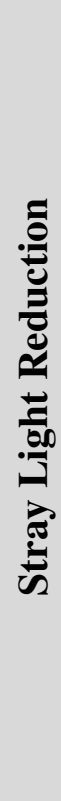 & 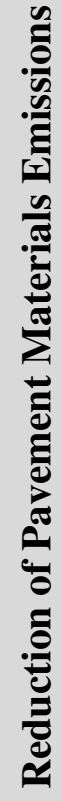 & 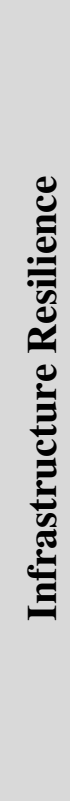 & 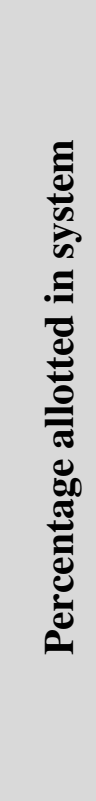 \\
\hline ENVISION & 18 & $x$ & 20 & $\diamond$ & 11 & $\diamond$ & $\diamond$ & $\diamond$ & $6 \%$ \\
\hline GreenLITES & 10 & 29 & $x$ & 15 & $x$ & 3 & $\diamond$ & $\diamond$ & $37 \%$ \\
\hline INVEST & 8 & $\diamond$ & $x$ & $x$ & $x$ & $\diamond$ & 3 & 12 & $13 \%$ \\
\hline
\end{tabular}

Table 2.10 represents the percentage of each system's rating allocated to the Water Quality Category. This Category focuses on the management of both Potable water and Stormwater. The ENVISION rating system leads in this category with a $12 \%$ allocation of its ratings. The GreenLITES and INVEST rating system are nearly even with percentage allocations of $7 \%$ and $6 \%$ respectively. Although the GreenLITES and INVEST rating system have 7\% and 6\% of their ratings respectively focused directly on the Water Category, they seem to be missing out a number of aspects, such as the reduction of potable water use and protection of freshwater availability, related to this category. 
Table 2.10: Points achievable by Credits related to the Water Category in each Rating System.

\begin{tabular}{|c|c|c|c|c|c|c|c|c|}
\hline \multicolumn{9}{|c|}{ WATER QUALITY CATEGORY } \\
\hline Rating System & 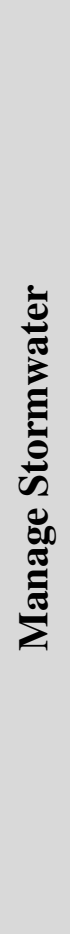 & 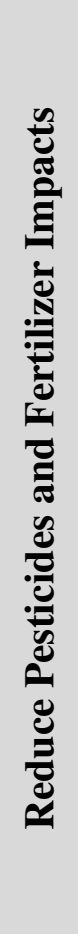 & 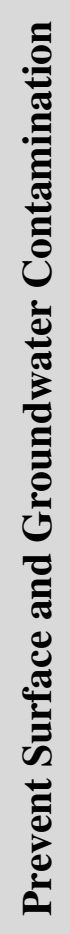 & 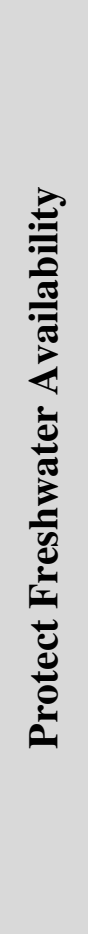 & 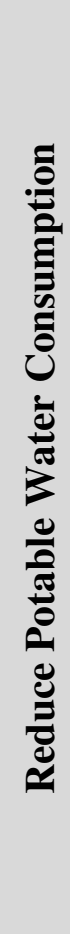 & 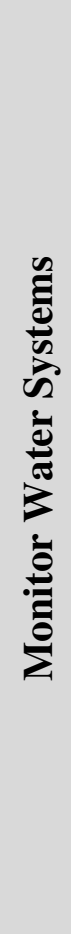 & 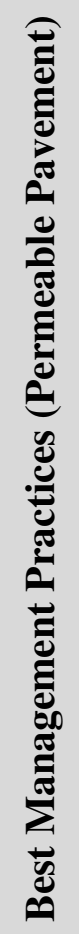 & 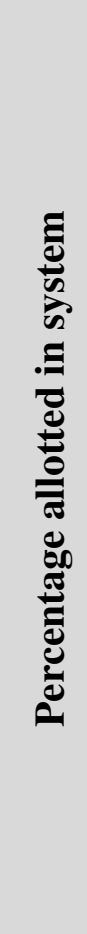 \\
\hline ENVISION & 21 & 9 & 18 & 21 & 21 & 11 & $\diamond$ & $12 \%$ \\
\hline GreenLITES & 10 & $x$ & $x$ & $x$ & $x$ & $\diamond$ & 10 & $7 \%$ \\
\hline INVEST & 6 & $x$ & $x$ & $x$ & $x$ & $x$ & 5 & $6 \%$ \\
\hline
\end{tabular}

\subsection{Discussion}

The comparison of Transportation Sustainability Rating Systems carried out in Tables 2.6 - 2.10 has highlighted similarities and differences that the three rating systems have. This discussion will further highlight peculiarities to all three rating systems.

The ENVISION rating system is an infrastructure sustainability rating system that applies not only to Road Transportation projects but also to other infrastructure projects such as pipelines, 
airports, landfills, levees, railways, water treatment systems, dams and other civil works components (ISI, 2015). This rating system, being a third-party verified system, requires that an ENVISION certified sustainability professional be on the project team for projects that seek ENVISION certification and recognition (ISI, 2015). The ENVISION rating system has been developed to incorporate the triple bottom line (economic, social and environmental) of sustainability. With its five categories and 60 credits, the ENVISION rating system can be said to give the following distribution of its ratings to the economic, social and environmental aspects of sustainability respectively: $15 \%, 22 \%$ and $63 \%$. It can be deduced from this that the ENVISION rating system places more focus on the environmental impacts of infrastructure projects.

The ENVISION rating system has been applied to 38 projects since its inception (ISI, 2017d). A verified project may be awarded ENVISION Bronze, Silver, Gold or Platinum. Since its inception, ENVISION has awarded 5 projects with ENVISION Bronze, 8 projects with ENVISION Silver, 7 projects with ENVISION Gold and 15 projects with Platinum. There are 16 projects awaiting verification and award (ISI, 2017d).

The INVEST rating system has seven project scorecards intended to cater diverse types of project depending on the project type and its location (FHWA, 2017f). Six of these scorecards have pre-determined credits that will apply projects that fall under these scorecards. However, one of these scorecards, the Custom Scorecard, allows a project that does not fit into the other scorecards to develop criteria (credits) that best suit it (FHWA, 2017f). The use of the Custom Scorecard requires the addition of 11 core criteria that must be included in the final score of the Custom project (FHWA, 2017f). With the use of the other scorecards, the INVEST rating system acknowledges that some projects may not meet all its criteria at initial use as each criterion may not perfectly meet the project context (FHWA, 2017g). Therefore, a project's final score is 
determined based on criteria that are relevant to the project (Simpson, 2013). The INVEST rating system allocates the following distribution of its ratings to the economic, social and environmental aspects of sustainability respectively: $12 \%, 16 \%$ and $72 \%$. The INVEST rating system has been used to evaluate at least 1771 projects (FHWA, 2017m).

The GreenLITES rating system is a self-assessed rating system that was developed for inhouse use for the New York State Department of Transportation (McVoy et al., 2010; NYSDOT, 2017a). Of the three systems, this rating system places the greatest focus on the environmental aspect of sustainability with a percentage allocation of $86 \%$. The economic and social aspects of sustainability have ratings of $10 \%$ and $4 \%$ respectively.

The ENVISION, INVEST and GreenLITES rating systems also have peculiarities in the credits covered by each of them. A peculiarity of the ENVISION rating system, which the other rating systems lack, is the category; Quality of Life. This category, along with its credits, specifically focus on the social aspect of the triple bottom line. The other rating systems being studied (INVEST and GreenLITES) place some focus on the social aspect of sustainability. The INVEST rating system has its credits individually outlined without being sectioned into categories, however, in the GreenLITES rating system, credits related to the social aspects are embedded in categories that focus on the environmental or economical aspects of sustainability. Another peculiarity of the ENVISION rating system is the Leadership category which places focus, solely, on stakeholder involvement on a project. This category is important as it highlights the importance and benefits of applying integrated project delivery to a project. While the INVEST and GreenLITES rating systems touch on this aspect, the importance and benefits of involving all stakeholders on a project is not highlighted. A peculiarity of the GreenLITES rating system is the focus it places on resources (Material and Energy). Sixty-one percent (61\%) of its score are 
allocated to the resources. The ENVISION rating system focuses $23 \%$ of its score on resources while INVEST rating system focuses $31 \%$ of its score on resources.

Figure 2.3 shows the Rating Systems' credit distribution across the Economic, Social and Environmental aspects of Sustainability.

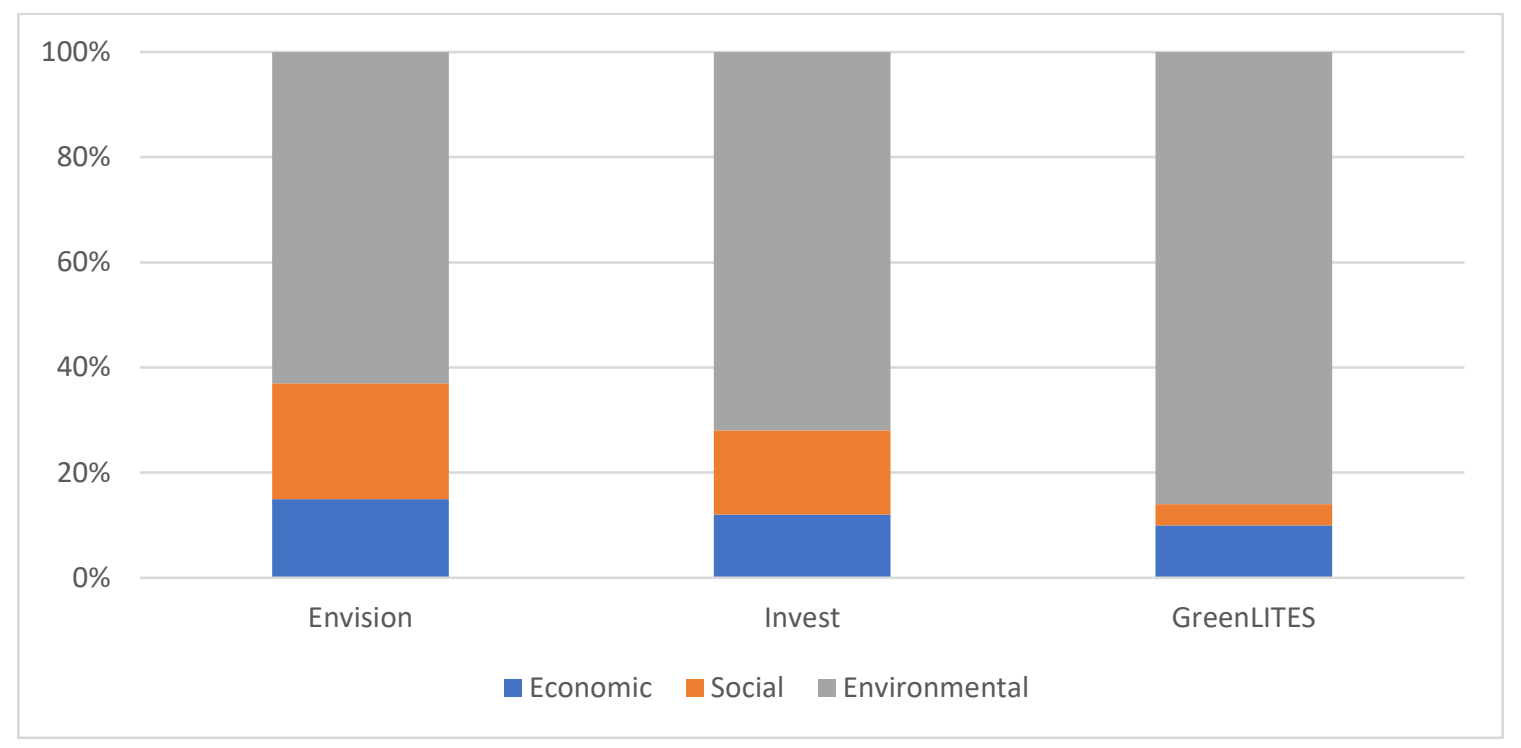

Figure 2.3: Distribution of the Rating Systems' Credits across the Triple Bottom Line.

\subsection{Summary of Transportation Sustainability Rating Systems Utilized in This Study}

Table 2.11 provides a summary of the three TSRS utilized in this study.

Table 2.11: Summary of TSRS utilized in this study.

\begin{tabular}{|l|l|l|l|}
\hline & ENVISION & INVEST & GREENLITES \\
\hline Year of Creation & 2012 & 2012 & 2008 \\
\hline Place of Creation & $\begin{array}{l}\text { United States of } \\
\text { America }\end{array}$ & $\begin{array}{l}\text { United States of } \\
\text { America }\end{array}$ & $\begin{array}{l}\text { United States of } \\
\text { America }\end{array}$ \\
\hline $\begin{array}{l}\text { Developer of Rating } \\
\text { System }\end{array}$ & $\begin{array}{l}\text { Zofnass Institute in } \\
\text { Alliance with } \\
\text { Institute of } \\
\text { Sustainable } \\
\text { Infrastructure (ISI) }\end{array}$ & $\begin{array}{l}\text { Federal Highway } \\
\text { Administration } \\
\text { (FHWA) }\end{array}$ & $\begin{array}{l}\text { New York State } \\
\text { Department of } \\
\text { Transportation } \\
\text { (NYSDOT) }\end{array}$ \\
& & & \\
\hline
\end{tabular}




\begin{tabular}{|l|l|l|l|}
\hline $\begin{array}{l}\text { Type of Rating } \\
\text { System }\end{array}$ & $\begin{array}{l}\text { Third-Party Rating } \\
\text { System }\end{array}$ & $\begin{array}{l}\text { Self-Assessed } \\
\text { Rating System }\end{array}$ & $\begin{array}{l}\text { In-house Self-Assessed } \\
\text { Rating System }\end{array}$ \\
\hline $\begin{array}{l}\text { Phases of } \\
\text { Construction } \\
\text { applicable }\end{array}$ & $\begin{array}{l}\text { Planning } \\
\text { Design }\end{array}$ & $\begin{array}{l}\text { Planning } \\
\text { Design } \\
\text { Construction } \\
\text { Operations \& } \\
\text { Maintenance }\end{array}$ & $\begin{array}{l}\text { Planning } \\
\text { Design }\end{array}$ \\
\hline $\begin{array}{l}\text { Sustainability } \\
\text { Practices accounted } \\
\text { for }\end{array}$ & $\begin{array}{l}\text { Quality of Life } \\
\text { Leadership } \\
\text { Resource Allocation } \\
\text { Natural World } \\
\text { Climate and Risk }\end{array}$ & $\begin{array}{l}\text { Social } \\
\text { Economic } \\
\text { Environment }\end{array}$ & $\begin{array}{l}\text { Sustainable Sites } \\
\text { Water Quality } \\
\text { Materials and } \\
\text { Resources Energy and } \\
\text { Atmosphere } \\
\text { Innovation/Unlisted }\end{array}$ \\
\hline Levels of Award & $\begin{array}{l}\text { Bronze Award } \\
\text { Silver Award } \\
\text { Gold Award } \\
\text { Platinum Award }\end{array}$ & $\begin{array}{l}\text { Bronze Award } \\
\text { Silver Award } \\
\text { Gold Award } \\
\text { Platinum Award }\end{array}$ & $\begin{array}{l}\text { GreenLITES Certified } \\
\text { GreenLITES Gold } \\
\text { GreenLITES Evergreen }\end{array}$ \\
\hline $\begin{array}{l}\text { Number of Projects } \\
\text { Awarded }\end{array}$ & 38 & at least 1771 & at least 220 \\
\hline $\begin{array}{l}\text { Version of tool used in } \\
\text { study }\end{array}$ & 2 & 1.3 & 2.1 .0 \\
\hline
\end{tabular}

\subsection{Previous Studies on Comparative Assessment of Transportation Sustainability Rating}

Tools

Little research has been carried out on transportation/infrastructure sustainability rating systems and their application (K. A. Griffiths et al., 2017). Research carried out on TSRS with respect to application have focused on the application of one tool to a single project or to multiple projects (Anderson \& Muench, 2013; Bosco \& Buckingham, 2013). Comparative research that have been done on TSRS have focused on the content of the tool (Caroline M. Clevenger et al., 2016; Simpson, 2013). However, a recent study was carried out in New Zealand to analyze how four third-party infrastructure sustainability rating systems (Infrastructure Sustainability (IS); ENVISION; CEEQUAL and Greenroads recognize performance by applying all four rating 
systems to a New Zealand highway viaduct project (K. A. Griffiths et al., 2017). The objective of this study "was to analyze how four-industry based tools recognize performance and to examine similarities and differences in outcome, with the goal of providing practical insights on tool selection and use for infrastructure owners and design and construction practitioners and also to provide new readers with information on the intent, function, potential benefits and shortcomings of these rating system.” ((K. A. Griffiths et al., 2017), Page 3).

The study began with a literature review on the background of rating tools, both in the building and infrastructure industry. The study also explored what research had been done on the rating tools in both industries. Like in other studies (Caroline M. Clevenger et al., 2016; Simpson, 2013), this study also discovered that little research had been done on infrastructure sustainability rating systems and its application (K. A. Griffiths et al., 2017). This finding, thus, inspired the researchers (K. A. Griffiths et al., 2017), to embark on a study of the application of four third-party infrastructure sustainability rating systems, Envision, Infrastructure Sustainability (IS), CEEQUAL and Greenroads, that are commonly used by the industry on a New Zealand Highway Viaduct Project (K. A. Griffiths et al., 2017).

An overview of all four rating system was provided containing information such as year of creation of the tools, the country of origin, the construction phases covered by these tool, the sustainability topics covered in each tool, award levels for each tool, the version of rating tool used for analysis, the number of awarded projects for each tool and the levels of award received by these projects (K. A. Griffiths et al., 2017). An overview of the project being analyzed was also provided with information such as the project type, the project cost, project country, type of environment in which the project was located, reason for the project, the project duration, the 
procurement method used for the project and a physical description of the project given (K. A. Griffiths et al., 2017).

The methodology for this study involved an assessment of the New Zealand Highway Viaduct Project on each of the rating system utilized in the study and a comparison of the results gotten from each rating system was carried out. The project details needed to carry out an analysis were gotten from publicly available information. The researcher who carried out the assessments was an accredited sustainability professional (K. A. Griffiths et al., 2017).

The first step in carrying out the assessment of the New Zealand Highway Viaduct Project was to identify the credits within each rating system that were applicable to the project and scope out the credits that were not applicable to the project. Once this was done, the project's sustainability practices and performance levels were assessed against the requirement of the credits. The total score for each rating system was gotten and awards levels were given to the project on each rating system (K. A. Griffiths et al., 2017). The ratings for the project was carried out using each tool's spreadsheet, online tools and relevant manuals. The practices and outputs derived in all four ratings were tabulated and checked to verify that the approach was transparent as well as consistent. An interview with the project design manager and the assessor who worked on the New Zealand Highway Viaduct Project was also carried out. The results gotten from each rating system was normalized to percentages of the total points and compared (K. A. Griffiths et al., 2017).

One limitation highlighted in this study was that different assessors could derive different results as an exact consistency and science between assessors was not guaranteed (K. A. Griffiths et al., 2017). 


\section{CHAPTER 3: METHODOLOGY}

The comparative assessment of the TSRS utilized in this study were carried out based on a case study research method that will be implemented on five rehabilitation, reconstruction and safety improvement projects by the researcher. The TSRS utilized in this study are ENVISION, INVEST and GreenLITES. ENVISION is a third-party rating system, INVEST is a self-assessed rating and GreenLITES is an in-house rating system. These TSRS are being employed in this study because they provide unique parameters required to achieve the goal of this research. The rehabilitation, reconstruction and safety improvement projects utilized in this study were obtained from publicly available resources provided by the New York State Department of Transportation (NYSDOT). The study focused on only rehabilitation, reconstruction and safety improvement projects because the NYSDOT engages more in these types projects than new projects as they encourage and advance sustainability (NYSDOT, 2017d). In carrying out the comparative assessment of the above-named rating systems, the following steps were taken:

A thorough literature review that examined the various properties and capabilities of each rating system was carried out.

* The rating systems were each applied to five projects gotten from NYSDOT that fall under the category of rehabilitation, reconstruction or safety improvement projects.

* The results gotten from the ratings were compared and assessed based on the triple bottom line (economic, social and environmental).

\subsection{Carrying out a Literature Review}

The literature review is a very important part of this study as it explores the three TSRS employed in the research and exposes their properties. The literature review section provides 
detailed information of the characteristics and capabilities of each rating system employed in the study. Due to the presence of only a few published journal articles on TSRS, the websites of the various developers of the rating systems served as the major source of information for the literature review. The literature review provides vital information such as the project phases in which the rating systems can be applied, the different categories and criteria the rating systems cover (i.e. their capabilities), the awards and recognition each rating system offers, amongst others. The literature review process is done at the inception of the study. However, literature evolves constantly (Simpson, 2013). Therefore, continuous review of literature continued throughout the research process to ensure that the study is up to date on information available to enhance it.

\subsection{Case Study Research Method}

According to the United States General Accounting Office (GAO), a case study is defined as a method utilized in gaining knowledge about a complex case based on comprehensively understanding that case (GAO, 1990). This understanding is derived from a thorough account and examination of that case taken in whole and within context (GAO, 1990). The Case Study Design and Methods textbook by Robert K. Yin defines case study as "an empirical inquiry that investigates a contemporary phenomenon in depth and within its real life context." ((Yin, 2009); Page 18). According to this definition, the case study method is used to gain an in-depth understanding of real life phenomenon. The case study research methodology is applied in studies in which the researcher carries out an in-depth analysis of a process, activity, case, event or program (Creswell, 2013).This research methodology, which is a type of qualitative research method, is interpretative research in which the researcher is involved gives a summary of his interpretations of a process, activity, case, event or program (Creswell, 2013). 
The Case Study Research Methodology is employed in this study by the researcher with the aim of carrying out ratings on the five projects utilized in the study.

The rehabilitation, reconstruction and safety improvement projects investigated in this study were selected based on these criteria:

* The date of completion of the project. According to the Envision Training, the completion date of any projects assessed by the rating system must not be later than the last three years.

Projects that provide contract documents such as plans, specifications and additional information such as environmental assessment reports and bid proposals. This is because the provision of all these information makes assessing each project less tedious and more complete.

The researcher carried out ratings for each of the five projects investigated in this study.

\subsection{The Scoring Process}

The steps taken in the scoring process include:

$>$ An initial review of categories, credits and criteria contained in each rating system so as to inform the researcher of practices and performance covered by each rating system.

$>$ A thorough study of each project and the sustainability practices integrated in them.

Each project was scored and rated with each rating system. The rating process involved assessing the project's sustainability practices and performance levels against the requirement of the credits/criteria of each rating system.

The total score for each rating system was identified and awards levels were given to each of the projects on each rating system. 
The ratings for the project was carried out using the spreadsheets, online tools and relevant manuals/guides for each rating system as suggested in the New Zealand study (K. A. Griffiths et al., 2017). The results obtained from the ratings was analyzed based on how the projects performed in each category of the rating system as well as their overall performance on each rating system. The results obtained from running each of the projects through the three rating systems were compared. The results were compared consistently by comparing criteria/credits/categories that fall under each aspect of the triple bottom line (economic, social and environmental). Through this comparison, trends or consistencies were identified. The trends or consistencies were identified by looking out for similarities or differences in a project's performance in each category of the three rating systems being investigated as well as their overall performance on these rating systems.

The research methodology utilized in this study replicates the methodology applied in the (K. A. Griffiths et al., 2017) study. However, this study addresses a limitation identified in the New Zealand Study (K. A. Griffiths et al., 2017) by running multiple transportation projects through each rating system. Due to the presence of more data, this approach is likely to produce more confidence in recognizing consistencies (or a lack thereof).

\subsection{Description of Projects Analyzed in Study}

Five rehabilitation, reconstruction and safety improvement projects have been analyzed in this study. These projects were carried out by the NYSDOT. They were selected based on their completion date and available contract documents such as plans, specifications, and additional information such as environmental assessment reports and bid proposals. 


\subsubsection{D262883 F. A. Project - Route 28, Old Forge to Hamilton County Line, Herkimer County,}

New York.

The D262883 F A. Project is a 9.3-mile pavement rehabilitation project that started in the Hamlet of Old Forge and ended at the Hamilton County Line. Located in the Herkimer County in the state of New York, the project aims to improve pavement conditions for the next ten years while ensuring the safety of the travelling public (NYSDOT, 2014b). The pavement improvement was achieved by applying cost effective pavement treatments to restore the pavement surfaces and maintain its structural integrity. These treatments include Mill and Fill and Cold-in-Place Recycle (CIPR) with a two-course overlay (NYSDOT, 2014b). The project also replaced the box beam guiderail, which had become rustic, with new galvanized rail. Other works carried out on this project include the replacement of two snowmobile crossings, work on driveways and intersections and the replacement of handicap ramps in the Hamlet of Old Forge (NYSDOT, 2014b).

Due to the project being located in a rural area, public involvement was excluded. However, local officials were advised on the project scope as well as schedule so as to obtain their input on Work Zone Traffic Control concerns. Travel advisories were also issued out to advise the public on potential traffic disruptions throughout the construction process (NYSDOT, 2014b). The procurement method utilized in this project is the design-bid-build method (NYSDOT, 2014a). The estimated cost of this project is $\$ 9,720,000.00$ (nine million, seven hundred and twenty million dollars) (NYSDOT, 2014b). 
3.4.2. D263387 F. A. Project-I390, I490, and Lyell Avenue Interchange Improvements, Phase 2, City of Rochester, Town of Gates.

The D263387 F. A. Project is the second stage of a four-stage project for the I390 interchange improvements at I490 located in the Town of Gates, Monroe County (NYSDOT, 2018b). The objective of this project is to improve rush hour traffic flow, while decreasing accidents that occur due to congestion for the nearly 200,000 vehicles that ply the interchange daily. This improvement will occur specifically at two locations namely; I490 westbound ramp to route 390 northbound and route 390 southbound ramp to I490 eastbound (NYSDOT, 2018a). The project also aims to improve the traffic flow for vehicles exiting route 390 at the Lyell Avenue Interchange and carry out improvements to Lyell Avenue (Route 31) and the Lyell Avenue Bridge over route 390 (NYSDOT, 2018a).

In the early design stage, the design team utilized community input/contributions to establish the project's purpose, document the project's objectives/aim and identify transport related needs peculiar to the community (NYSDOT, 2018a). The project is located in an urban area. The procurement method employed in this project is the design-bid-build method (NYSDOT, 2015a). The estimated cost of this project is $\$ 51,170,864.00$ (fifty one million, one hundred and seventy thousand, eight hundred and sixty four dollars) (NYSDOT, 2018b).

3.4.3. D263411 F. A. Project - Route 146 (Hamburg Street) Safety Improvements (1.5 miles, roundabout, new waterline and sewer system), Town of Rotterdam.

The D263411 F. A. Project is a safety improvement project that involves the reconstruction of Hamburg Street from Curry Road to the bridge over Chrisler Avenue (NYSDOT, 2018e). Located in the Town of Rotterdam, Schenectady County, the project will include safety 
improvements such as access management, pedestrian and ADA (Americans with Disability Acts) facility upgrades, shared turn lanes and stormwater system improvements. A municipal sewer line will also be installed within the project limits. This sewer line is intended to service the residential and business needs of the neighborhood (NYSDOT, 2018e).

Community involvement was a part of this project as a town hall meeting was held to inform and engage the community in the project design process (NYSDOT, 2015d). The project is located in an urban area surrounded by residents and businesses (NYSDOT, 2018e). The procurement method applied in this project is the design-bid-build method (NYSDOT, 2015b). The estimated cost of the project is $\$ 12,529,755.00$ (Twelve million, five hundred and twenty nine thousand, seven hundred and fifty five dollars) (NYSDOT, 2018e).

\subsubsection{D263477 F. A. Project - NYS Route 231 Safety Improvements at Northern State Parkway} Interchange in the Town of Huntington.

The D263477 F. A. Project is a safety improvement project carried out on NY Route 231 at the Northern State Parkway Interchange in the Town of Huntington, Suffolk County (NYSDOT, 2018c). The project aims to improve traffic flow, reduce delays and accidents and improve overall safety and traffic operations of NY Route 231 at the interchange. Parkway ramps will be improved upon or constructed within the existing right -of-way of the parkway property. Improvements of pedestrian access will also be carried out (NYSDOT, 2018c).

This project incorporates community involvement by conducting public information sessions, publishing flyers in the newspaper to inform the community about the project and posting project brochures and information from meetings on a project specific web page. The project is located in an urban area. The procurement method applied in this project is the design-bid-build 
method (NYSDOT, 2016). The estimated cost of the project is $\$ 15,696,275.00$ (Fifteen million, six hundred and ninety six thousand, two hundred and seventy five dollars) (NYSDOT, 2018c).

\subsubsection{D263572 F. A. Project-Highway Reconstruction on Route 5S (1 Mile) in the City of Utica.}

The D263572 F. A. Project is a highway reconstruction project carried out on a mile of route 5S (Oriskany Street) in the City of Utica, Oneida County (NYSDOT, 2015c). This project has been identified to have a crash rate higher than the statewide average rate. The project, therefore, aims to address this safety concern along route $5 \mathrm{~S}$ by reducing the potential for vehicle conflicts, reducing the overall accident rates within the project limits, improving the overall operational conditions of roadway, improving pedestrian and bicyclist safety, access and mobility using complete street strategies, providing ADA compliant facilities supporting projects and initiatives for economic revitalization of the project area and creating an attractive gateway to downtown Utica (NYSDOT, 2017a, 2017b).

The project starts on the west end at the intersection of 5S and Cornelia Street and proceeds nearly 4,400 feet east to the intersection of $5 \mathrm{~S}$ and Broad Street. The work to be carried out consists of reconfiguration and reconstruction of significant portions of route $5 \mathrm{~S}$, lane reductions/removal, construction of a roundabout at the intersection with John Street, significant improvements to pedestrian and bicycle accommodations and facilities, pavement markings, new/modified overhead sign structures, new/replacement signals and the addition of substantial landscaping to enhance the aesthetic of the project corridor (NYSDOT, 2017a, 2017b).

Members of the public, stakeholder groups with the City of Utica as well as community groups across the city were met in over thirty meeting. Public information meetings were held at different stages of the project development where inputs and concerns that helped to shape the 
project were discussed (WKTV, 2018). There was also a project specific website where information on the project was regularly updated. The project is located in an urban area surrounded by residents and businesses. The procurement method employed in this project is the design-bid-build method (NYSDOT, 2015c). The estimated construction cost is $\$ 16,515,001$ (Sixteen million, five hundred and fifteen thousand and one dollar) (NYSDOT, 2018d).

\subsection{Addressing the Triple Bottom Line}

The results of this study are presented based on how the projects performed in each rating system and in relation to the triple bottom line (environment, social and economic). The triple bottom line has been addressed under five categories as a result of being unable to completely delineate some credits as providing solely economic or social or environmental benefits of Sustainability. For example, the use of renewable energy as well as managing stormwater have both environmental and economic implications and benefits.

Given the foregoing, the five categories in which the triple bottom line will be addressed in this study are: Environment, Quality of Life/Social, Material, Energy and Water Quality. 


\section{CHAPTER 4: RATING OF PROJECTS AND FINDINGS}

This chapter presents the findings gotten from the rating of five road transportation projects with the three rating systems (Envision, INVEST and GreenLITES) being studied in this research. Each project was run through each of the rating system and the results derived from the rating are discussed here.

A literature review was first carried out by the researcher, in which, the three rating systems, their credits/criteria and their peculiarities and differences were discussed at length. While most previous studies on transportation sustainability rating systems have been limited to comparing the rating systems based on just the content, this study goes further by comparatively assessing these rating systems based on their application to transportation projects. Each transportation project studied will be discussed based on performance on each rating system, performance in relation to the triple bottom line (Environment, Social and Economic) and consistencies or trends observed in the rating systems. The transportation projects being studied have been discussed in Chapter 3.

The ratings derived from Envision and INVEST rating systems were carried out by the researcher. However, the ratings derived from GreenLITES were retrieved from the NYSDOT. It is necessary to note that the GreenLITES ratings have not gone through any review or verification process as the rating system is a self-certified program.

\subsection{Rating the Projects}

The location of a project as well as the project type and scope, among other things, determine the credits/criteria that may or may not apply to the project. For instance, a project located in a rural area with no residents or business around it may not be required to incorporate 
HOV (high occupancy vehicle) lanes. In running the projects through the rating system, an important step was to identify credits/criteria that are applicable to the project based on its context (K. A. Griffiths et al., 2017). However, the Envision rating system was the only system that gave the option of manually selecting credits that did not apply to the project (ISI, 2015).

The project development module of INVEST rating system, which was applied in this study, has seven scorecards, one of which can be selected to rate a project depending on the project type (FHWA, 2017h). The scorecard selected automatically scopes out credits that are considered irrelevant to the project type. The GreenLITES rating system neither gave the option of selecting applicable credits nor did it automatically scope out any credit. Therefore, all 175 credits contained in the GreenLITES rating system were considered in the rating of the five projects studied in this research.

\subsection{D262883 F. A. Project - Route 28, Old Forge to Hamilton County Line, Herkimer County, New York.}

Project D262883 is a 9.3 mile rehabilitation project located in the rural area of Adirondack Park, Town of Webb, Herkimer County in the state of New York (NYSDOT, 2014b). Due to the project's location and scope, a few credits/criteria under the rating systems were not applicable to the project. Under the Envision and INVEST rating systems, the inapplicable credits/criteria were scoped out. However, with the GreenLITES rating system, it was impossible to do that. Table 4.1 shows how project D262883 performed on the three rating systems. When run through the Envision rating system, project D262883 scored 98 points out of 711 applicable points. This result was normalized to $13.8 \%$ leaving the project with no award. On the INVEST rating system, project D262883 scored 34 points out of 119 points which was insufficient to earn an award. The result 
was normalized to $28.6 \%$. On the GreenLITES rating system, the project scored 4 out of 278 points. This score was also insufficient to earn any award. The normalized score was $1.4 \%$.

Table 4.1: Project D262883's Normalized Score and Award Level on Each Rating System

\begin{tabular}{lccl}
\hline Rating System & $\begin{array}{c}\text { Points } \\
\text { assessed/Points } \\
\text { Applicable }\end{array}$ & $\begin{array}{c}\text { Normalized Score (\% } \\
\text { of Applicable Points) }\end{array}$ & Award Level \\
\hline Envision & $98 / 711$ & $13.8 \%$ & No certification \\
\hline INVEST & $34 / 119$ & $28.6 \%$ & No certification \\
\hline GreenLITES & $4 / 278$ & $1.4 \%$ & No certification \\
\hline
\end{tabular}

Figure 4.1 shows the points achieved across the five categories considered in this study. With all three rating systems, the Energy category received no points while the Quality of Life/Social and the Material categories achieved some points. In applying the three rating systems, Envision, INVEST and GreenLITES, to the project, it achieved $7.6 \%, 3.4 \%$ and $0.7 \%$ respectively in the Quality of Life/Social category and $1.1 \%, 14.3 \%$ and $0.7 \%$ respectively in the Material category. Under the Envision and INVEST rating systems, project D262883 scored 4.8\% and $10.9 \%$ respectively in the Environment category while it scored no points under the GreenLITES system for that category. Project D262883 scored 0.3\% under the Envision rating system but attained no points under the other rating systems. It can be noted that these points achieved under the Quality of Life/Social, Material, Environment and Water Quality categories are not evenly distributed. 


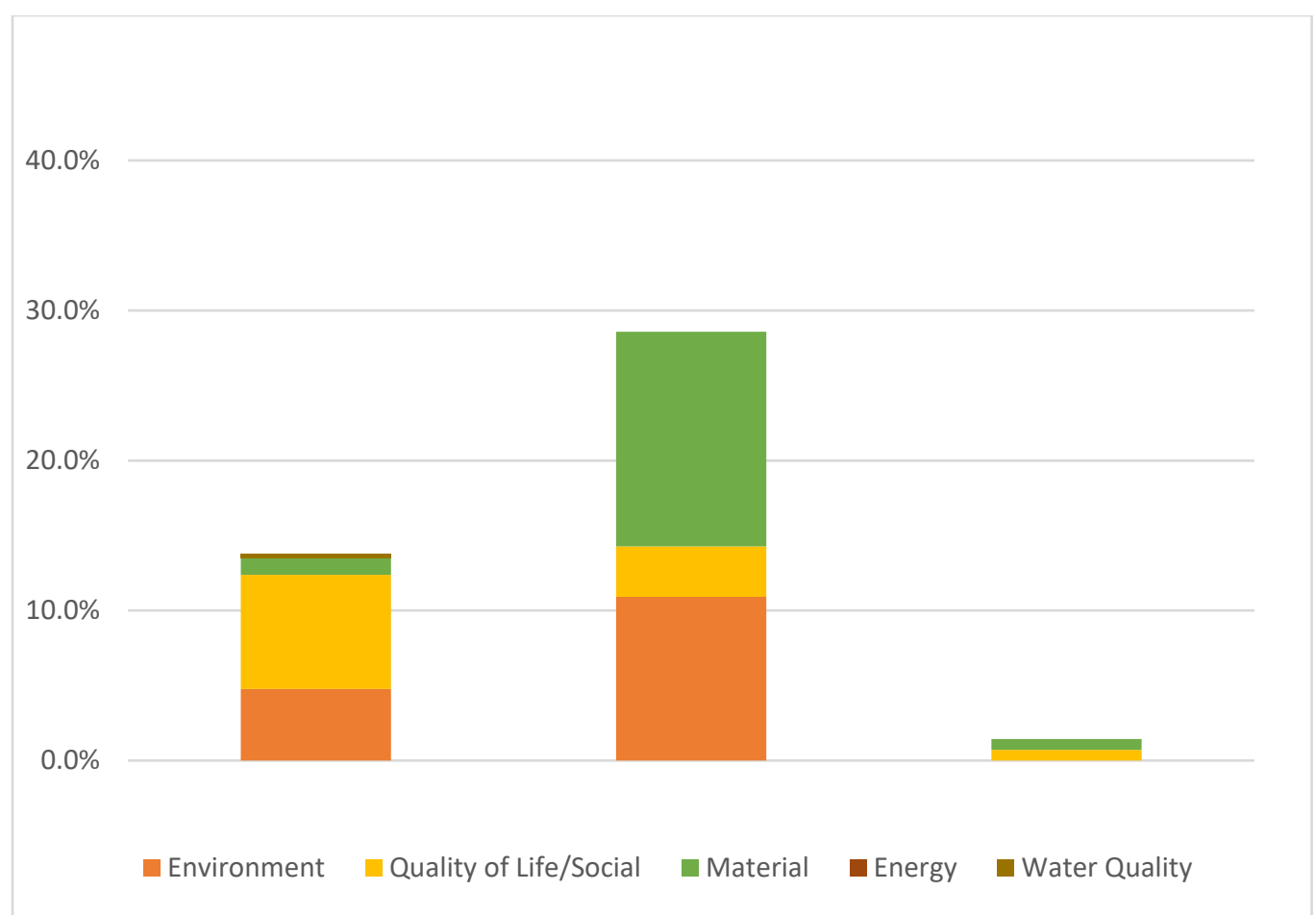

Figure 4.1. Project D262883 points spread across the five categories considered in this study.

\subsubsection{Envision Rating for Project D262883}

Under the Envision rating system, project D262883 had a normalized score of $13.8 \%$ resulting from a score of 98 points out of 711 applicable points. Nine credits were scoped out due to their inapplicability to the project. These credits were scoped out based on information provided in the project documents used to carry out the ratings for this project. No points were given for innovation in all categories. Hence, all five innovation credits were inapplicable to the project. Forty-six (46) credits out of the sixty (60) credits in the Envision rating system were applicable to this project. Project D262883 scored no points in 26 of the applicable credits. Table 4.2 shows the Envision credits applicable to project D262883. Figure 4.2 shows the points the project earned across the categories in the Envision rating system in relation to the applicable points for each category. 
Table 4.2: Envision Credits Applicable to Project D262883

\begin{tabular}{|l|l|c|}
\hline \multicolumn{2}{|l|}{ ENVISION CREDITS } & D262883 \\
\hline Quality of Life & $\mathrm{X}$ \\
\hline QL1.1 & Improve Quality of Life & $\mathrm{X}$ \\
\hline QL1.2 & Stimulate Sustainable Growth and Development & $\mathrm{X}$ \\
\hline QL1.3 & Develop Local Skills and Capabilities & $\mathrm{X}$ \\
\hline QL2.1 & Enhance Public Health and Safety & $\mathrm{X}$ \\
\hline QL2.2 & Minimize Noise and Vibration & $\mathrm{X}$ \\
\hline QL2.3 & Minimize Light Pollution & $\mathrm{X}$ \\
\hline QL2.4 & Improve Community Mobility and Access & $\mathrm{X}$ \\
\hline QL2.5 & Encourage Alternative Modes of Transportation & $\mathrm{X}$ \\
\hline QL2.6 & Improve Site Accessibility, Safety and Wayfinding & \\
\hline QL3.1 & Preserve Historic and Cultural Resources & \\
\hline QL3.2 & Preserve Views and Local Character & \\
\hline QL3.3 & Enhance Public Space & \\
\hline QL0.0 & Innovate or Exceed Credit Requirements & $\mathrm{X}$ \\
\hline Leadership & & $\mathrm{X}$ \\
\hline LD1.1 & Provide Effective Leadership and Commitment & $\mathrm{X}$ \\
\hline LD1.2 & Establish a Sustainability Management System & $\mathrm{X}$ \\
\hline LD1.3 & Foster Collaboration and Teamwork & $\mathrm{X}$ \\
\hline LD1.4 & Provide for Stakeholder Involvement & $\mathrm{X}$ \\
\hline LD2.1 & Pursue Byproduct Synergy Opportunities & $\mathrm{X}$ \\
\hline LD2.2 & Improve Infrastructure Integration & $\mathrm{X}$ \\
\hline LD3.1 & Plan for Long-term Monitoring and Maintenance & $\mathrm{X}$ \\
\hline LD3.2 & Address Conflicting Regulations and Policies & $\mathrm{X}$ \\
\hline LD3.3 & Extend Useful Life & $\mathrm{X}$ \\
\hline LD0.0 & Innovate or Exceed Credit Requirements & $\mathrm{X}$ \\
\hline Resource Allocation & $\mathrm{X}$ \\
\hline RA1.1 & Reduce Net Embodied Energy & $\mathrm{X}$ \\
\hline RA1.2 & Support Sustainable Procurement Practices & \\
\hline RA1.3 & Use Recycled Materials & \\
\hline RA1.4 & Use Regional Material & \\
\hline RA1.5 & Divert Waste from Landfills & \\
\hline RA1.6 & Reduce Excavated Materials Taken Off Site & \\
\hline RA1.7 & Provide for Deconstruction and Recycling & \\
\hline RA2.1 & Reduce Energy Consumption & \\
\hline RA2.2 & Use Renewable Energy & \\
\hline RA2.3 & Commission and Monitor Energy Systems & \\
\hline RA3.1 & Protect Fresh Water Availability & \\
\hline RA3.2 & Reduce Potable Water Consumption & \\
\hline RA3.3 & Monitor Water Systems & \\
\hline RA0.0 & Innovate or Exceed Credit Requirements & \\
\hline
\end{tabular}




\begin{tabular}{|l|l|c|}
\hline \multicolumn{2}{|l|}{ Natural World } & X \\
\hline NW1.1 & Preserve Prime Habitat & $X$ \\
\hline NW1.2 & Protect Wetlands and Surface Water & \\
\hline NW1.3 & Preserve Prime Farmland & $X$ \\
\hline NW1.4 & Avoid Adverse Geology & \\
\hline NW1.5 & Preserve Floodplain Functions & $X$ \\
\hline NW1.6 & Avoid Unsuitable Development on Steep Slopes & $X$ \\
\hline NW1.7 & Preserve Greenfield & $X$ \\
\hline NW2.1 & Manage Stormwater & $X$ \\
\hline NW2.2 & Reduce Pesticide and Fertilizer Impacts & $X$ \\
\hline NW2.3 & Prevent Surface and Groundwater Contamination & $X$ \\
\hline NW3.1 & Preserve Species Biodiversity & $X$ \\
\hline NW3.2 & Control Invasive Species & $X$ \\
\hline NW3.3 & Restore Disturbed Soils & \\
\hline NW3.4 & Maintain Wetland and Surface Water Functions & $X$ \\
\hline NW0.0 & Innovate or Exceed Credit Requirements & \\
\hline Climate and Risk & $X$ \\
\hline CR1.1 & Reduce Greenhouse Gas Emissions & $X$ \\
\hline CR1.2 & Reduce Air Pollutant Emissions & $X$ \\
\hline CR2.1 & Assess Climate Threat & $X$ \\
\hline CR2.2 & Avoid Traps and Vulnerabilities & \\
\hline CR2.3 & Prepare for Long-Term Adaptability & \\
\hline CR2.4 & Prepare for Short-Term Hazards & \\
\hline CR2.5 & Manage Heat Island Effects & \\
\hline CR0.0 & Innovate or Exceed Credit Requirements & \\
\hline
\end{tabular}

As shown in Figure 4.2, project D262883 performed best in the Leadership category earning a score of 37 points out of 113 . The Leadershipncategory was followed closely by the Natural World category where the project scored 36 points out of 177 . The project performed fairly in the Quality of Life and Resource Allocation categories scoring 17 points and 8 points respectively. The project scored no points in the Energy category.

The credits under the Envision rating system were split into the five categories considered in this study. The credits were split based on what aspect of the five categories they are related to. Figure 4.3 illustrates the points the project earned in the five categories considered in this study in relation to the applicable points for each category. 


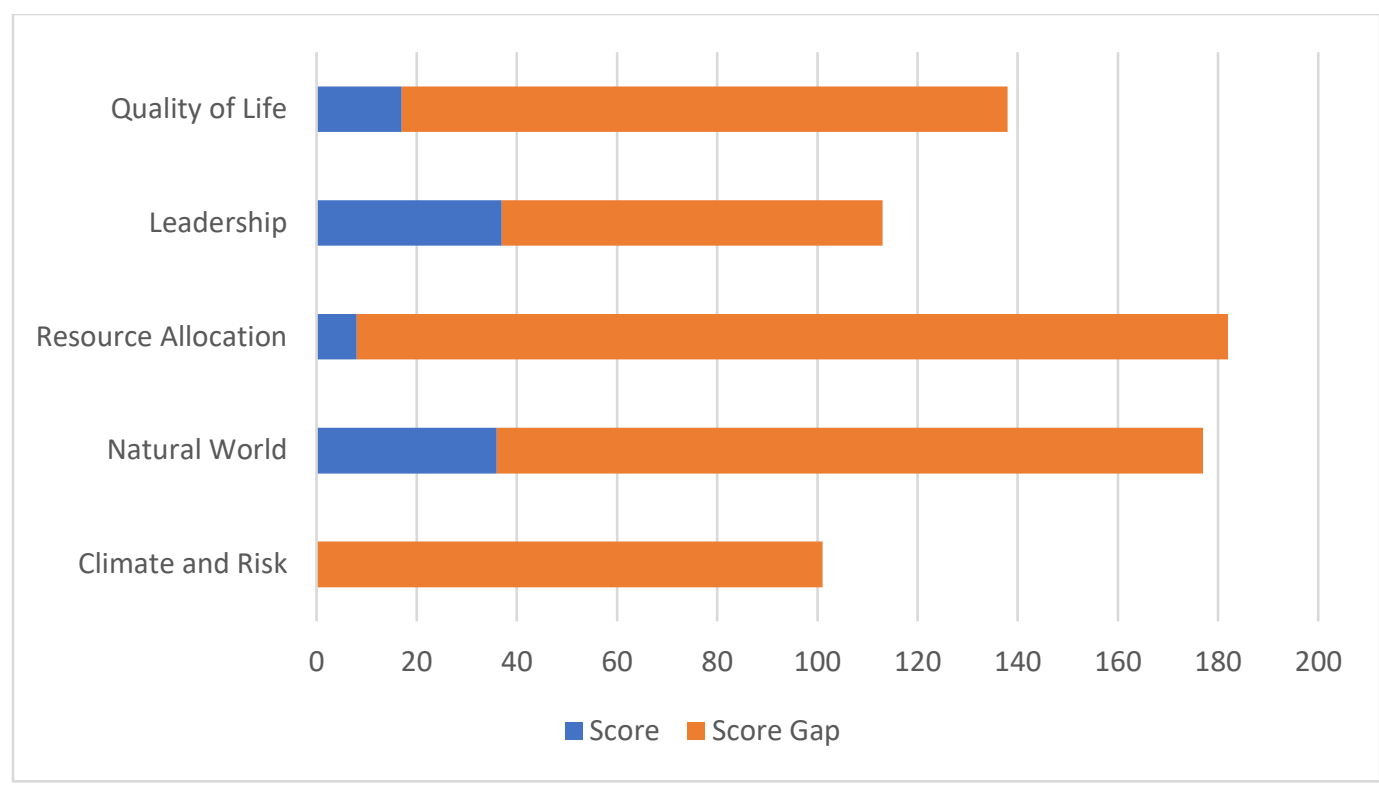

Figure 4.2. Points achieved in relation to applicable points across each category of Envision rating system for Project D262883.

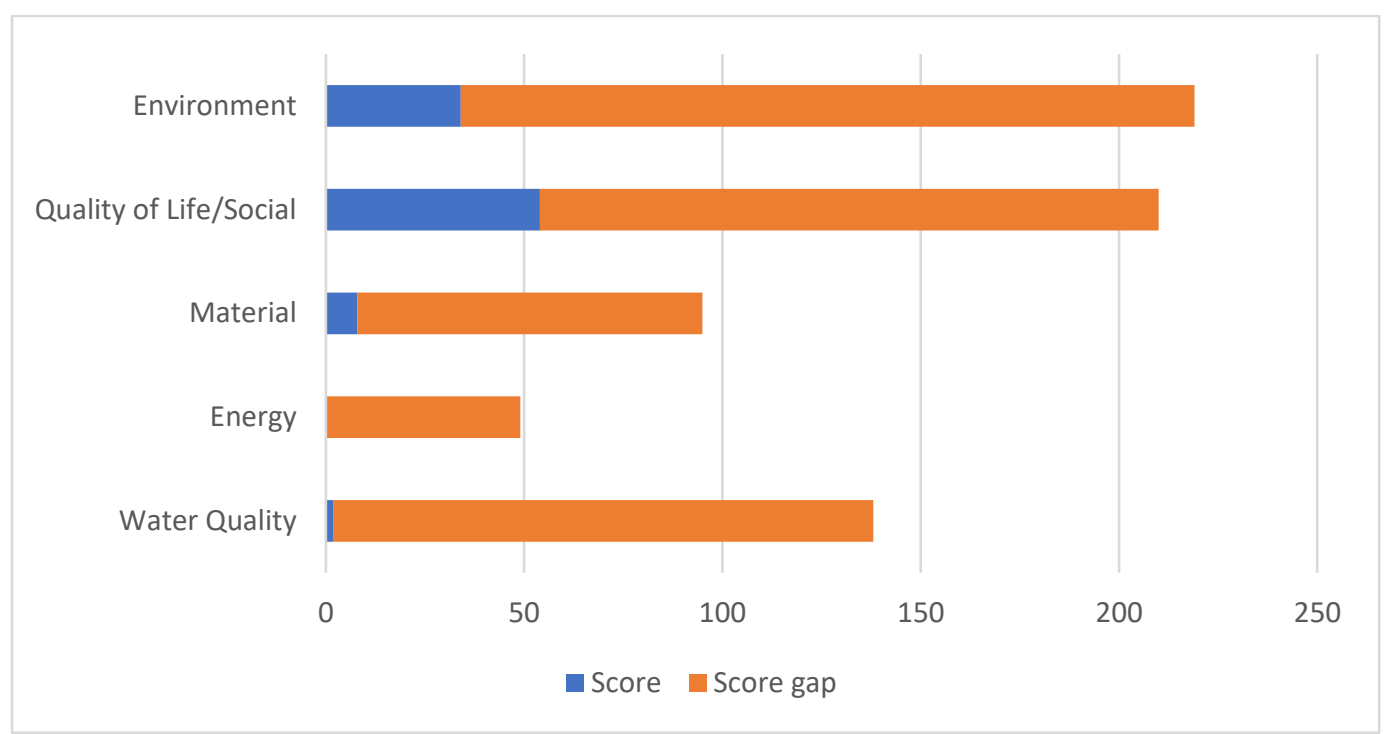

Figure 4.3. Points achieved in relation to applicable points across the five categories considered in this study for the Envision rating system for Project D262883.

The Environment category is made up of two applicable credits under the Leadership category namely: Improve Infrastructure Integration and Plan for Long-term Monitoring and Maintenance; six applicable credits under the Natural World category namely: Preserve Prime 
Habitat, Preserve Floodplain functions, Preserve Greenfields, Preserve Species Biodiversity, Control Invasive Species and Restore Disturbed Soils; and five applicable credits under the Climate and Risk category namely: Reduce Greenhouse Gas Emissions, Assess Climate Threats, Avoid Traps and Vulnerabilities, Prepare for Long-Term Adaptability and Prepare for Long Term Hazards. In this category, the project earned 34 points out of 219 applicable points.

The Quality of Life/Social category is made up of nine applicable credits under the Quality of Life category namely: Improve Community Quality of Life, Stimulate Sustainable Growth and Development, Develop Local Skills and Capabilities, Enhance Public Health and Safety, Minimize Noise and Vibration, Minimize Light Pollution, Improve Community Mobility and Access, Encourage Alternative Modes of Transportation, Improve Site Accessibility, Safety and Wayfinding; five credits under the Leadership category namely: Provide Effective Leadership and Commitment, Establish a Sustainability Management System, Foster Collaboration and Teamwork, Provide for Stakeholder Involvement and Extend Useful Life. In this category, the project earned 54 points out of 210 applicable points.

The Material category is made up of one applicable credit under the Leadership category namely: Pursue Byproduct Synergy Opportunities; and seven applicable credits under the Resource Allocation category namely: Reduce Net Embodied Energy, Support Sustainable Procurement Practices, Use Recycled Materials, Use Regional Materials, Divert Waste From Landfills, Reduce Excavated Materials Taken Off Site and Provide for Deconstruction and Recycling. In this category, the project earned 8 points out of 95 applicable points.

The Energy category is made up of three applicable credits under the Resource Allocation category namely: Reduce Energy Consumption, Use Renewable Energy and Commission and Monitor Energy Systems. In this category, the project earned 0 points out of 49 applicable points. 
The Water Quality category is made up of three applicable credits under the Resource Allocation category namely: Protect Fresh Water Availability, Reduce Potable Water Consumption and Monitor Water Systems; and five applicable credits under the Natural World category namely: Protect Wetlands and Surface Water, Manage Stormwater, Reduce Pesticide and Fertilizer Impacts, Prevent Surface and Groundwater Contamination and Maintain Wetland and Surface Water Functions. In this category, the project earned 2 points out of 138 applicable points.

In the five categories considered in this study, Project D262883 had its best performance in the Quality of Life category followed by the Environment category. The project had a poor performance in the Material, Energy and Water Quality categories.

\subsubsection{INVEST Rating for Project D262883}

The Project Development module of the INVEST rating system was applied in this study. The selected scorecard was the Basic Rural scorecard which applies to small rural reconstruction or rural bridge replacement project that does not expand the capacity of the roadway. This scorecard was chosen because the project is a rehabilitation project that does not require any road capacity expansion and is located in a rural area. With this scorecard, only 23 criteria out of the 33 criteria contained in the Project Development module were applicable to Project D262883. Project D262883 scored no points in 12 of these criteria. The project had an overall score of 34 points out of 119 achievable points. This score was normalized to $28.6 \%$. The INVEST rating system, unlike Envision and GreenLITES rating systems, is not divided into categories. Hence, the project performance will only be discussed with respect to the five categories considered in this study.

The criteria under the INVEST rating system were split into the five categories considered in this study. The criteria were split based on what aspect of the five categories they are related to. 
Figure 4.4 illustrates the points the project earned in the five categories considered in this study in relation to the applicable points for each category.

The Environment category is made up of six criteria namely: Tracking Environmental Commitments, Habitat Restoration, Ecological Connectivity, Site Vegetation, Maintenance and Irrigation, Construction Environmental Training and Light Pollution. The project earned a total of 13 points out of 26 achievable points.

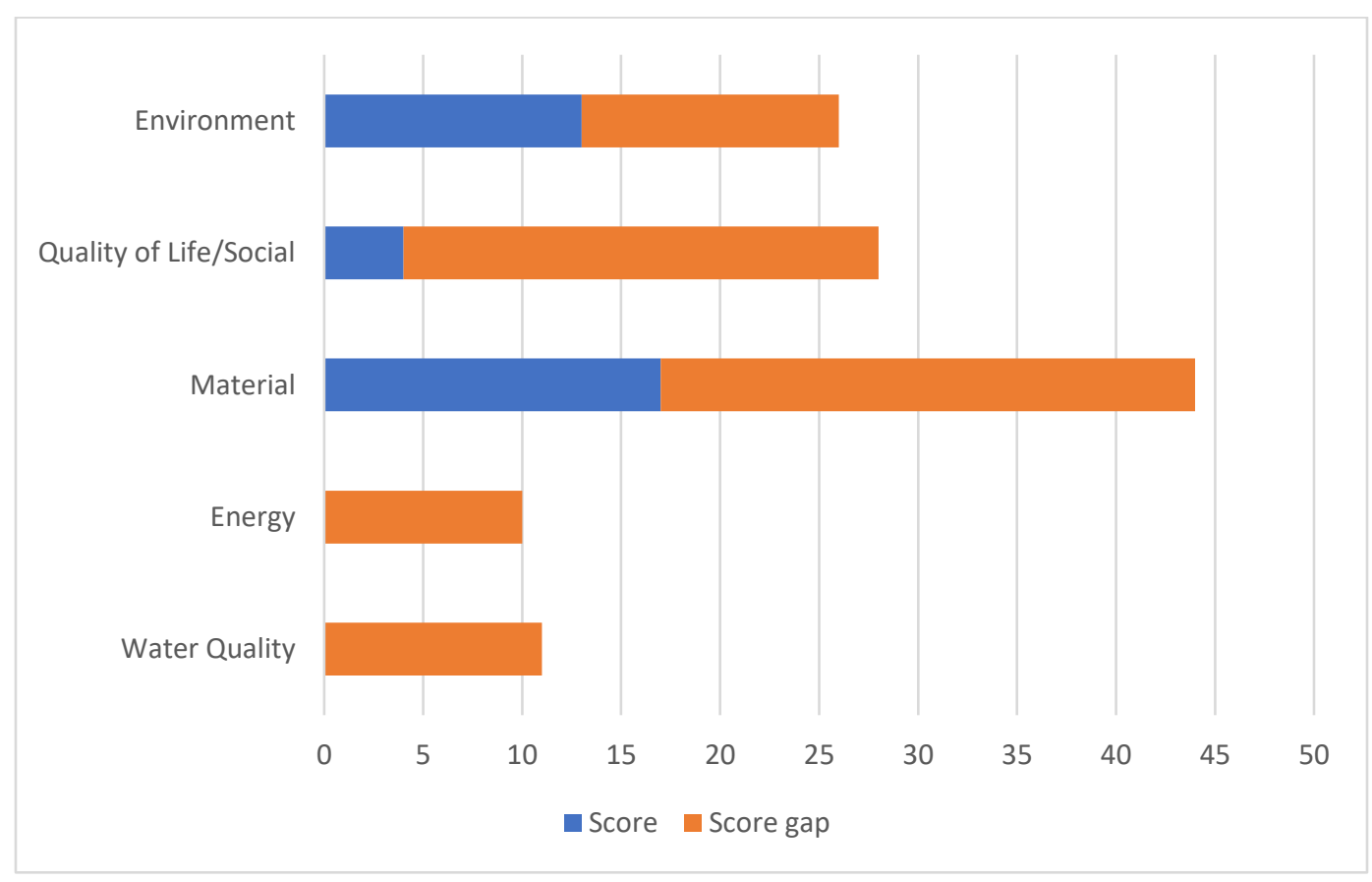

Figure 4.4. Points earned in relation to achievable points across the five categories considered in this study for the INVEST rating system for Project D262883.

The Quality of Life/Social category is made up of five criteria namely: Context Sensitive Project Development, Highway and Traffic Safety, Educational Outreach, Historic, Archaeological, and Cultural Preservation and Scenic, Natural or Recreational Qualities. The project earned a total of 4 points out of 28 achievable points. 
The Material category is made up of seven criteria namely: Lifecycle Cost Analyses, Reduce, Reuse and Repurpose Materials, Recycle Materials, Long-Life Pavement, Reduced Energy and Emissions in Pavement Materials, Construction Quality Control Plan and Construction Waste Management. The project earned 17 points out of 44 achievable points.

The Energy category is made up of two criteria namely: Energy Efficiency and Construction Equipment Emission Reduction. The project earned 0 points out of 10 achievable points. The last category, the Water Quality category, is made up of three criteria namely: Stormwater Quality and Flow Control, Permeable Pavement and Low Impact Development. The project earned 0 points out of 11 achievable points.

In the INVEST rating system, project D262883 had its best performance in the Materials category and Environment category. The project, however had a fair performance in the Quality of Life category and poor performances in the Energy and Water Quality categories.

\subsubsection{GreenLITES Rating for Project D262883}

When run through the GreenLITES rating system, project D262883 scored 4 points out of 278 achievable points with a normalized point of $1.4 \%$. Although not all credits were applicable to project D262883, no credit was scoped out in this rating system. The inability to scope out inapplicable credits based on the project context eventually affects the overall score/rating of the project. Project D262883 scored no points in 172 credits. Figure 4.5 displays the points earned across the categories in the GreenLITES rating system in relation to the applicable points for each category. As shown in Figure 4.5, the project had an overall poor performance on this rating systems scoring 2 points respectively in the Materials and Resources as well as Energy and Atmosphere categories. The project scored no points in the other categories. 
The credits under the GreenLITES rating system were split into the five categories considered in this study. The credits were split based on what aspect of the five categories they are related to. Figure 4.6 illustrates the points the project earned in the five categories considered in this study in relation to the applicable points for each category. It is important to note that the Innovation category of the GreenLITES system is a general category with seven applicable points that cannot be placed under any of the five categories considered in this study.

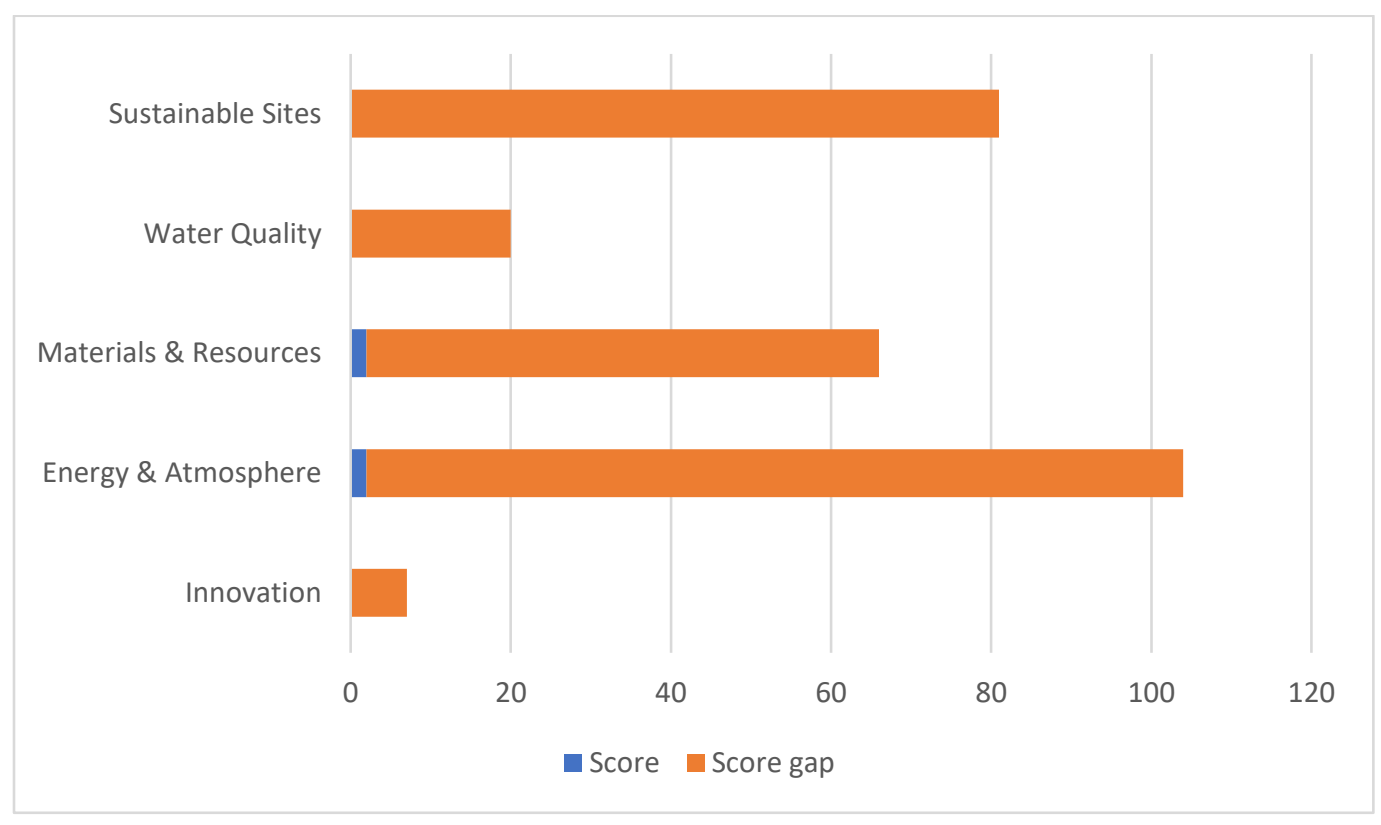

Figure 4.5. Points achieved in relation to applicable points across each category in GreenLITES rating system for Project D262883.

The Environment category is made up of five GreenLITES sub-categories namely: Alignment Selection, Protect, Enhance or Restore Wildlife Habitat, Protect, Plant or Mitigate for Removal of Trees \& Plant Communities, Noise Abatement and Stray Light Pollution. These subcategories have a total of 42 credits and 61 achievable points. In this category, the project earned 0 points out of 61 achievable points. 
The Quality of Life/Social category is made up of three sub-categories namely: Context Sensitive Solution, Land Use/Community Planning and Improve Bicycle and Pedestrian Facilities. These sub-categories have a total of 50 credits and 70 achievable points. In this category, the project scored 2 points out of 70 achievable points.

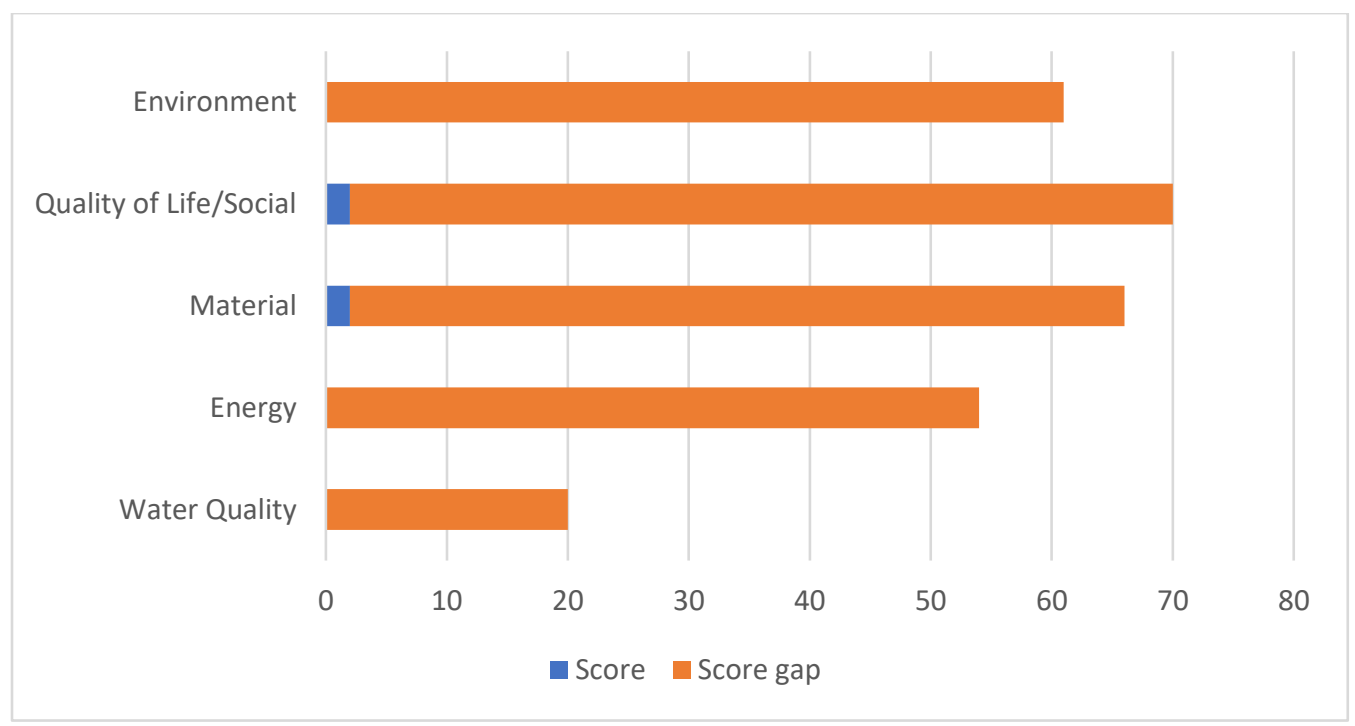

Figure 4.6. Points scored in relation to achievable points across the five categories considered in this study for the GreenLITES rating system for Project D262883.

The Material category is made up of five sub-categories namely: Reuse of Materials, Recycled Content, Local Materials, Bio-engineering Techniques and Hazardous Material Minimization. These sub-categories have a total of 39 credits and 66 achievable points. In this category, the project scored 2 points out of 66 achievable points.

The Energy category is made up of three sub-categories namely: Improved Traffic Flow, Reduce Electrical Consumption and Reduce Petroleum Consumption. These sub-categories have a total of 32 credits and 54 achievable points. In this category, the project scored 0 points out of 54 achievable points. 
The Water Quality category is made up of two sub-categories namely: Stormwater Management (Volume \& Quality) and Best Management Practices (BMPs). These subcategories have a total of 12 credits and 20 achievable points. In this category, project D262883 scored 0 out of 20 achievable points.

In the five categories considered, project D262883 also performed poorly, scoring 2 points respectively in the Quality of Life/Social and Material categories and no points in the other categories.

\subsection{D263387 F. A. Project - I390, I490, and Lyell Avenue Interchange Improvements, Phase 2, City of Rochester, Town of Gates.}

Project D263387 is the second phase of a four-phase project on the I390, I490 and Lyell Avenue. The project is located in an urban area in the City of Rochester, Town of Gates (NYSDOT, 2015a). Under the Envision and INVEST rating systems, credits/criteria that are inapplicable to the project were scoped out. Table 4.3 shows how project D263387 performed on the three rating systems. When run through the Envision rating system, project D263387 scored 170 points out of 725 applicable points. This result was normalized to $23.4 \%$ earning the project a Bronze award. On the INVEST rating system, project D263387 scored 41 points out of 135 points with a normalized score to $30.4 \%$. This score earned the project a Bronze award. On the GreenLITES rating system, the project scored 40 out of 278 points. This score earned the project a Silver award. The normalized score is $14.4 \%$. 
Table 4.3: Project D263387's Normalized Score and Award Level on Each Rating System

\begin{tabular}{lccc}
\hline Rating System & $\begin{array}{c}\text { Points } \\
\text { assessed/Points } \\
\text { Applicable }\end{array}$ & $\begin{array}{c}\text { Normalized Score } \\
\text { (\% of Applicable } \\
\text { Points) }\end{array}$ & Award Level \\
\hline Envision & $170 / 725$ & $23.4 \%$ & Bronze \\
\hline INVEST & $41 / 135$ & $30.4 \%$ & Bronze \\
\hline GreenLITES & $40 / 278$ & $14.4 \%$ & Silver \\
\hline
\end{tabular}

Figure 4.7 shows the points achieved across the five categories considered in this study. Under the Environment category, project D263387 scored 6.6\%, 5.2\% and 4.3\% in Envision, INVEST and GreenLITES rating systems respectively. In the Quality of Life category, project D263387 scored 9\%, 7.4\% and 5.4\% respectively in Envision, INVEST and GreenLITES rating systems. In the Material category, project D263387 recorded 3.2\%, 8.1\% and 1.1\% respectively in Envision, INVEST and GreenLITES rating systems. In the Energy category, project D263387 achieved $1.8 \%, 4.4 \%$ and $1.8 \%$ respectively in Envision, INVEST and GreenLITES rating systems. In the Water Quality category, project D263387 earned 2.9\%, 5.2\% and 1.8\% respectively in Envision, INVEST and GreenLITES rating systems. It can be noted, in this project as well, that the points achieved under the five categories are not evenly distributed. Some vary widely, like the Material category, in which the project earned $8.1 \%$ on the INVEST rating system and earned $3.2 \%$ and $1.1 \%$ respectively on the Envision and GreenLITES rating system respectively while the variance among some others are not as wide, like the Environment category. 


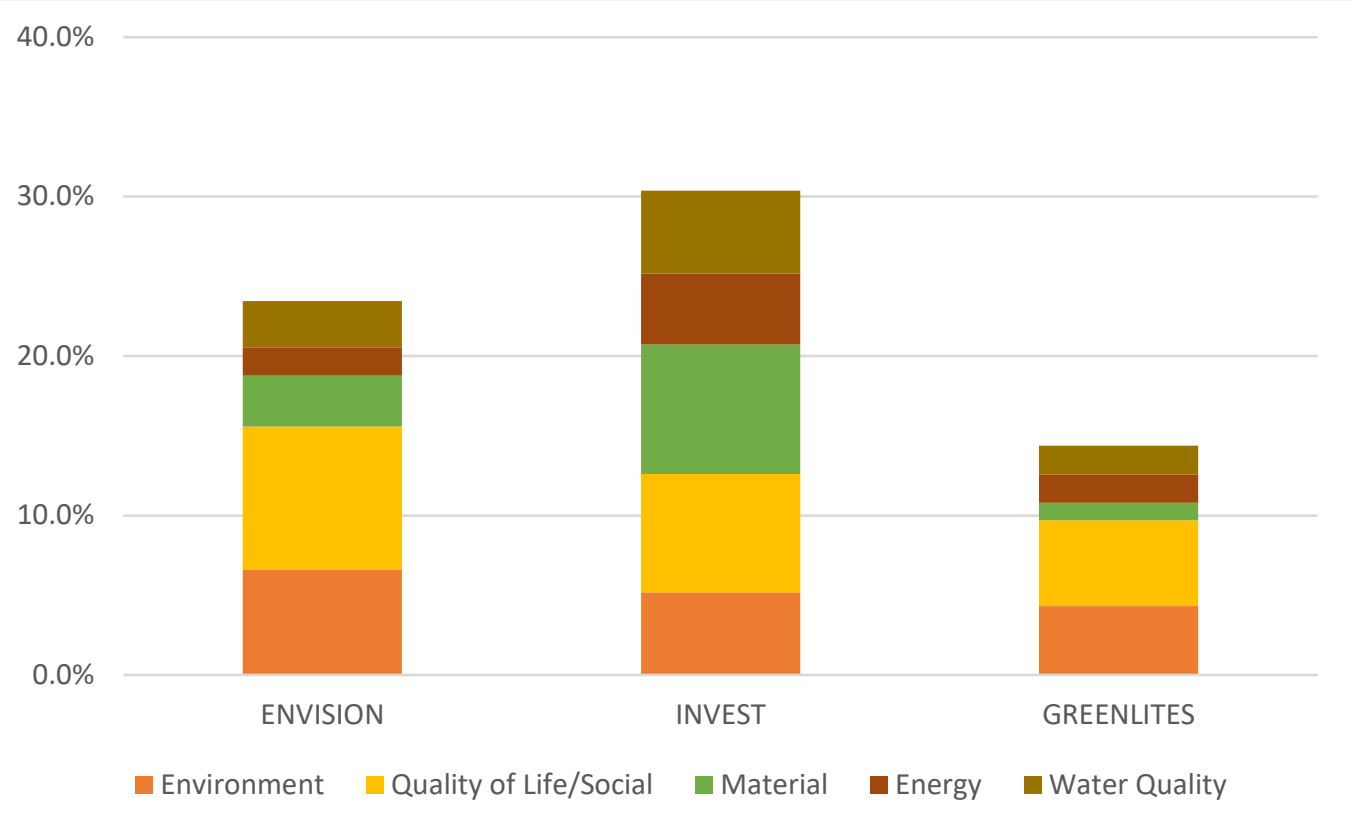

Figure 4.7. Project D263387 points spread across the five categories considered in this study.

\subsubsection{Envision Rating for Project D263387}

Under the Envision rating system, project D263387 had a normalized score of $24 \%$ resulting from a score of 170 points out of 725 applicable points. Eight credits were scoped out due to their inapplicability to the project. These credits were scoped out based on information provided in the project documents used to carry out the ratings for this project. No points were given for innovation in all categories. Hence, all five innovation credits were inapplicable to the project. Forty-seven (47) credits out of the sixty (60) credits in the Envision rating system were applicable to this project. Project D263387 scored no points in 16 of the applicable credits. Table 4.4 shows the Envision credits applicable to project D263387. Figure 4.8 shows the points the project earned across the categories in the Envision rating system in relation to the applicable points for each category. 
Table 4.4: Envision Credits applicable to Project D263387.

\begin{tabular}{|l|l|c|}
\hline \multicolumn{2}{|l|}{ ENVISION CREDITS } & D263387 \\
\hline Quality of Life & $\mathrm{X}$ \\
\hline QL1.1 & Improve Quality of Life & $\mathrm{X}$ \\
\hline QL1.2 & Stimulate Sustainable Growth and Development & $\mathrm{X}$ \\
\hline QL1.3 & Develop Local Skills and Capabilities & $\mathrm{X}$ \\
\hline QL2.1 & Enhance Public Health and Safety & $\mathrm{X}$ \\
\hline QL2.2 & Minimize Noise and Vibration & $\mathrm{X}$ \\
\hline QL2.3 & Minimize Light Pollution & $\mathrm{X}$ \\
\hline QL2.4 & Improve Community Mobility and Access & $\mathrm{X}$ \\
\hline QL2.5 & Encourage Alternative Modes of Transportation & $\mathrm{X}$ \\
\hline QL2.6 & Improve Site Accessibility, Safety and Wayfinding & \\
\hline QL3.1 & Preserve Historic and Cultural Resources & $\mathrm{X}$ \\
\hline QL3.2 & Preserve Views and Local Character & \\
\hline QL3.3 & Enhance Public Space & \\
\hline QL0.0 & Innovate or Exceed Credit Requirements & $\mathrm{X}$ \\
\hline Leadership & & $\mathrm{X}$ \\
\hline LD1.1 & Provide Effective Leadership and Commitment & $\mathrm{X}$ \\
\hline LD1.2 & Establish a Sustainability Management System & $\mathrm{X}$ \\
\hline LD1.3 & Foster Collaboration and Teamwork & $\mathrm{X}$ \\
\hline LD1.4 & Provide for Stakeholder Involvement & $\mathrm{X}$ \\
\hline LD2.1 & Pursue Byproduct Synergy Opportunities & $\mathrm{X}$ \\
\hline LD2.2 & Improve Infrastructure Integration & \\
\hline LD3.1 & Plan for Long-term Monitoring and Maintenance & $\mathrm{X}$ \\
\hline LD3.2 & Address Conflicting Regulations and Policies & $\mathrm{X}$ \\
\hline LD3.3 & Extend Useful Life & $\mathrm{X}$ \\
\hline LD0.0 & Innovate or Exceed Credit Requirements & $\mathrm{X}$ \\
\hline Resource Allocation & $\mathrm{X}$ \\
\hline RA1.1 & Reduce Net Embodied Energy & $\mathrm{X}$ \\
\hline RA1.2 & Support Sustainable Procurement Practices & $\mathrm{X}$ \\
\hline RA1.3 & Use Recycled Materials & \\
\hline RA1.4 & Use Regional Material & \\
\hline RA1.5 & Divert Waste from Landfills & \\
\hline RA1.6 & Reduce Excavated Materials Taken Off Site & \\
\hline RA1.7 & Provide for Deconstruction and Recycling & \\
\hline RA2.1 & Reduce Energy Consumption & \\
\hline RA2.2 & Use Renewable Energy & \\
\hline RA2.3 & Commission and Monitor Energy Systems & \\
\hline RA3.1 & Protect Fresh Water Availability & \\
\hline & & \\
\hline
\end{tabular}




\begin{tabular}{|c|c|c|}
\hline RA3.2 & Reduce Potable Water Consumption & $\mathrm{X}$ \\
\hline RA3.3 & Monitor Water Systems & $\mathrm{X}$ \\
\hline RA0.0 & Innovate or Exceed Credit Requirements & \\
\hline \multicolumn{3}{|c|}{ Natural World } \\
\hline NW1.1 & Preserve Prime Habitat & $\mathrm{X}$ \\
\hline NW1.2 & Protect Wetlands and Surface Water & $\mathrm{X}$ \\
\hline NW1.3 & Preserve Prime Farmland & \\
\hline NW1.4 & Avoid Adverse Geology & \\
\hline NW1.5 & Preserve Floodplain Functions & $\mathrm{X}$ \\
\hline NW1.6 & Avoid Unsuitable Development on Steep Slopes & \\
\hline NW1.7 & Preserve Greenfield & $\mathrm{X}$ \\
\hline NW2.1 & Manage Stormwater & $\mathrm{X}$ \\
\hline NW2.2 & Reduce Pesticide and Fertilizer Impacts & $\mathrm{X}$ \\
\hline NW2.3 & Prevent Surface and Groundwater Contamination & $\mathrm{X}$ \\
\hline NW3.1 & Preserve Species Biodiversity & $\mathrm{X}$ \\
\hline NW3.2 & Control Invasive Species & $\mathrm{X}$ \\
\hline NW3.3 & Restore Disturbed Soils & $\mathrm{X}$ \\
\hline NW3.4 & Maintain Wetland and Surface Water Functions & $\mathrm{X}$ \\
\hline NW0.0 & Innovate or Exceed Credit Requirements & \\
\hline \multicolumn{3}{|c|}{ Climate and Risk } \\
\hline CR1.1 & Reduce Greenhouse Gas Emissions & $\mathrm{X}$ \\
\hline CR1.2 & Reduce Air Pollutant Emissions & \\
\hline CR2.1 & Assess Climate Threat & $\mathrm{X}$ \\
\hline CR2.2 & Avoid Traps and Vulnerabilities & $\mathrm{X}$ \\
\hline CR2.3 & Prepare for Long-Term Adaptability & $\mathrm{X}$ \\
\hline CR2.4 & Prepare for Short-Term Hazards & $\mathrm{X}$ \\
\hline CR2.5 & Manage Heat Island Effects & \\
\hline CR0.0 & Innovate or Exceed Credit Requirements & \\
\hline
\end{tabular}

Project D263387 had its best performances in the Leadership category followed by the Natural World category earning 61 and 55 points respectively. The project performed averagely in the Resource Allocation and Quality of Life/Social categories with 34 and 20 points respectively. The project performed poorly in the Energy and Atmosphere categories scoring no points. 


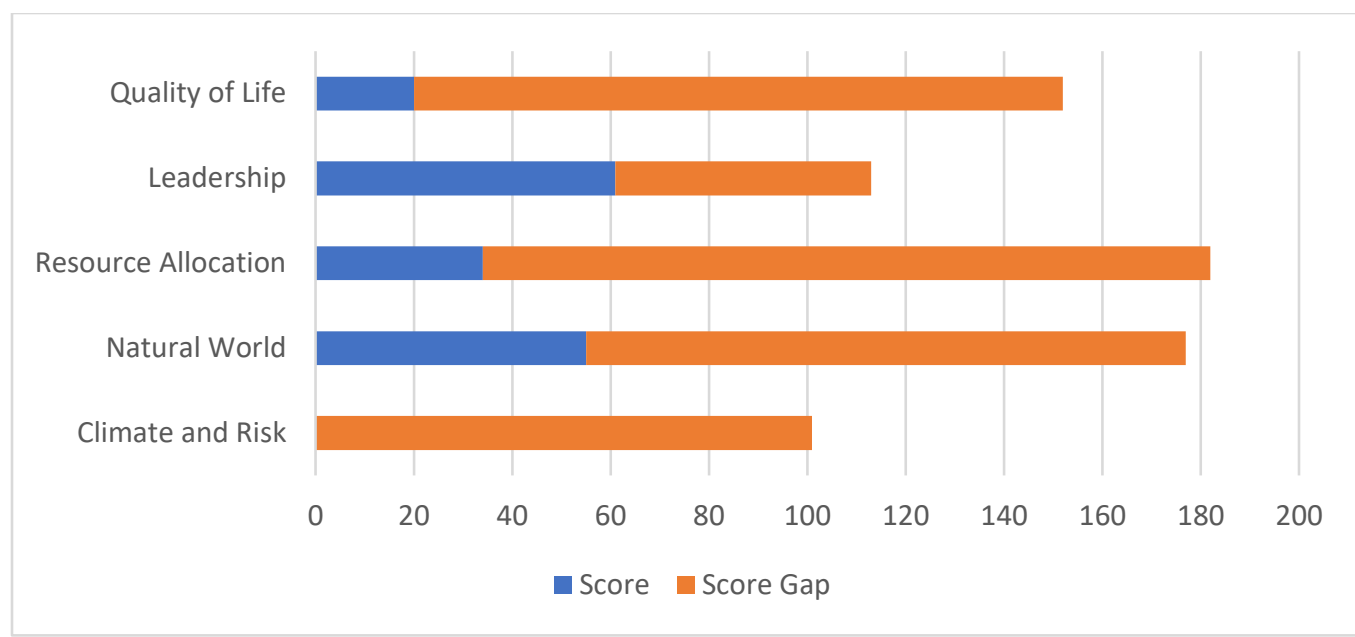

Figure 4.8. Points achieved in relation to applicable points across each category of Envision rating system for Project D263387.

The credits under the Envision rating system were split into the five categories considered in this study. The credits were split based on what aspect of the five categories they are related to. Figure 4.9 illustrates the points the project earned in the five categories considered in this study in relation to the applicable points for each category.

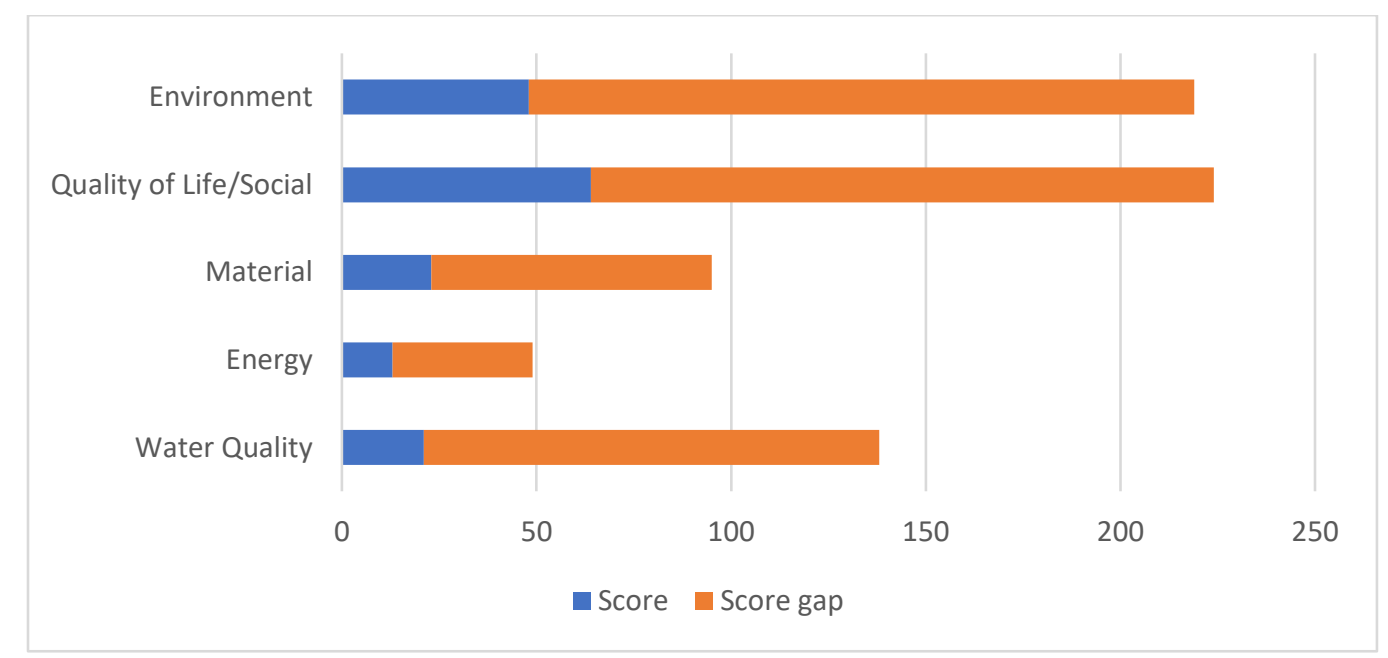

Figure 4.9. Points achieved in relation to applicable points across the five categories considered in this study for the Envision rating system for Project D263387. 
Project D263387 performed best in the the Quality of Life/Social category earning 64 points out of 224 applicable points followed by the Environment category earning 48 points out of 219 applicable points. The project performed fairly in the Material, Energy and Water Quality categories earning 23 points out of 95 applicable points, 13 points out of 49 applicable points and 21 points out of 138 applicable points respectively.

\subsubsection{INVEST Rating for Project D263387}

The Project Development module of the INVEST rating system was applied in this study. The selected scorecard was the Basic Urban scorecard which applies to small urban reconstruction or urban bridge replacement project that does not expand the capacity of the roadway. This scorecard was selected because the project involved some safety improvements that needed to be carried and it is located in an urban area. With this scorecard, only 27 criteria out of the 33 criteria contained in the Project Development module were applicable to Project D263387. Project D263387 scored no points in 11 of these criteria. The project had an overall score of 41 points out of 135 achievable points. This score was normalized to $30.4 \%$. The INVEST rating system, unlike Envision and GreenLITES rating systems, is not divided into categories. Consequently, the project performance will only be discussed with respect to the five categories considered in this study.

The criteria under the INVEST rating system were split into the five categories considered in this study. The criteria were split based on what aspect of the five categories they are related to. Figure 4.10 illustrates the points the project earned in the five categories considered in this study in relation to the applicable points for each category. The Environment category earned a total of 7 points out of 29 achievable points. The Quality of Life/Social category earned a total of 10 points out of 36 achievable points. The Material category earned 11 points out of 44 achievable points. The Energy earned 6 points out of 15 achievable points. The Water Quality category earned 7 
points out of 11 achievable points. The project performed averagely in all five categories considered.

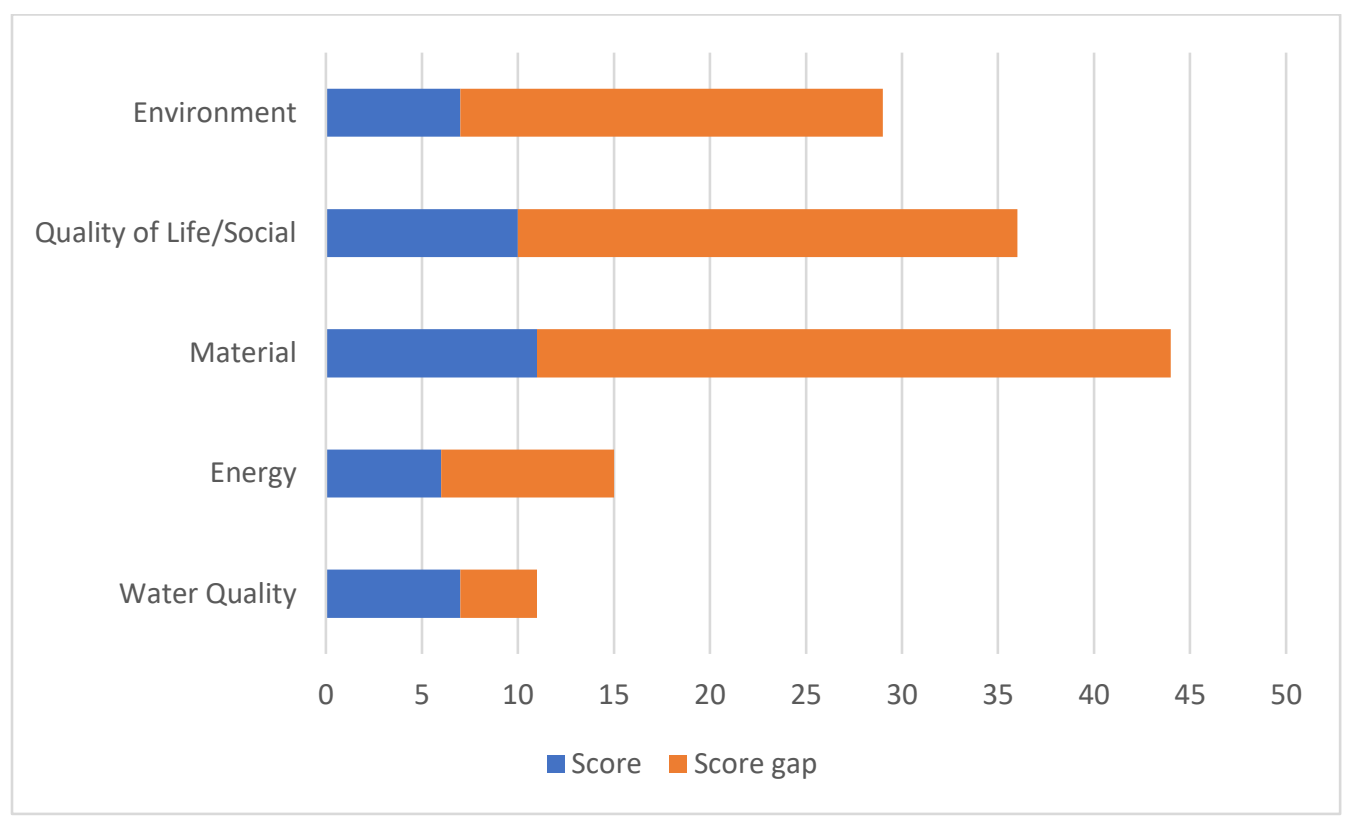

Figure 4.10. Points earned in relation to achievable points across the five categories considered in this study for the INVEST rating system for Project D263387.

\subsubsection{GreenLITES Rating for Project D263387}

With the GreenLITES rating system, project D263387 scored 40 points out of 278 achievable points with a normalized point of $14.4 \%$. Although not all credits were applicable to project D263387, no credit was scoped out in this rating system. Project D263387 scored no points in 148 credits. Figure 4.11 displays the points earned across the categories in the GreenLITES rating system in relation to the applicable points for each category.

Project D263387 had its best performance in the Sustainable Sites category followed by the Energy and Atmosphere category earing 17 points out of 81 points and 15 points out of 104 points respectively. The project performed fairly in the Water Quality category with a score of 5 
points out of 20 points. Project D263387 prformed poorly in the Materials and Resources category and the Innovation category scoring 3 points and 0 points respectively.

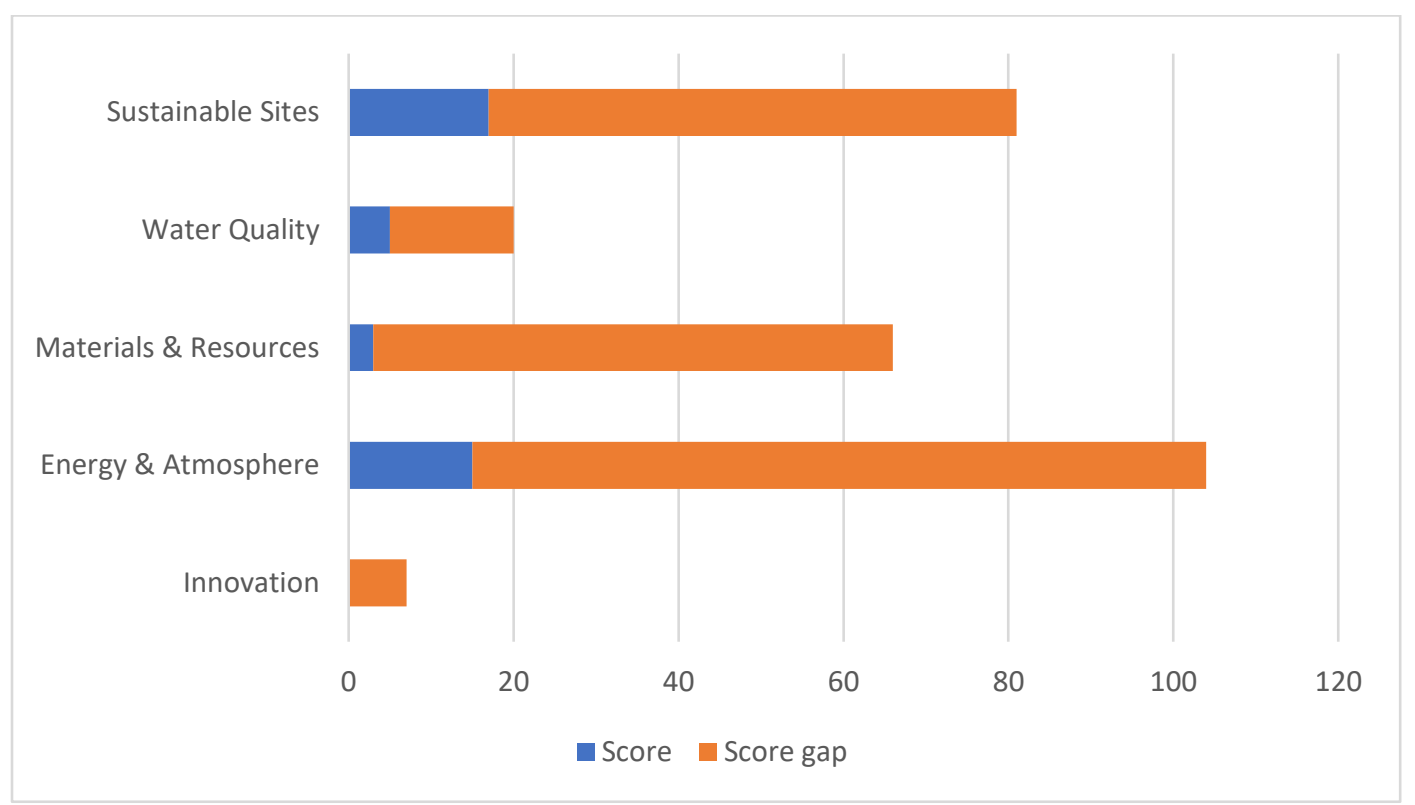

Figure 4.11. Points achieved in relation to applicable points across each category in GreenLITES rating system for Project D263387.

The credits under the GreenLITES rating system were split into the five categories considered in this study. The credits were split based on what aspect of the five categories they are related to. Figure 4.12 illustrates the points the project earned in the five categories considered in this study in relation to the applicable points for each category. It is important to note that the Innovation category of the GreenLITES system is a general category with seven applicable points that cannot be placed under any of the five categories considered in this study.

Project D263387 performed fairly well on this rating system with its best performances in the Quality of Life/Social categories and Environment category where it earned 15 points and 12 points respectively. The project had quite low scores in the other categories. However, with the overall score, project D263387 earned a Silver Award. 


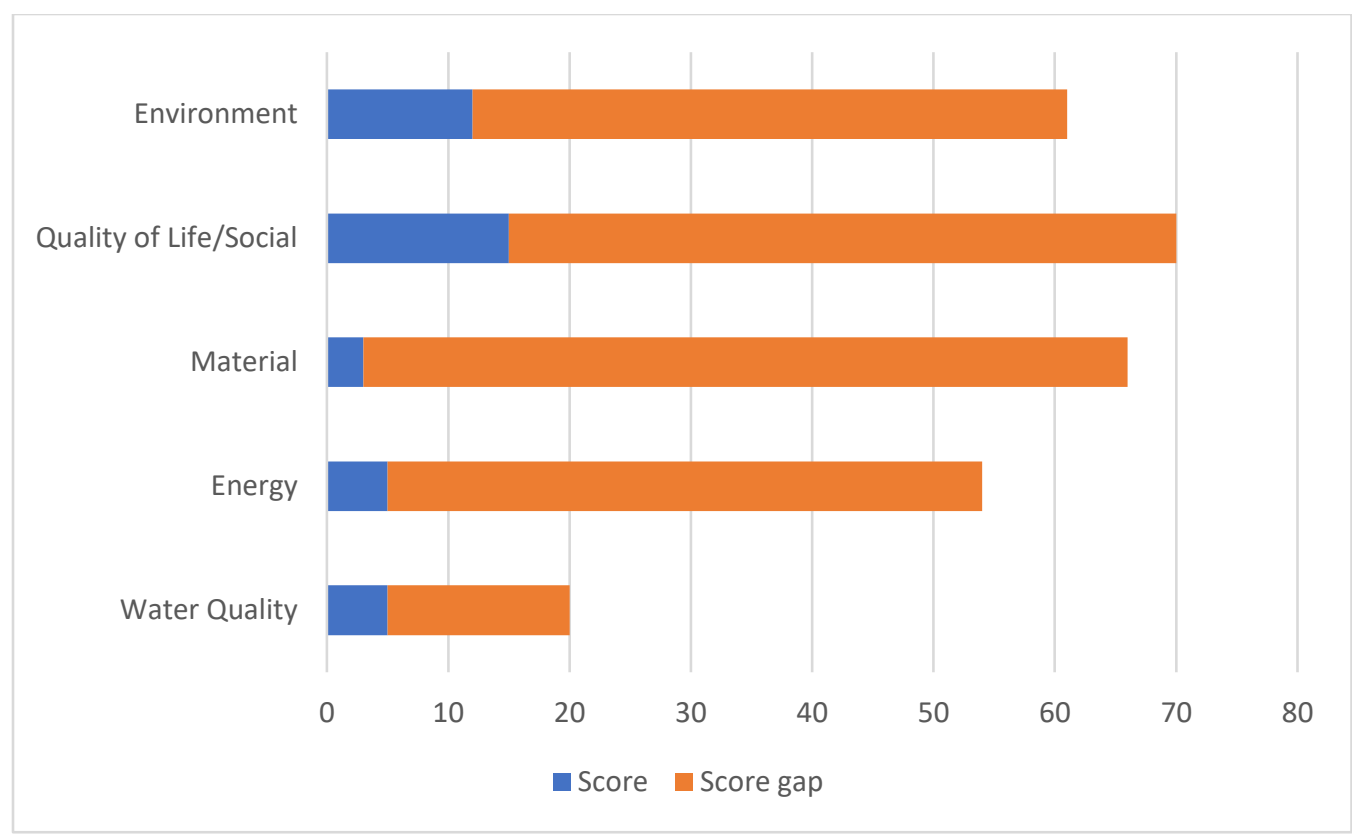

Figure 4.12. Points scored in relation to achievable points across the five categories considered in this study for the GreenLITES rating system for Project D263387.

\subsection{D263411 F. A. Project - Route 146 (Hamburg Street) Safety Improvements (1.5 miles, roundabout, new waterline and sewer system), Town of Rotterdam.}

Project D263411 is a safety improvement project that includes the reconstruction of Hamburg Street. The project is located in an urban area in Town of Rotterdam (NYSDOT, 2015b). Based on the project context, credits/criteria that are inapplicable to the project were scoped out in the Envision and INVEST rating systems. Table 4.5 shows how project D263411 performed on the three rating systems. When the Envision rating system was applied to project D263411, it scored 78 points out of 597 applicable points. This result was normalized to $13.1 \%$ which is insufficient to earn an award. On the INVEST rating system, project D263411 scored 19 points out of 135 points with a normalized score to $14.1 \%$. This score is also insufficient to earn an award on the INVEST rating system. On the GreenLITES rating system, the project scored 16 out of 278 
points. This score earned the project a certified award on the GreenLITES system. The normalized score is $5.8 \%$.

Table 4.5: Project D263411's Normalized Score and Award Level on Each Rating System

\begin{tabular}{lccc}
\hline Rating System & $\begin{array}{c}\text { Points } \\
\text { assessed/Points } \\
\text { Applicable }\end{array}$ & $\begin{array}{c}\text { Normalized Score } \\
\text { (\% of Applicable } \\
\text { Points) }\end{array}$ & Award Level \\
\hline Envision & $78 / 597$ & $13.1 \%$ & No certification \\
\hline INVEST & $19 / 135$ & $14.1 \%$ & No certification \\
\hline GreenLITES & $16 / 278$ & $5.8 \%$ & Certified \\
\hline
\end{tabular}

Figure 4.13 shows the points achieved across the five categories considered in this study. With all three rating systems, the Water Quality category received no points while the Environment and Quality of Life/Social categories achieved some points. When run through the Envision, INVEST and GreenLITES rating systems, the project achieved 3.2\%, $0.7 \%$ and $0.4 \%$ respectively in the Environment category and 8.9\%, 5.2\% and 5.4\% respectively in the Quality of Life/Social category. Under the Envision and INVEST rating systems, project D263411 scored 1\% and 5.2\% respectively in the Material category while it scored no points under the GreenLITES system for that category. With the Energy category, project D263411 scored 3.0\% under the INVEST rating system but attained no points under the other rating systems. It can be noted in this project also, that the points achieved under the Environment, Quality of Life/Social, Material and Energy categories are not evenly distributed. 


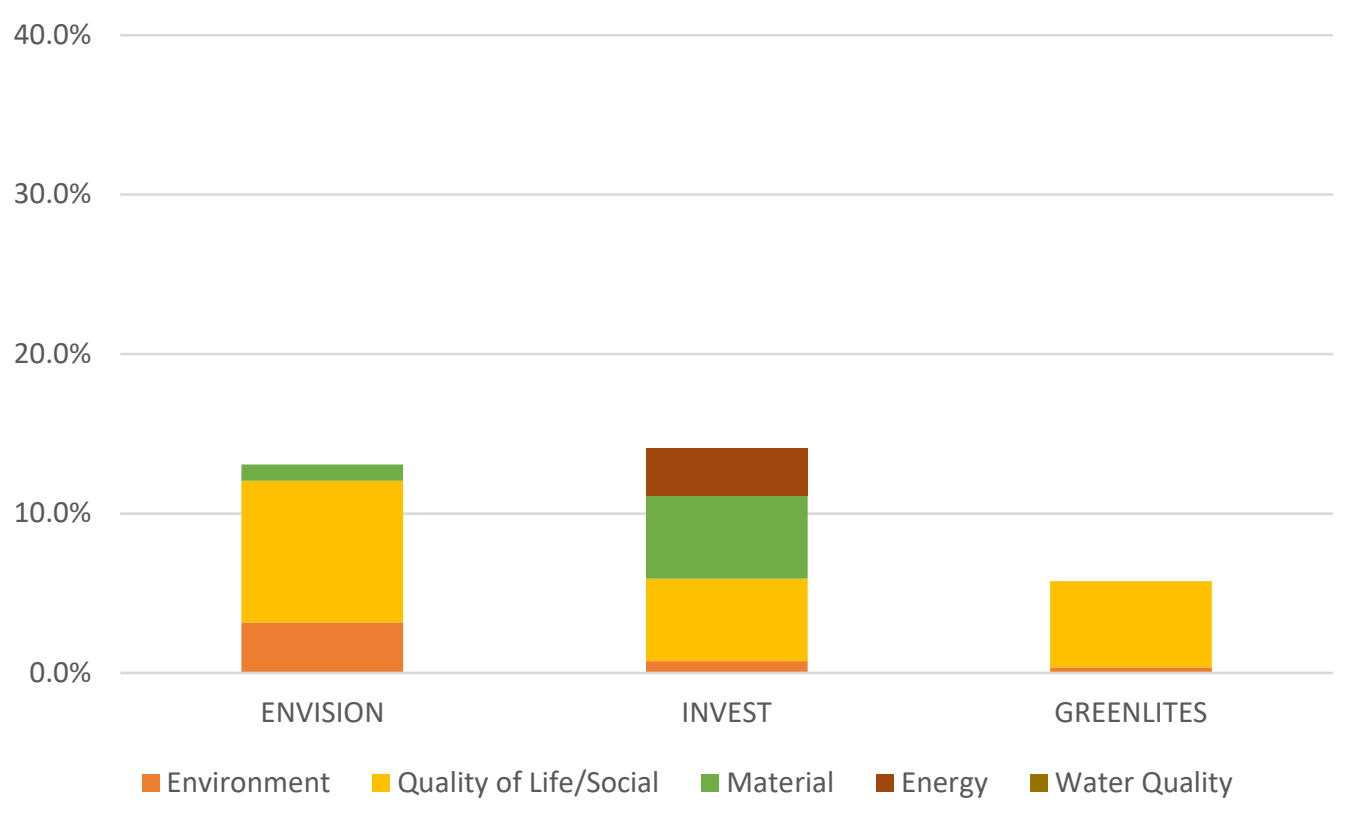

Figure 4.13. Project D263411 points spread across the five categories considered in this study.

\subsubsection{Envision Rating for D263411}

Under the Envision rating system, project D263411 had a normalized score of $13.1 \%$ resulting from a score of 78 points out of 597 applicable points. Sixteen credits were scoped out due to their inapplicability to the project. These credits were scoped out based on information provided in the government documents used to carry out the ratings for this project. No points were given for innovation in all categories. Hence, all five innovation credits were inapplicable to the project. Thirty-nine (39) credits out of the sixty (60) credits in the Envision rating system were applicable to this project. Project D263411 scored no points in 24 of the applicable credits. Table 4.6 show the Envision credits applicable to this project.

Table 4.6: Envision Credits Applicable to Project D263411

\begin{tabular}{|l|l|c|}
\hline & ENVISION CREDITS & D263411 \\
\hline Quality of Life & X \\
\hline QL1.1 & Improve Quality of Life & X \\
\hline QL1.2 & Stimulate Sustainable Growth and Development & X \\
\hline QL1.3 & Develop Local Skills and Capabilities & \\
\hline
\end{tabular}




\begin{tabular}{|c|c|c|}
\hline QL2.1 & Enhance Public Health and Safety & $\mathrm{X}$ \\
\hline QL2.2 & Minimize Noise and Vibration & $\mathrm{X}$ \\
\hline QL2.3 & Minimize Light Pollution & $\mathrm{X}$ \\
\hline QL2.4 & Improve Community Mobility and Access & $\mathrm{X}$ \\
\hline QL2.5 & Encourage Alternative Modes of Transportation & $\mathrm{X}$ \\
\hline QL2.6 & Improve Site Accessibility, Safety and Wayfinding & $\mathrm{X}$ \\
\hline QL3.1 & Preserve Historic and Cultural Resources & \\
\hline QL3.2 & Preserve Views and Local Character & \\
\hline QL3.3 & Enhance Public Space & \\
\hline QL0.0 & Innovate or Exceed Credit Requirements & \\
\hline \multicolumn{3}{|c|}{ Leadership } \\
\hline LD1.1 & Provide Effective Leadership and Commitment & $\mathrm{X}$ \\
\hline LD1.2 & Establish a Sustainability Management System & $\mathrm{X}$ \\
\hline LD1.3 & Foster Collaboration and Teamwork & $\mathrm{X}$ \\
\hline LD1.4 & Provide for Stakeholder Involvement & $\mathrm{X}$ \\
\hline LD2.1 & Pursue Byproduct Synergy Opportunities & $\mathrm{X}$ \\
\hline LD2.2 & Improve Infrastructure Integration & $\mathrm{X}$ \\
\hline LD3.1 & Plan for Long-term Monitoring and Maintenance & $\mathrm{X}$ \\
\hline LD3.2 & Address Conflicting Regulations and Policies & \\
\hline LD3.3 & Extend Useful Life & $\mathrm{X}$ \\
\hline LD0.0 & Innovate or Exceed Credit Requirements & \\
\hline \multicolumn{3}{|c|}{ Resource Allocation } \\
\hline RA1.1 & Reduce Net Embodied Energy & $\mathrm{X}$ \\
\hline RA1.2 & Support Sustainable Procurement Practices & $\mathrm{X}$ \\
\hline RA1.3 & Use Recycled Materials & $\mathrm{X}$ \\
\hline RA1.4 & Use Regional Material & $\mathrm{X}$ \\
\hline RA1.5 & Divert Waste from Landfills & $\mathrm{X}$ \\
\hline RA1.6 & Reduce Excavated Materials Taken Off Site & $\mathrm{X}$ \\
\hline RA1.7 & Provide for Deconstruction and Recycling & $\mathrm{X}$ \\
\hline RA2.1 & Reduce Energy Consumption & $\mathrm{X}$ \\
\hline RA2.2 & Use Renewable Energy & $\mathrm{X}$ \\
\hline RA2.3 & Commission and Monitor Energy Systems & $\mathrm{X}$ \\
\hline RA3.1 & Protect Fresh Water Availability & $\mathrm{X}$ \\
\hline RA3.2 & Reduce Potable Water Consumption & $\mathrm{X}$ \\
\hline RA3.3 & Monitor Water Systems & $\mathrm{X}$ \\
\hline RA0.0 & Innovate or Exceed Credit Requirements & \\
\hline \multicolumn{3}{|c|}{ Natural World } \\
\hline NW1.1 & Preserve Prime Habitat & \\
\hline NW1.2 & Protect Wetlands and Surface Water & \\
\hline NW1.3 & Preserve Prime Farmland & \\
\hline NW1.4 & Avoid Adverse Geology & \\
\hline
\end{tabular}




\begin{tabular}{|l|l|c|}
\hline NW1.5 & Preserve Floodplain Functions & \\
\hline NW1.6 & Avoid Unsuitable Development on Steep Slopes & \\
\hline NW1.7 & Preserve Greenfield & X \\
\hline NW2.1 & Manage Stormwater & X \\
\hline NW2.2 & Reduce Pesticide and Fertilizer Impacts & \\
\hline NW2.3 & Prevent Surface and Groundwater Contamination & \\
\hline NW3.1 & Preserve Species Biodiversity & X \\
\hline NW3.2 & Control Invasive Species & \\
\hline NW3.3 & Restore Disturbed Soils & \\
\hline NW3.4 & Maintain Wetland and Surface Water Functions & X \\
\hline NW0.0 & Innovate or Exceed Credit Requirements & \\
\hline Climate and Risk & $X$ \\
\hline CR1.1 & Reduce Greenhouse Gas Emissions & X \\
\hline CR1.2 & Reduce Air Pollutant Emissions & X \\
\hline CR2.1 & Assess Climate Threat & X \\
\hline CR2.2 & Avoid Traps and Vulnerabilities & \\
\hline CR2.3 & Prepare for Long-Term Adaptability & \\
\hline CR2.4 & Prepare for Short-Term Hazards & \\
\hline CR2.5 & Manage Heat Island Effects & \\
\hline CR0.0 & Innovate or Exceed Credit Requirements & \\
\hline
\end{tabular}

Figure 4.14 shows the points the project earned across the categories in the Envision rating system in relation to the applicable points for each category. Project D263411 had its best performance in the Leadership category with a score of 50 points. However, the project did not perform as well in the other categories scoring 10 and 18 points in the Quality of Life and Natural World categories and no points in the Resource Allocation and Climate and Risk categories. 


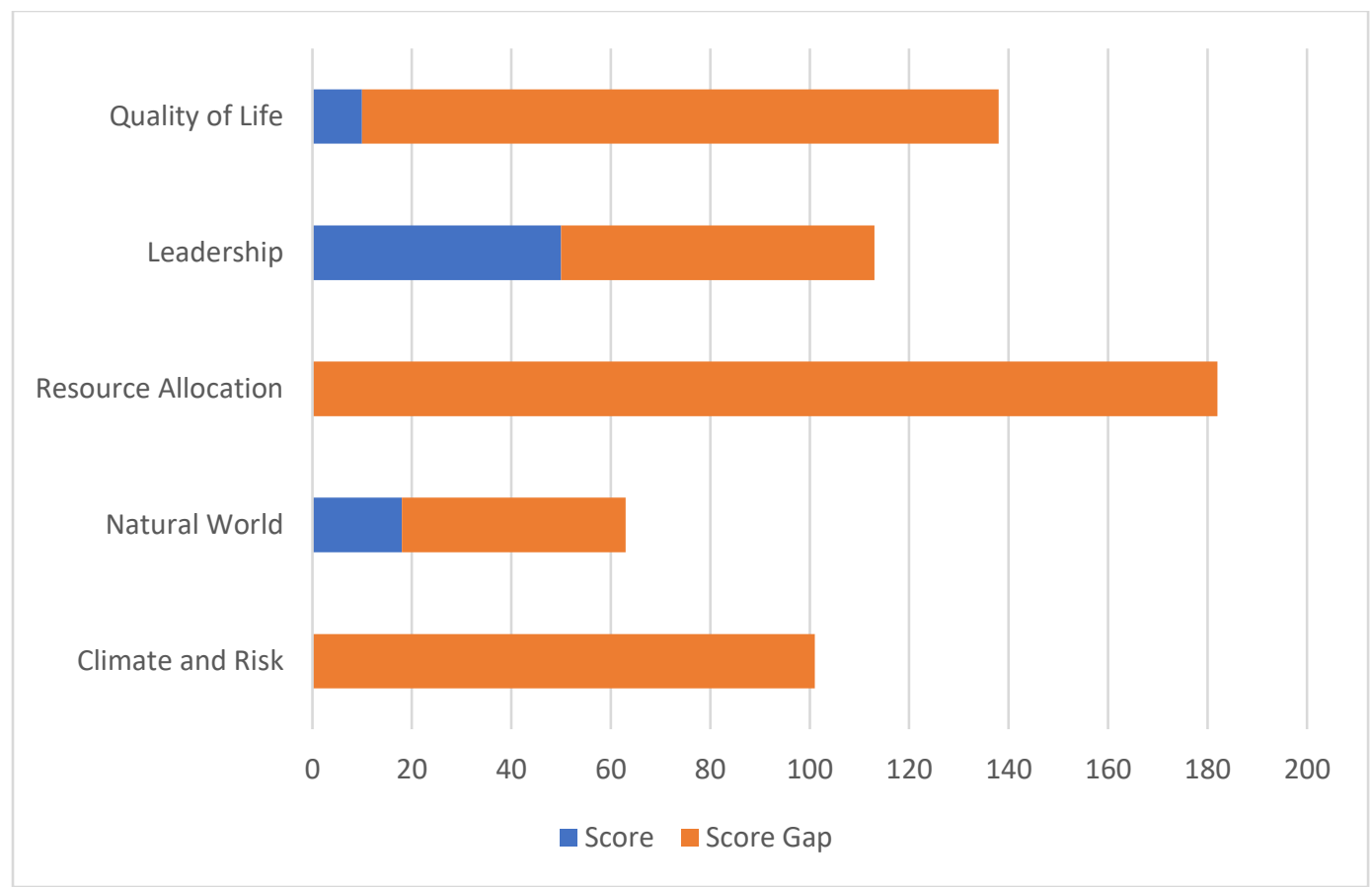

Figure 4.14. Points achieved in relation to applicable points across each category of Envision rating system for D263411.

The credits under the Envision rating system were split into the five categories considered in this study. The credits were split based on what aspect of the five categories they are related to. Figure 4.15 illustrates the points the project earned in the five categories considered in this study in relation to the applicable points for each category. Project D263411 had its best performance in the Quality of Life/Social category with a score of 53 points out of 210 applicable points. However, it had a lower performance in the other categories where it scored 19 points out of 160 applicable points in the Environment category, 6 points out of 95 points in the Material category and 0 points in the Energy and Water Quality category. 


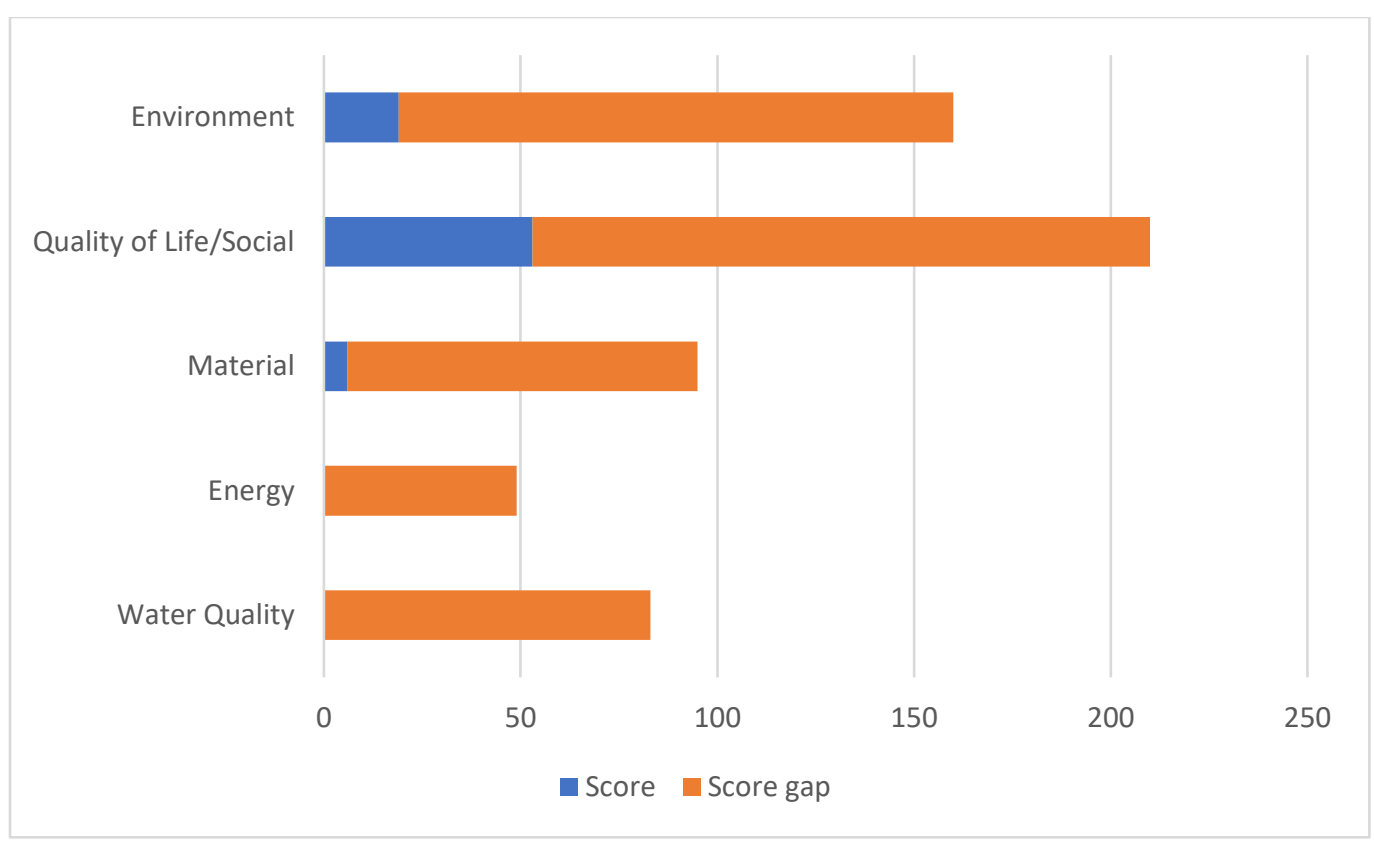

Figure 4.15. Points achieved in relation to applicable points across the five categories considered in this study for the Envision rating system for D263411.

\subsubsection{INVEST Rating for D263411}

The Project Development module of the INVEST rating system was applied in this study. The selected scorecard was the Basic Urban scorecard which applies to small urban reconstruction or urban bridge replacement project that does not expand the capacity of the roadway. This scorecard was selected because the project involved safety improvements carried out in an urban area. With this scorecard, only 27 criteria out of the 33 criteria contained in the Project Development module were applicable to Project D263411. Project D263411 scored no points in 19 of these criteria. The project had an overall score of 19 points out of 135 achievable points. This score was normalized to $14.1 \%$. The INVEST rating system, unlike Envision and GreenLITES rating systems, is not divided into categories. Therefore, the project performance will only be discussed with respect to the five categories considered in this study. 
The criteria under the INVEST rating system were split into the five categories considered in this study. The criteria were split based on what aspect of the five categories they are related to. Figure 4.16 illustrates the points the project earned in the five categories considered in this study in relation to the applicable points for each category.

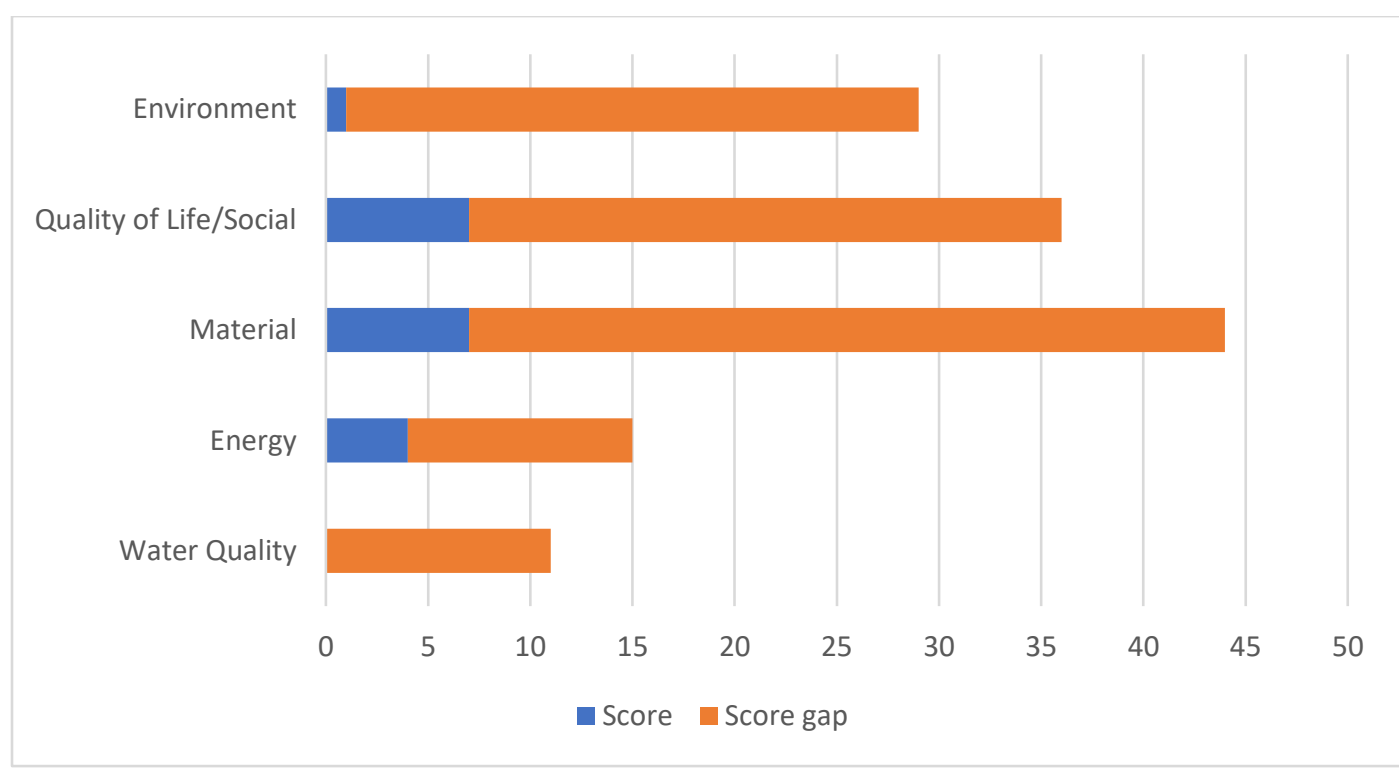

Figure 4.16. Points earned in relation to achievable points across the five categories considered in this study for the INVEST rating system for D263411.

The Quality of Life/Social category and Materials categories had the best scores with 7 points each out of 36 and 44 achievable points respectively. These were followed by the Energy category with 4 points out of 15 achievable points and the Environment category with 1 point out of 29 points. The project scored no point in the Water Quality category.

\subsubsection{GreenLITES Rating for D263411}

With the GreenLITES rating system, project D263411 scored 16 points out of 278 achievable points with a normalized point of 5.8\%. Although not all credits were applicable to project D263411, no credit was scoped out in this rating system. Project D263411 scored no points 
in 163 credits. Figure 4.17 displays the points earned across the categories in the GreenLITES rating system in relation to the applicable points for each category.

Project D263411 had its best performance in the Energy and Atmosphere category with 10 points out of 104 achievable points followed by the Sustainable Sites category, which scored 6 points out of 81 achievable points. The project scored no points in the Water Quality category, Materials and Resources category and Innovation/Unlisted category.

The credits under the GreenLITES rating system were split into the five categories considered in this study. The credits were split based on what aspect of the five categories they are related to. Figure 4.18 illustrates the points the project earned in the five categories considered in this study in relation to the applicable points for each category. It is important to note that the "Innovation" category of the GreenLITES system is a general category with seven available points which cannot be placed under any of the five categories considered in this study.

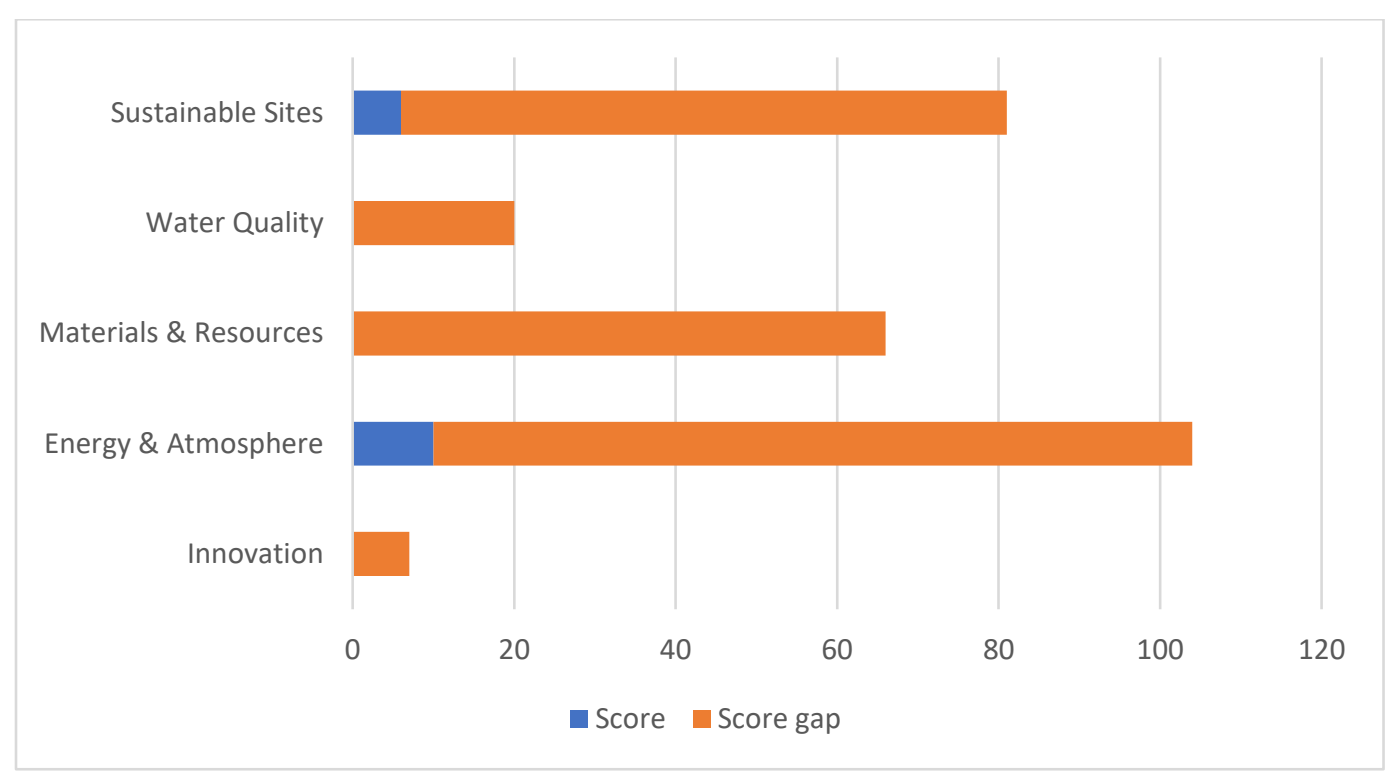

Figure 4.17. Points achieved in relation to applicable points across each category in GreenLITES rating system for D263411. 


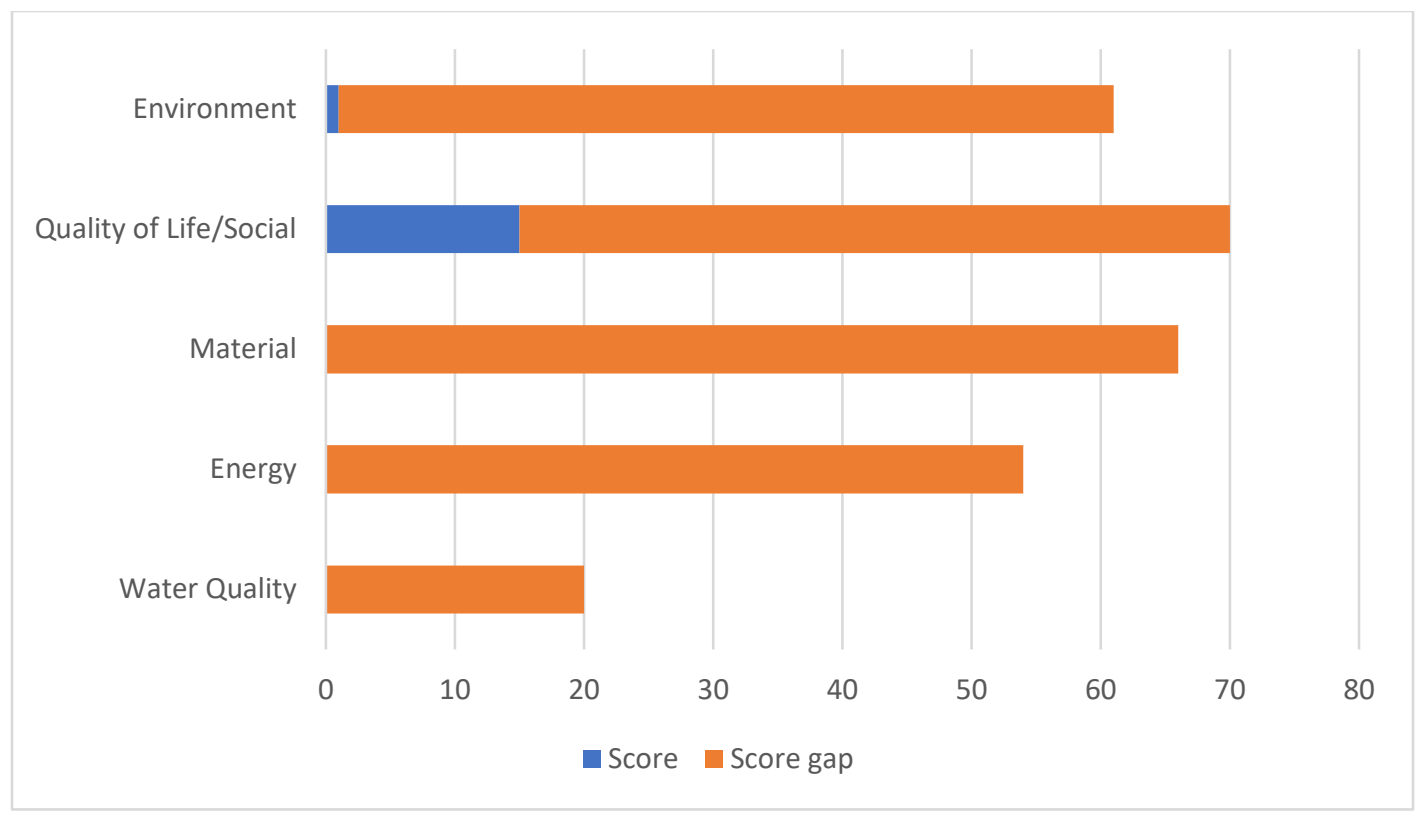

Figure 4.18. Points scored in relation to achievable points across the five categories considered in this study for the GreenLITES rating system for D263411.

Project D263411 had its best performance in the Quality of Life/Social category with 15 points out of 70 achievable points. This was followed by the Environment category with 1 point out of 61 achievable points. The project scored no points in the other three categories.

\subsection{D263477 F. A. Project - NYS Route 231 Safety Improvements at Northern State Parkway Interchange in the Town of Huntington.}

The D263477 F. A. Project is a safety improvement project carried out on NY Route 231 at the Northern State Parkway Interchange in the Town of Huntington, Suffolk County (NYSDOT, 2018c). Credits/criteria that are inapplicable to the project based on its context, were scoped out in the Envision and INVEST rating systems. Table 4.7 shows how project D263477 performed on the three rating systems. When the Envision rating system was applied to project D263477, it scored 141 points out of 711 applicable points. This result was normalized to $19.8 \%$ which earned the project a Bronze award. On the INVEST rating system, project D263477 scored 31 points out 
of 135 points with a normalized score of $23 \%$. This score was insufficient to earn an award on the INVEST rating system. On the GreenLITES rating system, the project scored 42 out of 278 points. This score earned the project a Silver award on the GreenLITES system. The normalized score is $15.1 \%$.

Table 4.7: Project D263477's Normalized Score and Award Level on Each Rating System

\begin{tabular}{lccc}
\hline Rating System & $\begin{array}{c}\text { Points } \\
\text { assessed/Points } \\
\text { Applicable }\end{array}$ & $\begin{array}{c}\text { Normalized Score } \\
(\% \text { of Applicable } \\
\text { Points) }\end{array}$ & Award Level \\
\hline Envision & $141 / 711$ & $19.8 \%$ & Bronze \\
\hline INVEST & $31 / 135$ & $23.0 \%$ & No certification \\
\hline GreenLITES & $42 / 278$ & $15.1 \%$ & Silver \\
\hline
\end{tabular}

Figure 4.19 shows the points achieved across the five categories considered in this study. With all three rating systems, the Environment, Quality of Life/Social and Material categories achieved some points. When the Envision, INVEST and GreenLITES rating systems were applied to project D263477, the project achieved 4.9\%, 5.9\% and 4\% respectively in the Environment category, $11.4 \%, 7.4 \%$ and $8.6 \%$ respectively in the Quality of Life/Social category and 3\%, 5.9\% and $1.1 \%$ respectively in the Material category. Under the INVEST and GreenLITES rating systems, project D263477 scored 3.7\% and 1.4\% respectively in the Energy category while it scored no points under the Envision system for that category. With the Water Quality category, project D263477 scored 0.6\% under the Envision rating system but attained no points under the other rating systems. Also noted in this project is the uneven distribution of the points achieved under the Environment, Quality of Life/Social, Material and Energy categories. 


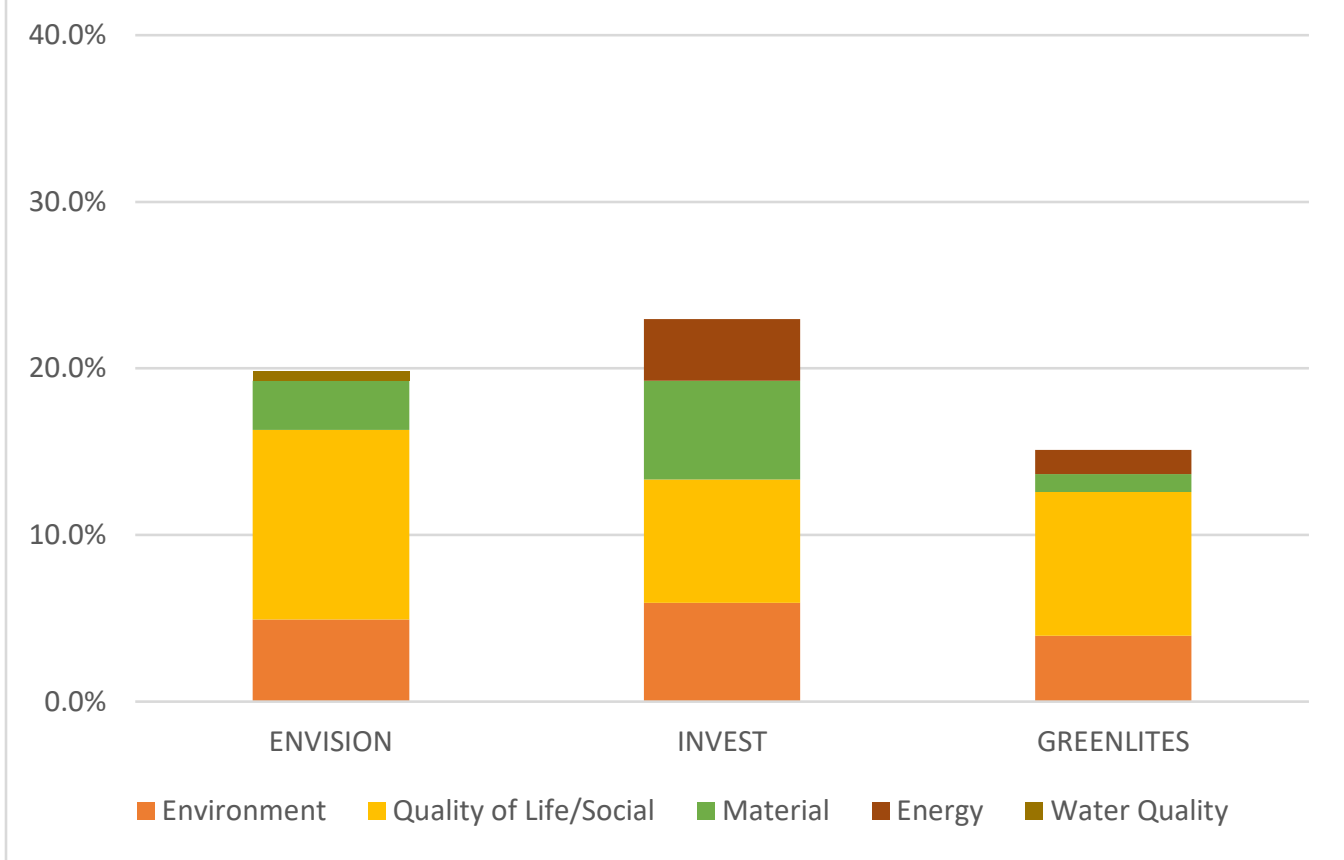

Figure 4.19. Project D263477 points spread across the five categories considered in this study.

\subsubsection{Envision Rating for D263477}

Under the Envision rating system, project D263477 had a normalized score of $19.8 \%$ resulting from a score of 141 points out of 711 applicable points. Nine credits were scoped out due to their inapplicability to the project.. These credits were scoped out based on information provided in the project documents used to carry out the ratings for this project. No points were given for innovation in all categories. Hence, all five innovation credits were inapplicable to the project. Forty-six (46) credits out of the sixty (60) credits in the Envision rating system were applicable to this project. Project D263477 scored no points in 23 of the applicable credits. Table 4.8 shows the Envision credits applicable to project D263477. 
Table 4.8: Envision Credits Applicable to Project D263477

\begin{tabular}{|c|c|c|}
\hline & ENVISION CREDITS & D263477 \\
\hline \multicolumn{3}{|c|}{ Quality of Life } \\
\hline QL1.1 & Improve Quality of Life & $\mathrm{X}$ \\
\hline QL1.2 & Stimulate Sustainable Growth and Development & $\mathrm{X}$ \\
\hline QL1.3 & Develop Local Skills and Capabilities & $\mathrm{X}$ \\
\hline QL2.1 & Enhance Public Health and Safety & $\mathrm{X}$ \\
\hline QL2.2 & Minimize Noise and Vibration & $\mathrm{X}$ \\
\hline QL2.3 & Minimize Light Pollution & $\mathrm{X}$ \\
\hline QL2.4 & Improve Community Mobility and Access & $\mathrm{X}$ \\
\hline QL2.5 & Encourage Alternative Modes of Transportation & $\mathrm{X}$ \\
\hline QL2.6 & Improve Site Accessibility, Safety and Wayfinding & $\mathrm{X}$ \\
\hline QL3.1 & Preserve Historic and Cultural Resources & \\
\hline QL3.2 & Preserve Views and Local Character & $\mathrm{X}$ \\
\hline QL3.3 & Enhance Public Space & \\
\hline QL0.0 & Innovate or Exceed Credit Requirements & \\
\hline \multicolumn{3}{|c|}{ Leadership } \\
\hline LD1.1 & Provide Effective Leadership and Commitment & $\mathrm{X}$ \\
\hline LD1.2 & Establish a Sustainability Management System & $\mathrm{X}$ \\
\hline LD1.3 & Foster Collaboration and Teamwork & $\mathrm{X}$ \\
\hline LD1.4 & Provide for Stakeholder Involvement & $\mathrm{X}$ \\
\hline LD2.1 & Pursue Byproduct Synergy Opportunities & $\mathrm{X}$ \\
\hline LD2.2 & Improve Infrastructure Integration & $\mathrm{X}$ \\
\hline LD3.1 & Plan for Long-term Monitoring and Maintenance & $\mathrm{X}$ \\
\hline LD3.2 & Address Conflicting Regulations and Policies & \\
\hline LD3.3 & Extend Useful Life & $\mathrm{X}$ \\
\hline LD0.0 & Innovate or Exceed Credit Requirements & \\
\hline \multicolumn{3}{|c|}{ Resource Allocation } \\
\hline RA1.1 & Reduce Net Embodied Energy & $\mathrm{X}$ \\
\hline RA1.2 & Support Sustainable Procurement Practices & $\mathrm{X}$ \\
\hline RA1.3 & Use Recycled Materials & $\mathrm{X}$ \\
\hline RA1.4 & Use Regional Material & $\mathrm{X}$ \\
\hline RA1.5 & Divert Waste from Landfills & $\mathrm{X}$ \\
\hline RA1.6 & Reduce Excavated Materials Taken Off Site & $\mathrm{X}$ \\
\hline RA1.7 & Provide for Deconstruction and Recycling & $\mathrm{X}$ \\
\hline RA2.1 & Reduce Energy Consumption & $\mathrm{X}$ \\
\hline RA2.2 & Use Renewable Energy & $\mathrm{X}$ \\
\hline RA2.3 & Commission and Monitor Energy Systems & $\mathrm{X}$ \\
\hline RA3.1 & Protect Fresh Water Availability & $\mathrm{X}$ \\
\hline RA3.2 & Reduce Potable Water Consumption & $\mathrm{X}$ \\
\hline RA3.3 & Monitor Water Systems & $\mathrm{X}$ \\
\hline RA0.0 & Innovate or Exceed Credit Requirements & \\
\hline
\end{tabular}




\begin{tabular}{|l|l|c|}
\hline Natural World & X \\
\hline NW1.1 & Preserve Prime Habitat & X \\
\hline NW1.2 & Protect Wetlands and Surface Water & \\
\hline NW1.3 & Preserve Prime Farmland & \\
\hline NW1.4 & Avoid Adverse Geology & \\
\hline NW1.5 & Preserve Floodplain Functions & $\mathrm{X}$ \\
\hline NW1.6 & Avoid Unsuitable Development on Steep Slopes & $\mathrm{X}$ \\
\hline NW1.7 & Preserve Greenfield & $\mathrm{X}$ \\
\hline NW2.1 & Manage Stormwater & $\mathrm{X}$ \\
\hline NW2.2 & Reduce Pesticide and Fertilizer Impacts & $\mathrm{X}$ \\
\hline NW2.3 & Prevent Surface and Groundwater Contamination & $\mathrm{X}$ \\
\hline NW3.1 & Preserve Species Biodiversity & $\mathrm{X}$ \\
\hline NW3.2 & Control Invasive Species & $\mathrm{X}$ \\
\hline NW3.3 & Restore Disturbed Soils & \\
\hline NW3.4 & Maintain Wetland and Surface Water Functions & \\
\hline NW0.0 & Innovate or Exceed Credit Requirements & $\mathrm{X}$ \\
\hline Climate and Risk & $\mathrm{X}$ \\
\hline CR1.1 & Reduce Greenhouse Gas Emissions & $\mathrm{X}$ \\
\hline CR1.2 & Reduce Air Pollutant Emissions & $\mathrm{X}$ \\
\hline CR2.1 & Assess Climate Threat & $\mathrm{X}$ \\
\hline CR2.2 & Avoid Traps and Vulnerabilities & \\
\hline CR2.3 & Prepare for Long-Term Adaptability & \\
\hline CR2.4 & Prepare for Short-Term Hazards & \\
\hline CR2.5 & Manage Heat Island Effects & \\
\hline CR0.0 & Innovate or Exceed Credit Requirements & \\
\hline
\end{tabular}

Figure 4.20 shows the points the project earned across the categories in the Envision rating system in relation to the applicable points for each category. Project D263477 had its best performance in the Leadership category where it scored 57 points out of 113 applicable points followed by the Quality of Life and Natural World categories with 36 and 33 points respectively. The project performed fairly in the Resource Allocation category with 15 points and scored no points in the Climate and Risk Category. 


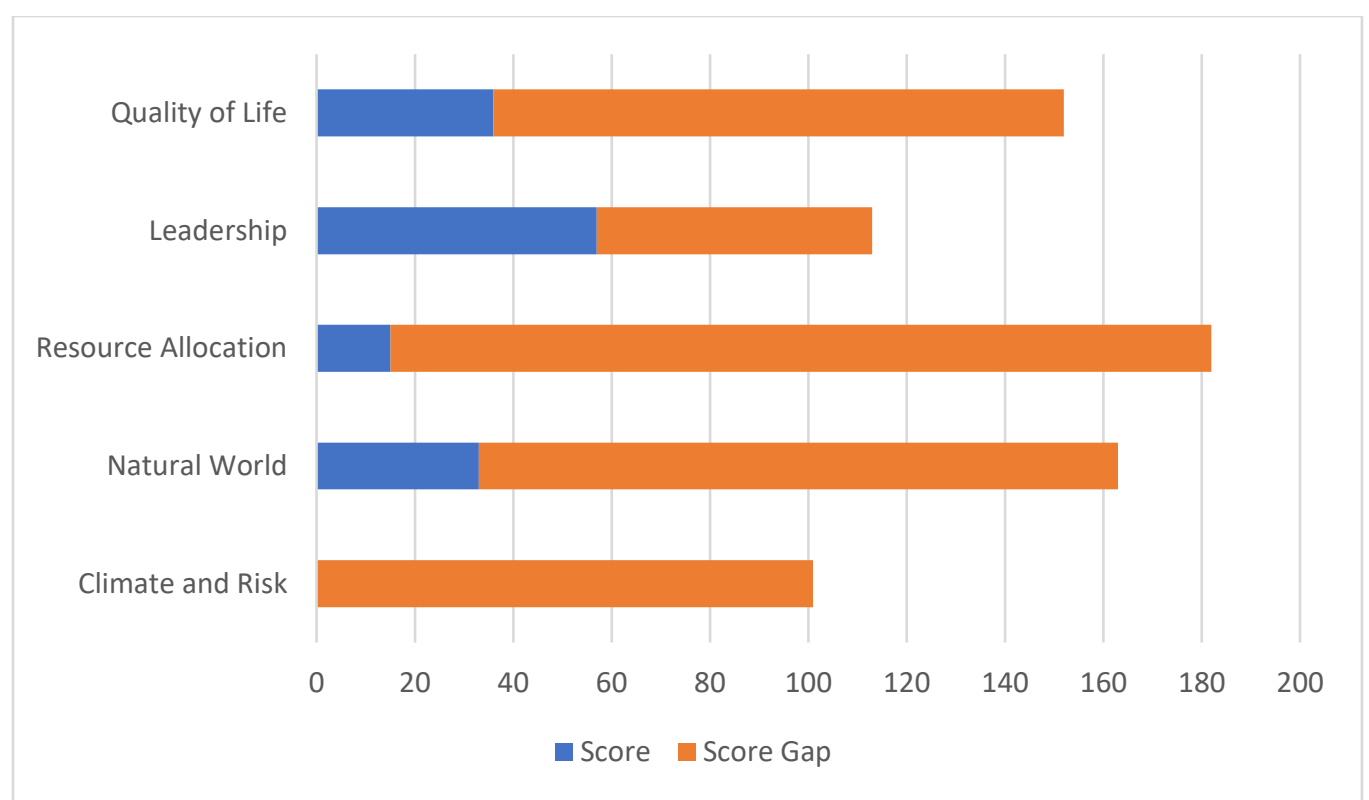

Figure 4.20. Points achieved in relation to applicable points across each category of Envision rating system for D263477.

The credits under the Envision rating system were split into the five categories considered in this study. The credits were split based on what aspect of the five categories they are related to. Figure 4.21 displays the points the project earned in the five categories considered in this study in relation to the applicable points for each category.

Project D263477 perfumed best in the Quality of Life/Social category earning 81 points out of 224 applicable points followed by the Environment category with 35 points out of 205 applicable points. The Material category earned 21 points out of 95 applicable points while the Water Quality and Energy categories earned 4 and 0 points respectively. 


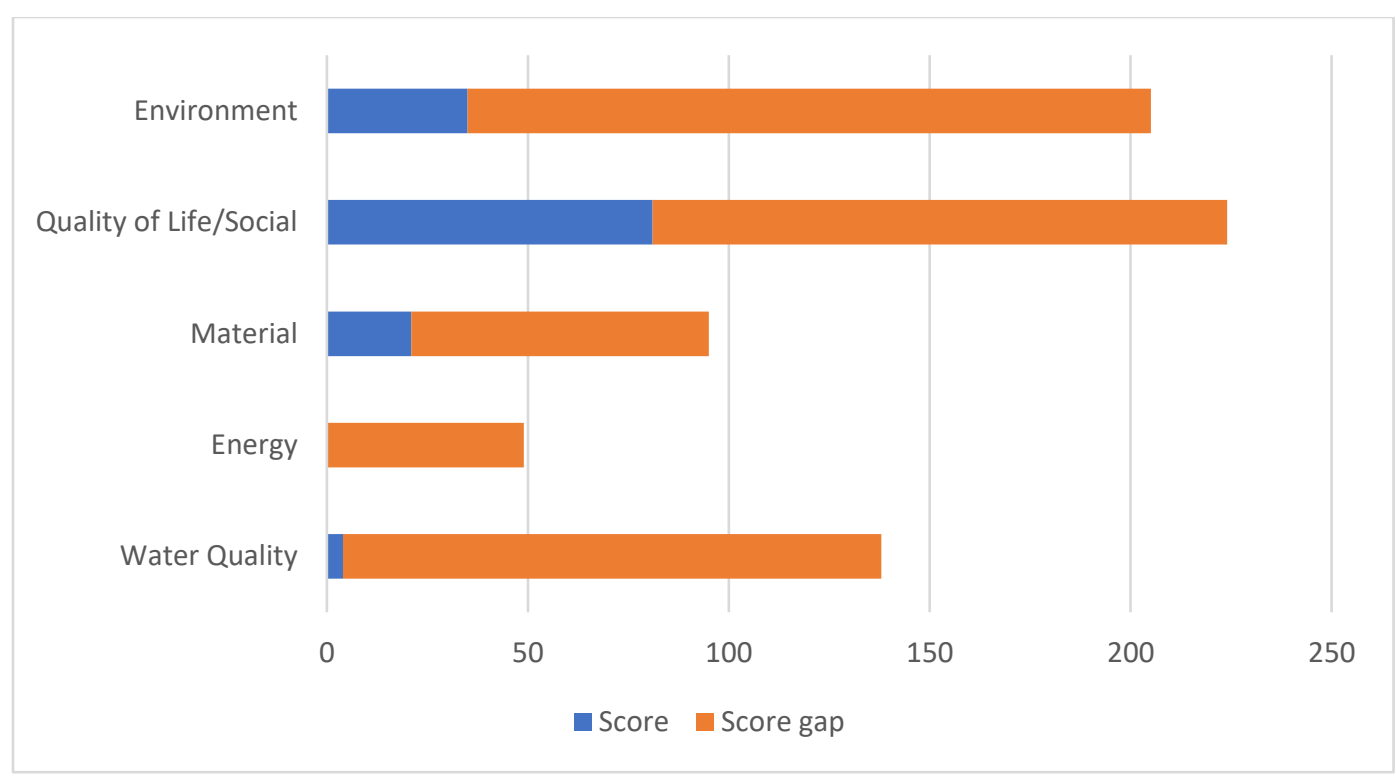

Figure 4.21. Points achieved in relation to applicable points across the five categories considered in this study for the Envision rating system for D263477.

\subsubsection{INVEST Rating for D263477}

The Project Development module of the INVEST rating system was applied in this study. The selected scorecard was the Basic Urban scorecard which applies to small urban reconstruction or urban bridge replacement project that does not expand the capacity of the roadway. This scorecard was selected because the project involved safety improvements carried out in an urban area. With this scorecard, only 27 criteria out of the 33 criteria contained in the Project Development module were applicable to Project D263477. Project D263477 scored no points in 11 of these criteria. The project had an overall score of 31 points out of 135 achievable points. This score was normalized to 23\%. Unlike Envision and GreenLITES rating systems, the INVEST rating system is not divided into categories. Thus, the project performance will only be discussed with respect to the five categories considered in this study.

The criteria under the INVEST rating system were split into the five categories considered in this study. The criteria were split based on what aspect of the five categories they are related to. 
Figure 4.22 shows the points the project earned in the five categories considered in this study in relation to the applicable points for each category.

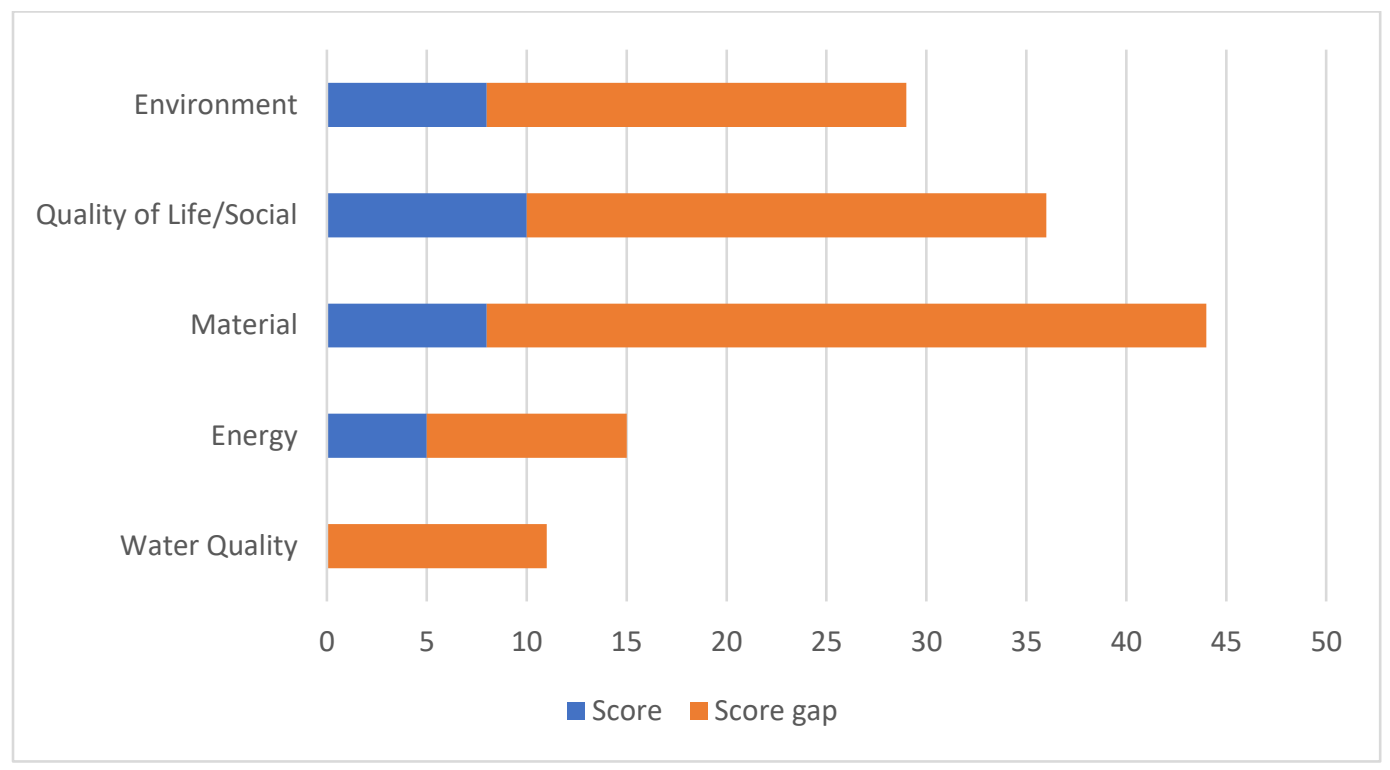

Figure 4.22. Points earned in relation to achievable points across the five categories considered in this study for the INVEST rating system for D263477.

In the INVEST rating system, project D263477 performed best in the Quality of Life/Social category, earning a total of 10 points out of 36 achievable points followed by the Environment category and the Material category with 8 points respectively. The project performed fairly in the Energy category with 5 points. The project, however, scored no points in the Water Quality category.

\subsubsection{GreenLITES Rating for Project D263477}

With the GreenLITES rating system, project D263477 scored 42 points out of 278 achievable points with a normalized point of $15.1 \%$. Not all credits were applicable to project D263477, however, no credit was scoped out in this rating system. Project D263477 scored no points in 149 credits. Figure 4.23 displays the points earned across the categories in the GreenLITES rating system in relation to the applicable points for each category. 
Project D263477 performed best in the Sustainable Sites category scoring 22 points out of 81 achievable points followed by Energy and Atmosphere category with 17 points. Project D263477 performed poorly in the Materials and Resources category scoring 3 points while the project scored no points in the Water category and in the Innovation/Unlisted category.

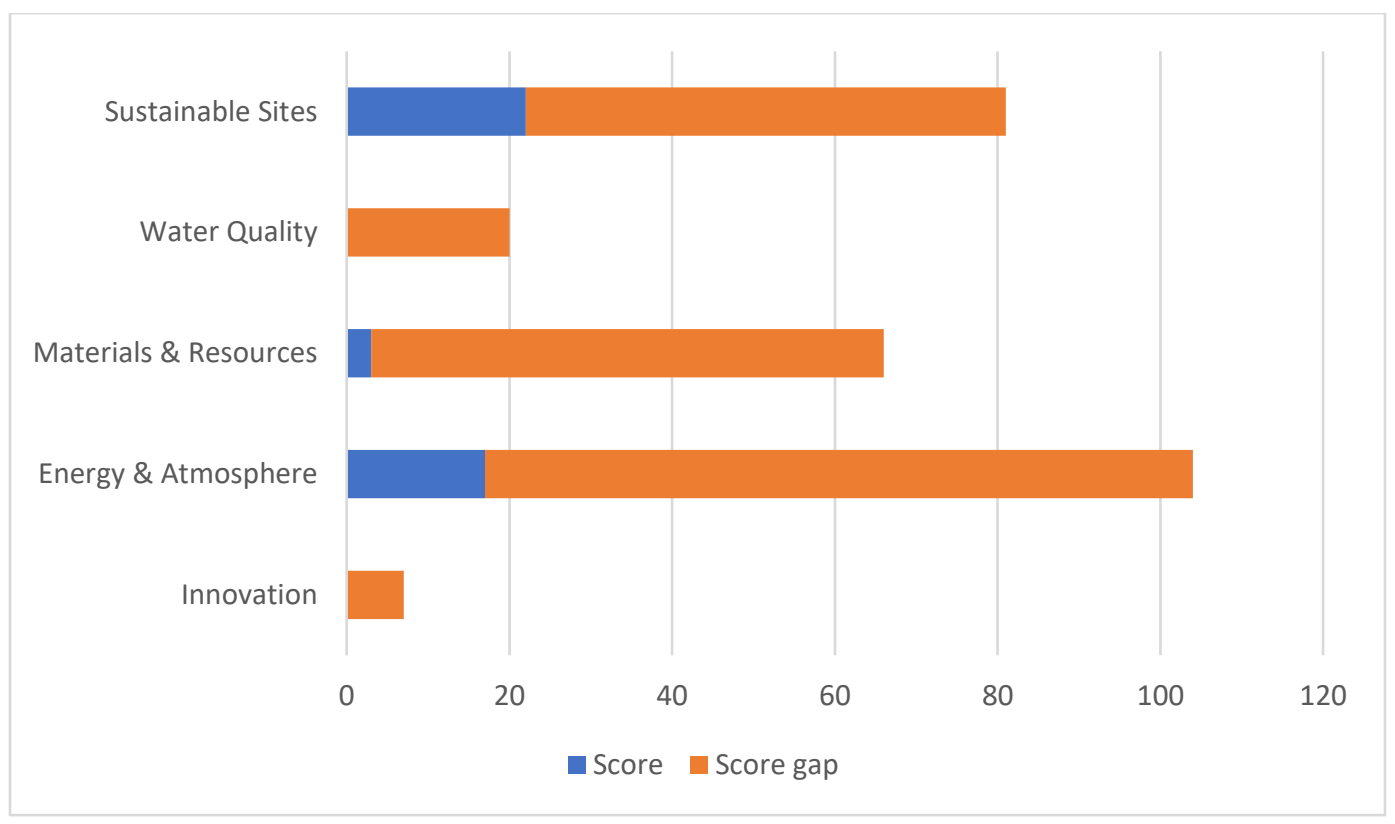

Figure 4.23. Points achieved in relation to applicable points across each category in GreenLITES rating system for D263477.

The credits under the GreenLITES rating system were split into the five categories considered in this study. The credits were split based on what aspect of the five categories they are related to. Figure 4.24 illustrates the points the project earned in each the five categories considered in this study in relation to the applicable points for each category. It is important to note that the "Innovation" category of the GreenLITES system is a general category with seven available points which cannot be placed under any of the five categories of the considered in this study

Project D263477 had its best performance in the Quality of Life/Social category and the Environment category with 24 points and 11 points respectively. The project, however, performed 
poorly in the other categories scoring 3 points, 4 points and 0 point respectively in the Material category, Energy category and Water category.

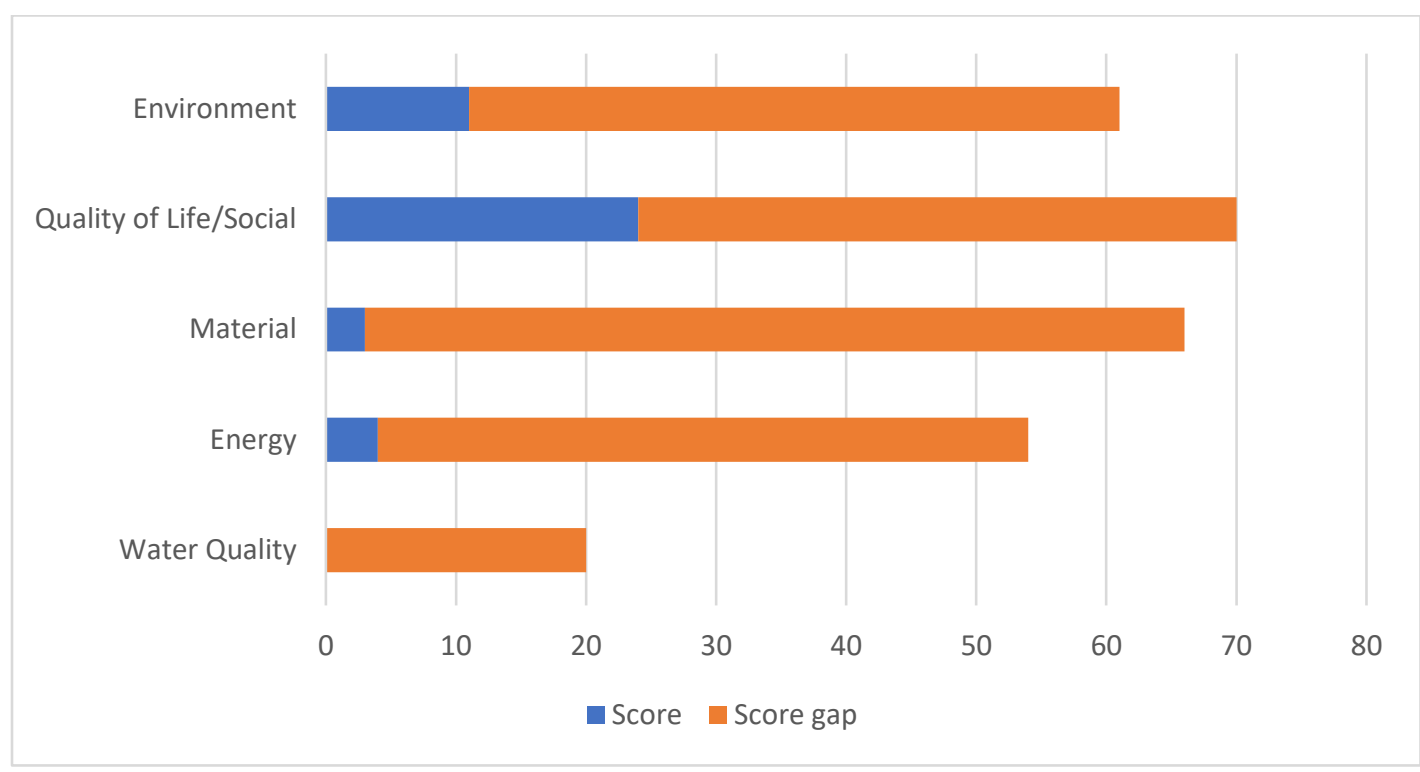

Figure 4.24. Points scored in relation to achievable points across the five categories considered in this study for the GreenLITES rating system for D263477.

\subsection{D263572 F. A. Project - Highway Reconstruction on Route 5S (1 Mile) in the City of Utica.}

The D263572 F. A. Project is a highway reconstruction project carried out on a mile of route 5S (Oriskany Street) in the City of Utica, Oneida County (NYSDOT, 2015c). Credits/criteria that are inapplicable to the project based on its context, were scoped out in the Envision and INVEST rating systems. Table 4.9 shows how project D263572 performed on the three rating systems. When run through the Envision rating system, project D263572 scored 230 points out of 683 applicable points. This result was normalized to $33.7 \%$ which earned the project a Silver award. On the INVEST rating system, project D263572 scored 65 points out of 171 points with a normalized score of $38 \%$. This score earned the project a Bronze award on the INVEST rating system. On the GreenLITES rating system, the project scored 71 out of 278 points. This score earned the project an Evergreen award on the GreenLITES system. The normalized score is $25.5 \%$. 
Table 4.9: Project D263572's Normalized Score and Award Level on Each Rating System

\begin{tabular}{lccc}
\hline Rating System & $\begin{array}{c}\text { Points } \\
\text { assessed/Points } \\
\text { applicable }\end{array}$ & $\begin{array}{c}\text { Normalized Score } \\
\text { (\% of Applicable } \\
\text { Points })\end{array}$ & Award Level \\
\hline Envision & $230 / 683$ & $33.7 \%$ & SILVER \\
\hline INVEST & $65 / 171$ & $38.0 \%$ & BRONZE \\
\hline GreenLITES & $71 / 278$ & $25.5 \%$ & EVERGREEN \\
\hline
\end{tabular}

Figure 4.25 shows the points achieved across the five categories considered in this study. With all three rating systems, the Environment, Quality of Life/Social, Material and Water Quality categories achieved some points. When run through the Envision, INVEST and GreenLITES rating systems project D263572, the project achieved $9.1 \%, 3.5 \%$ and $2.5 \%$ respectively in the Environment category, 19\%, $18.1 \%$ and $14.4 \%$ respectively in the Quality of Life/Social category, $2.8 \%, 11.1 \%$ and $1.8 \%$ respectively in the Material category and $2.8 \%, 3.5 \%$ and $2.2 \%$ respectively in the Water Quality category. In the INVEST and GreenLITES rating systems, project D263572 scored $1.8 \%$ and $4.7 \%$ respectively in the Energy category while it scored no points under the Envision system for that category. This project, like the other projects, has an uneven distribution of points achieved under the five categories considered in this study. 


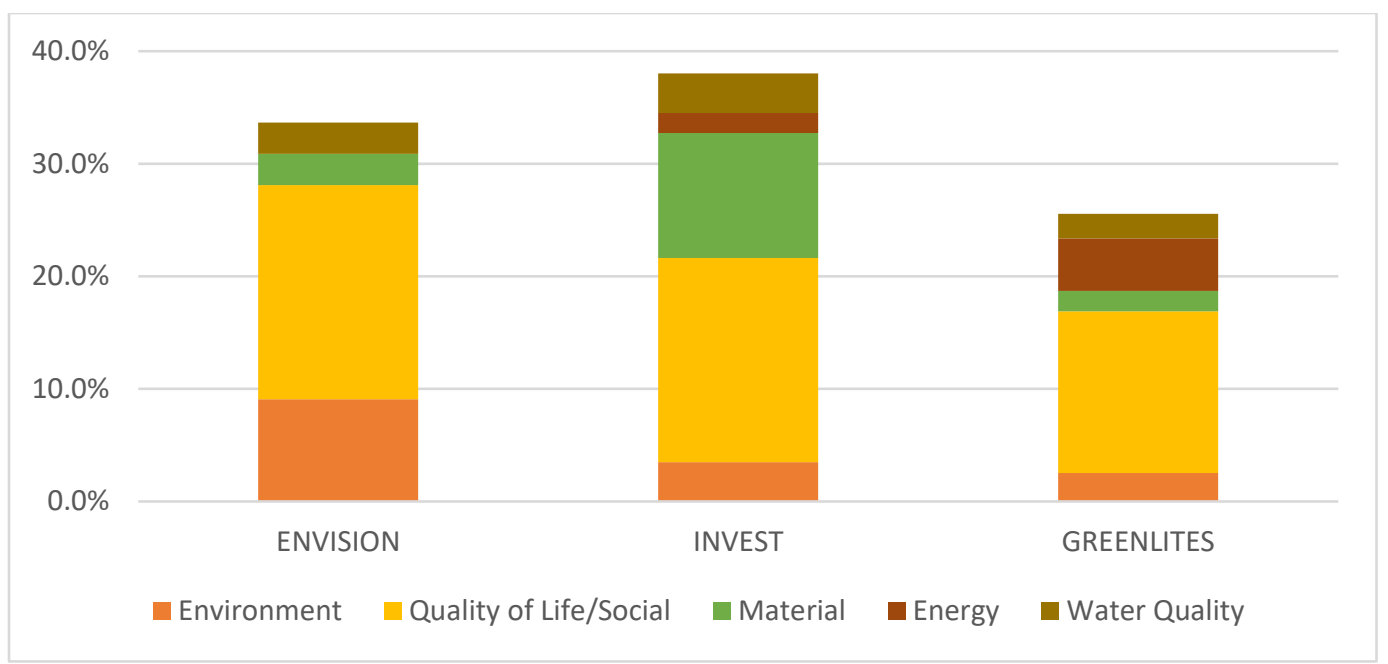

Figure 4.25. Project D263572 points spread across the five considered in this study.

\subsubsection{Envision Rating for Project D263572}

In the Envision rating system, project D263572 had a normalized score of $33.7 \%$ resulting from a score of 230 points out of 683 applicable points. Eleven credits were scoped out due to their inapplicability to the project. These credits were scoped out based on information provided in the project documents used to carry out the ratings for this project. No points were given for innovation in all categories. Hence, all five innovation credits were inapplicable to the project. Forty-four (44) credits out of the sixty (60) credits in the Envision rating system were applicable to this project. Project D263572 scored no points in 14 of the applicable credits. Table 4.10 shows the Envision credits applicable to Project D263572. Figure 4.26 shows the points the project earned across the categories in the Envision rating system in relation to the applicable points for each category.

Table 4.10: Envision Credits Applicable to Project D263572

\begin{tabular}{|l|l|c|}
\hline & ENVISION CREDITS & D263572 \\
\hline Quality of Life & X \\
\hline QL1.1 & Improve Quality of Life & X \\
\hline QL1.2 & Stimulate Sustainable Growth and Development & X \\
\hline QL1.3 & Develop Local Skills and Capabilities & X \\
\hline QL2.1 & Enhance Public Health and Safety & X \\
\hline QL2.2 & Minimize Noise and Vibration & \\
\hline
\end{tabular}




\begin{tabular}{|l|l|c|}
\hline QL2.3 & Minimize Light Pollution & $\mathrm{X}$ \\
\hline QL2.4 & Improve Community Mobility and Access & $\mathrm{X}$ \\
\hline QL2.5 & Encourage Alternative Modes of Transportation & $\mathrm{X}$ \\
\hline QL2.6 & Improve Site Accessibility, Safety and Wayfinding & $\mathrm{X}$ \\
\hline QL3.1 & Preserve Historic and Cultural Resources & \\
\hline QL3.2 & Preserve Views and Local Character & \\
\hline QL3.3 & Enhance Public Space & \\
\hline QL0.0 & Innovate or Exceed Credit Requirements & \\
\hline Leadership & \multicolumn{2}{|l|}{} \\
\hline LD1.1 & Provide Effective Leadershp and Commitment & $\mathrm{X}$ \\
\hline LD1.2 & Establish a Sustainability Management System & $\mathrm{X}$ \\
\hline LD1.3 & Foster Collaboration and Teamwork & $\mathrm{X}$ \\
\hline LD1.4 & Provide for Stakeholder Involvement & $\mathrm{X}$ \\
\hline LD2.1 & Pursue Byproduct Synergy Opportunities & $\mathrm{X}$ \\
\hline LD2.2 & Improve Infrastructure Integration & $\mathrm{X}$ \\
\hline LD3.1 & Plan for Long-term Monitoring and Maintenance & $\mathrm{X}$ \\
\hline LD3.2 & Address Conflicting Regulations and Policies & \\
\hline LD3.3 & Extend Useful Life & $\mathrm{X}$ \\
\hline LD0.0 & Innovate or Exceed Credit Requirements & $\mathrm{X}$ \\
\hline Resource Allocation & $\mathrm{X}$ \\
\hline RA1.1 & Reduce Net Embodied Energy & $\mathrm{X}$ \\
\hline RA1.2 & Support Sustainable Procurement Practices & $\mathrm{X}$ \\
\hline RA1.3 & Use Recycled Materials & $\mathrm{X}$ \\
\hline RA1.4 & Use Regional Material & $\mathrm{X}$ \\
\hline RA1.5 & Divert Waste from Landfills & $\mathrm{X}$ \\
\hline RA1.6 & Reduce Excavated Materials Taken Off Site & $\mathrm{X}$ \\
\hline RA1.7 & Provide for Deconstruction and Recycling & $\mathrm{X}$ \\
\hline RA2.1 & Reduce Energy Consumption & $\mathrm{X}$ \\
\hline RA2.2 & Use Renewable Energy & \\
\hline RA2.3 & Commission and Monitor Energy Systems & \\
\hline RA3.1 & Protect Fresh Water Availability & \\
\hline RA3.2 & Reduce Potable Water Consumption & \\
\hline RA3.3 & Monitor Water Systems & \\
\hline RA0.0 & Innovate or Exceed Credit Requirements & \\
\hline Natural World & \\
\hline NW1.1 & Preserve Prime Habitat & \\
\cline { 2 - 3 } NW1.2 & Protect Wetlands and Surface Water & \\
\hline NW1.3 & Preserve Prime Farmland & \\
\hline NW1.4 & Avoid Adverse Geology & \\
\hline NW1.5 & Preserve Floodplain Functions & \\
\hline NW1.6 & Avoid Unsuitable Development on Steep Slopes & \\
\hline NW1.7 & Preserve Greenfield & \\
\hline
\end{tabular}




\begin{tabular}{|l|l|c|}
\hline NW2.1 & Manage Stormwater & $X$ \\
\hline NW2.2 & Reduce Pesticide and Fertilizer Impacts & $X$ \\
\hline NW2.3 & Prevent Surface and Groundwater Contamination & $X$ \\
\hline NW3.1 & Preserve Species Biodiversity & $X$ \\
\hline NW3.2 & Control Invasive Species & $X$ \\
\hline NW3.3 & Restore Disturbed Soils & $X$ \\
\hline NW3.4 & Maintain Wetland and Surface Water Functions & $X$ \\
\hline NW0.0 & Innovate or Exceed Credit Requirements & \\
\hline Climate and Risk & $X$ \\
\hline CR1.1 & Reduce Greenhouse Gas Emissions & \\
\hline CR1.2 & Reduce Air Pollutant Emissions & $X$ \\
\hline CR2.1 & Assess Climate Threat & $X$ \\
\hline CR2.2 & Avoid Traps and Vulnerabilities & $X$ \\
\hline CR2.3 & Prepare for Long-Term Adaptability & $X$ \\
\hline CR2.4 & Prepare for Short-Term Hazards & \\
\hline CR2.5 & Manage Heat Island Effects & \\
\hline CR0.0 & Innovate or Exceed Credit Requirements \\
\hline
\end{tabular}

Project D263572 had its best performance in the Quality of Life category and the Leadership category with 83 points and 63 points respectively. The project performed fairly in the Natural World category with 46 points. The project scored 23 points in the Climate and Risk category, which gives it an edge compared to the other project which scored no points. The project performed poorly in the Resource Allocation category with 15 points.

The credits under the Envision rating system were split into the five categories considered in this study. The credits were split based on what aspect of the five categories they are related to. 


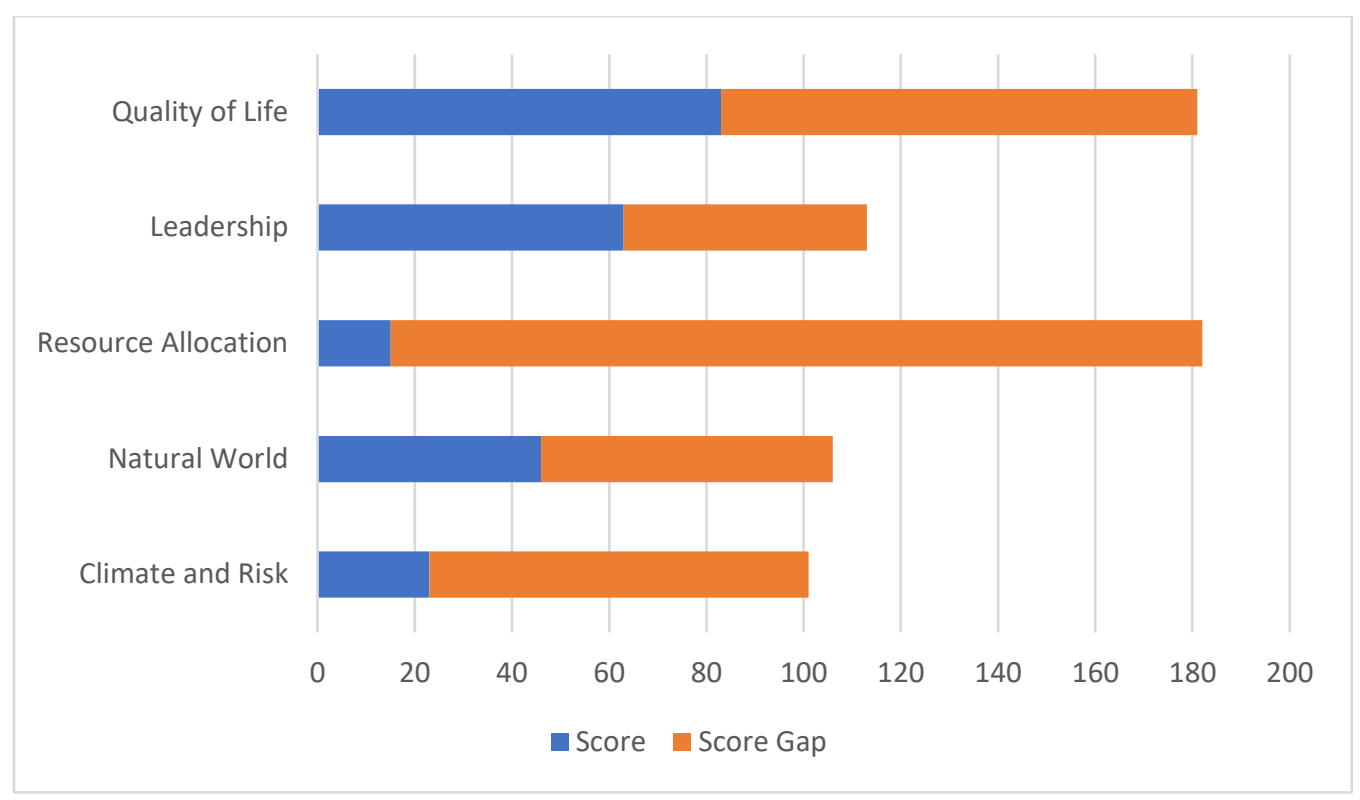

Figure 4.26. Points achieved in relation to applicable points across each category of Envision rating system for D263572.

Figure 4.27 displays the points the project earned in the five categories considered in this study in relation to the applicable points for each category. Project D263572 had its best performance in the Quality of Life/Social category with earned points of 130 out of 253 applicable points. This was followed by the Environment category which earned 62 points out of 194 applicable points. The Material category and Water Quality categories both performed fairly, each scoring 19 points out of 95 and 92 applicable points respectively. The Energy category had a poor performance scoring no points. 


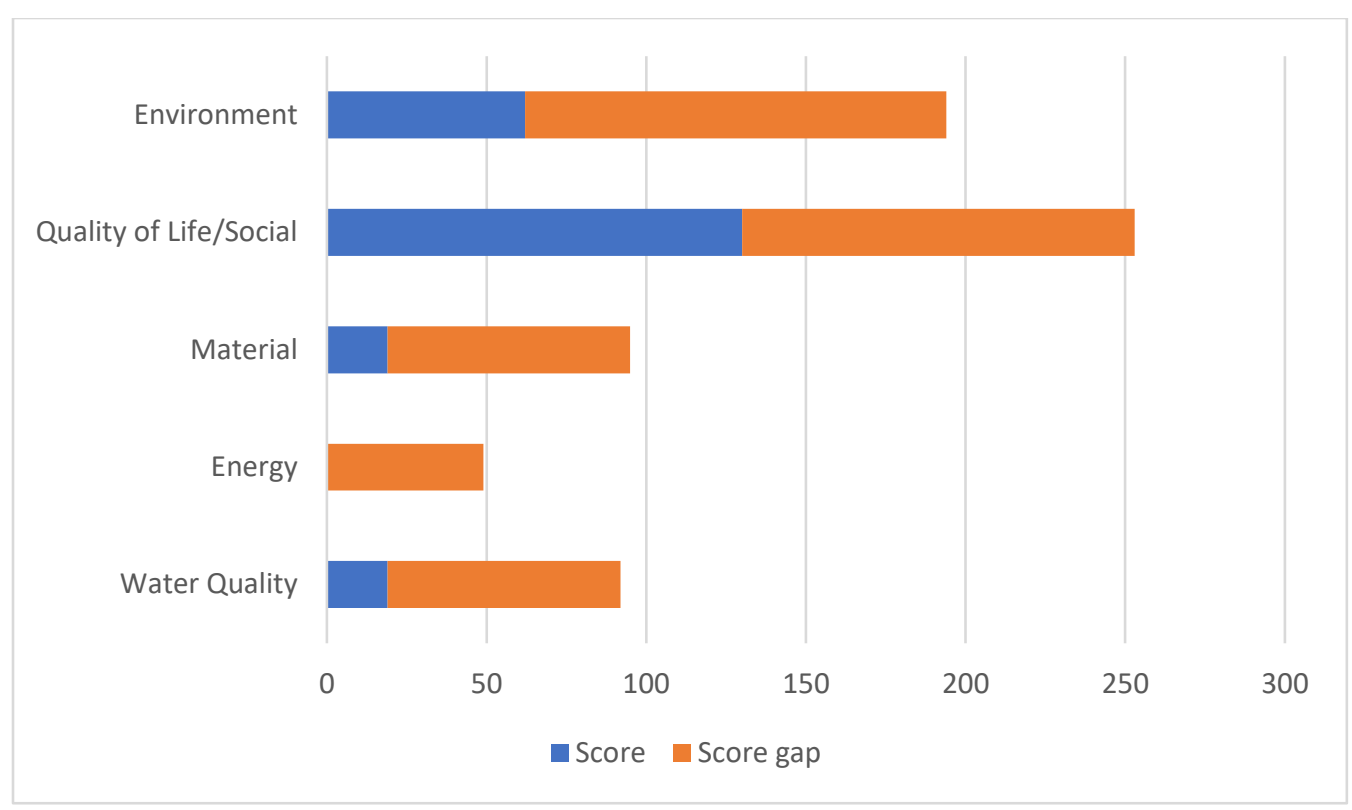

Figure 4.27. Points achieved in relation to applicable points across the five categories considered in this study for the Envision rating system for D263572.

\subsubsection{INVEST Rating for D263572}

The Project Development module of the INVEST rating system was applied in this study. The selected scorecard was the Extended Urban scorecard which is used in urban construction project of a new roadway facility or structure where nothing of its kind currently exists and major reconstruction projects that add travel lanes to an existing roadway or bridge. This scorecard was selected because the project involved the construction of a new traffic circle in an urban area. With this scorecard, all 33 criteria contained in the Project Development module were applicable to Project D263572. Project D263572 scored no points in 14 of these criteria. The project had an overall score of 65 points out of 171 achievable points. This score was normalized to $38 \%$. A distinct feature of the INVEST rating system is that it is not divided into categories. Thus, the project performance will only be discussed with respect to the five categories considered in this study. 
The criteria under the INVEST rating system were split into the five categories considered in this study. The criteria were split based on what aspect of the five categories they are related to. Figure 4.28 shows the points the project earned in the five categories considered in this study in relation to the applicable points for each category.

Project D263572 had its best performance in the Quality of Life/Social category with a score of 31 points out of 39 applicable points while performing averagely in the Material category with a score of 19 points out of 49 points. The project had a fair performance in the Water Quality category while it had a poor performance in the Environment and Energy categories.

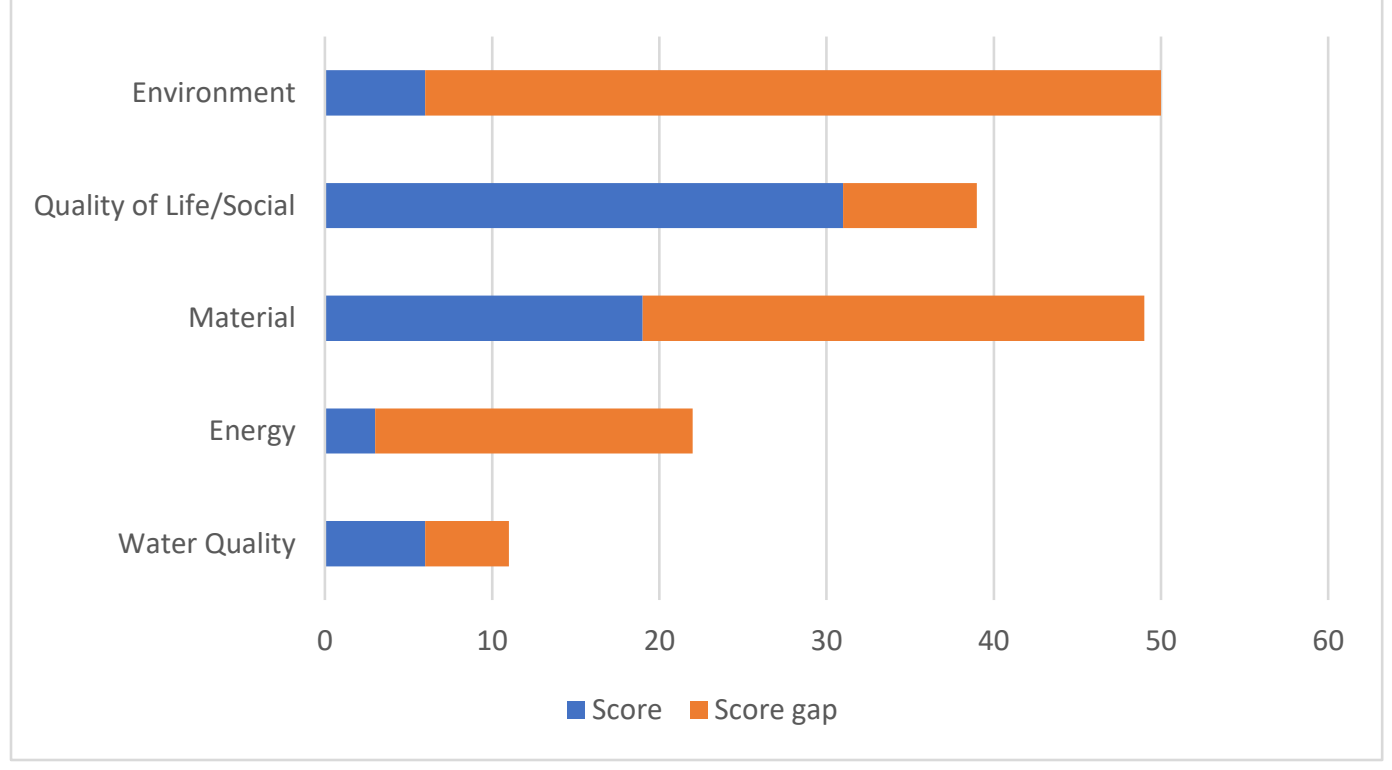

Figure 4.28. Points earned in relation to achievable points across the five categories considered in this study for the INVEST rating system for D263572.

\subsubsection{GreenLITES Rating for D263572}

With the GreenLITES rating system, project D263572 scored 71 points out of 278 achievable points with a normalized point of $25.5 \%$. Not all credits were applicable to project D263572, nonetheless, no credit was scoped out in this rating system. Project D263572 scored no 
points in 128 credits. Figure 4.29 displays the points earned across the categories in the GreenLITES rating system in relation to the applicable points for each category.

Project D263572 had its best performance in the Energy and Atmosphere category as well as the Sustainable Sites category earning 38 points out of 104 achievable points and 22 points out of 81 achievable points respectively. In the other categories, however, the project performed poorly.

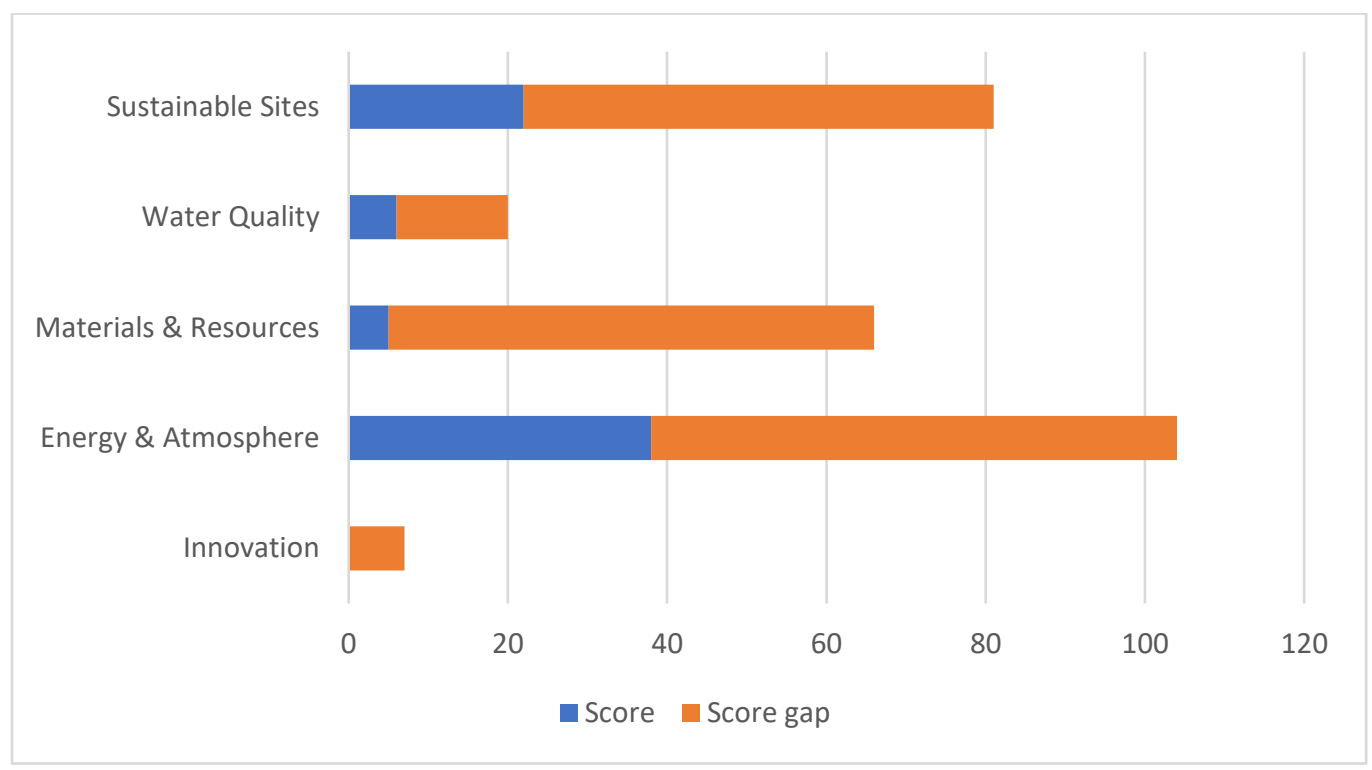

Figure 4.29. Points achieved in relation to applicable points across each category in GreenLITES rating system for D263572.

The credits under the GreenLITES rating system were split into the five categories considered in this study. The credits were split based on what aspect of the five categories they are related to. Figure 4.30 illustrates the points the project earned in the five categories considered in this study in relation to the applicable points for each category.

Project D263572 had its best performance in the Quality of Life/Social category with a score of 40 points out of 70 achievable points. The project had a fair performance in the Energy category and Water Quality category scoring 13 points out of 54 achivable points and 6 points out 
of 20 achievable points respectively. The project performed poorly in the Environment and Material categories.

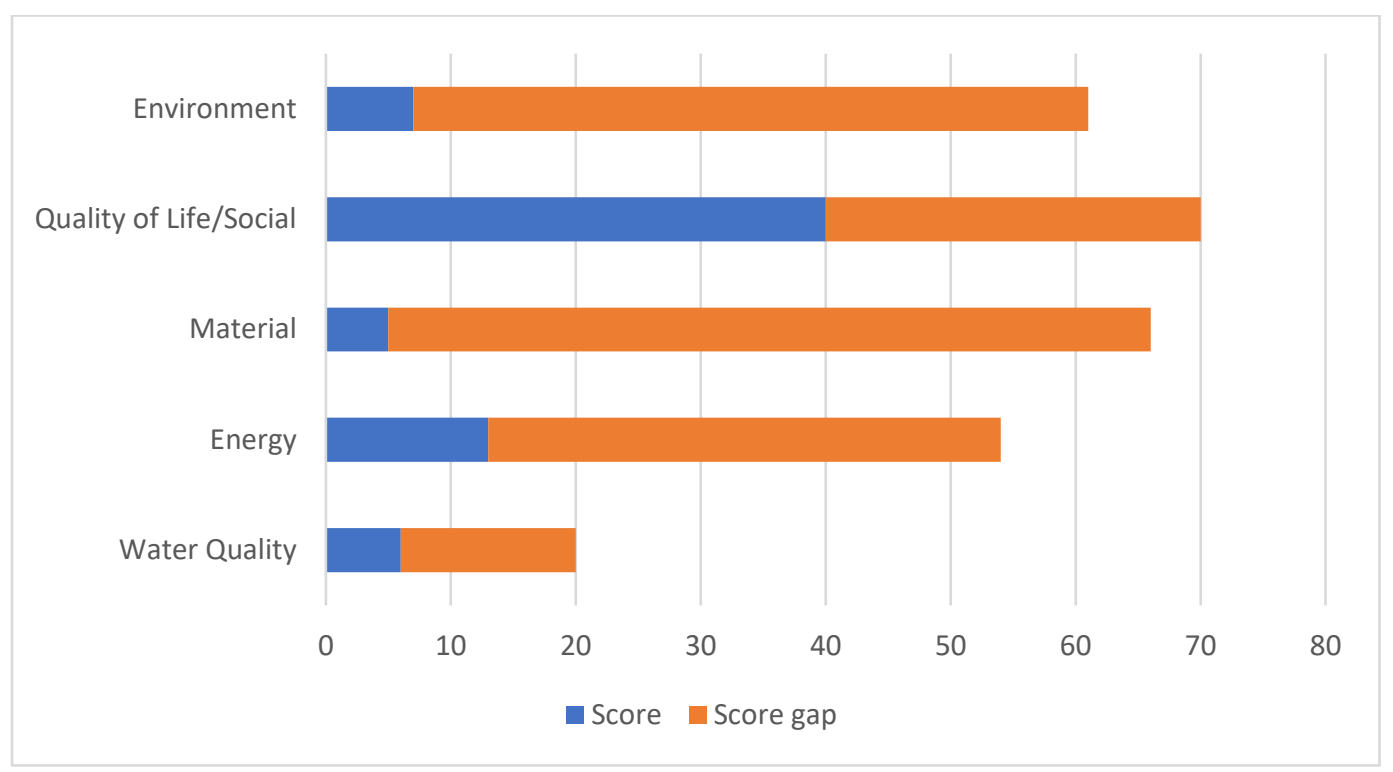

Figure 4.30. Points scored in relation to achievable points across the five categories considered in this study for the GreenLITES rating system for D263572.

\subsection{Comparsion of Rating Systems Across the Projects}

Figure 4.31 shows a comparison of the how the projects fared on the three rating systems when put side by side. As seen from the chart below, all five projects had the highest normalized score on the INVEST rating, the lowest normalized score on the GreenLITES rating system while the Envision rating system always stayed in between the INVEST and GreenLITES rating systems.

However, while the INVEST rating system always had the highest normalized score, this did not always translate into the project getting the highest award or being awarded. It is worthy of note that although the INVEST rating system always had the highest normalized score, it never awarded a project the highest award level when all three rating systems were compared. On the other hand, the GreenLITES rating system, always gave a higher award level, with the exception of project D262883, though it always had the lowest normalized score. 


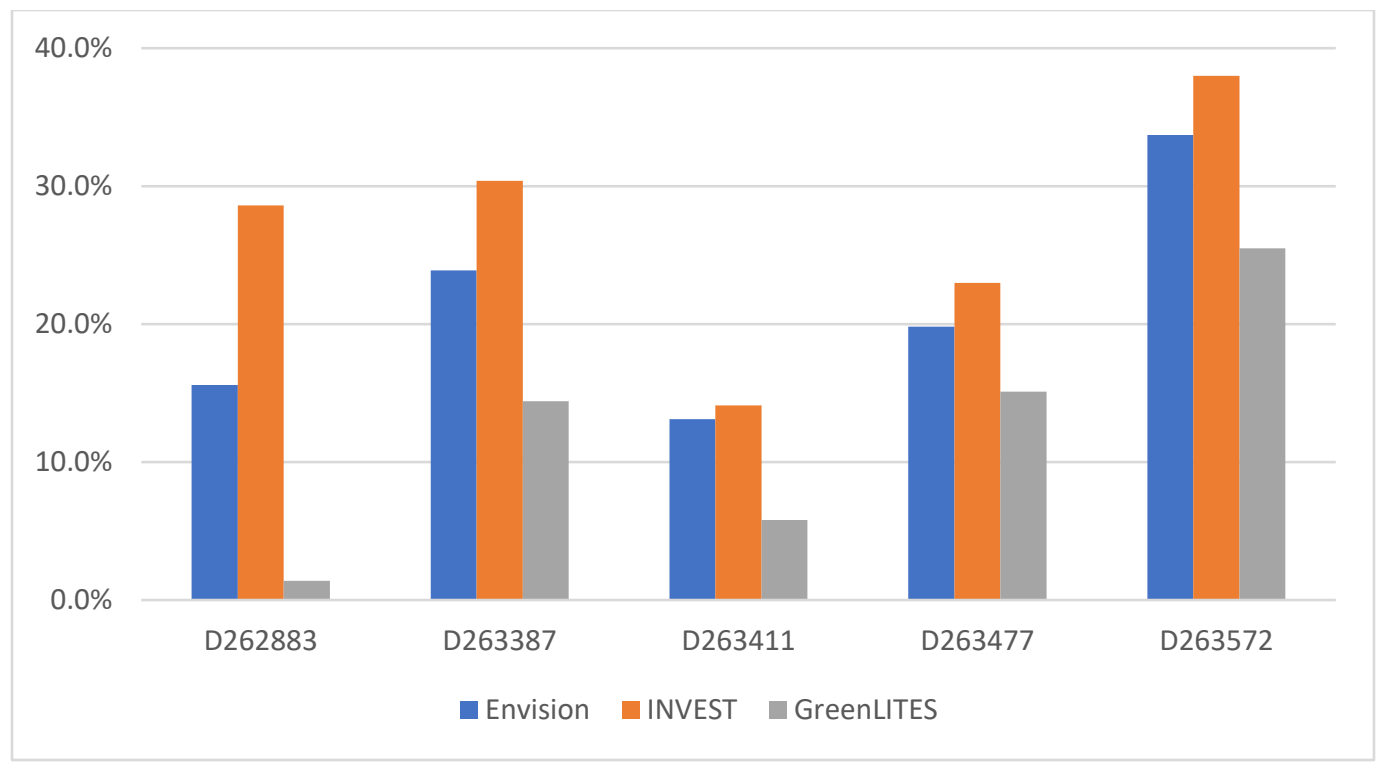

Figure 4.31. Comparison of Rating Systems Across the Projects.

\subsection{Discussion of Results}

The above narrated analyses discusses the outcome of running five transportation projects through three transportation rating system.

The first project rated, project D262883, was generally a low-performing project as it did not perform well on any of the rating systems with normalized points of $13.8 \%, 28.6 \%$ and $1.4 \%$ on the Envision, INVEST and GreenLITES rating system respectively and thus earned no award. There was a wide variance in the results achieved on all three rating systems. However, the project performed better on the INVEST and Envision rating systems than it did on GreenLITES rating system. In this project, D262883, there was no peculiar pattern observed in how the three systems rated the project.

With project D263387, its performance on the three rating systems was slightly better than the first project with the results being within 10\% of the other. INVEST had 30.4\%, Envision had $23.9 \%$ while GreenLITES had $14.4 \%$. The three rating systems had a lower variance in results in 
the Environment and Quality of Life/Social categories. In project D263387, no peculiar pattern was observed in how the rating systems assessed the project.

The third rated project, D263411, performed poorly in both the Envision and INVEST rating system with normalized scores of $13.1 \%$ and $14.1 \%$ respectively. However, it received a certified award in the GreenLITES rating system with a normalized score of $5.8 \%$. There was no pattern observed in how the three rating systems measured sustainability practices in this project.

The fourth rated project, D263477, performed averagely in the Envision and GreenLITES rating systems with a normalized score of $19.8 \%$ and $15.1 \%$ with awards of bronze and silver respectively. However, it received no award on the INVEST rating system. This could mainly be attributed to a lack of information needed to meet the sustainability practices required by the INVEST rating system.

The last rated project, D263572, had the best performance on all three rating systems compared to the other projects. It had awards of Silver, Bronze and evergreen on the Envision, INVEST and GreenLITES rating systems respectively. Despite the good performance of this project on the three rating systems, it is necessary to note that the project scored no points in the Energy category of the Envision rating system.

The results presented illustrate that the rating tools assess sustainability practices differently and also reward them differently. A project rated highly on one rating system does not imply that it will be rated as highly on another rating system and vice versa. This disparity may be the result of several conditions.

First, while it might seem like the rating systems look out for the same sustainability practices, the requirements needed to be fulfilled so as to get rewarded differ from each other. For 
instance, the three rating systems take into context sensitive solutions (CSS) into consideration. While it might look like the same externally, each rating system considers different sustainability practices in fulfilling these credits. Envision focuses on practices like stakeholder involvement, improvement of community quality of life, developing local skill and capabilities, preserving local character, etc. INVEST rating system focuses on a six-step CSS framework, a cradle to grave team, project champions amongst the stakeholders, etc. GreenLITES focuses on responding to unique local features. Etc. Each of the rating systems considers these different sustainability practices but in varying degree, thus affecting a project's performance in the different categories as well as overall.

Second, sustainability practices rewarded on a tool may not be rewarded on another tool. For instance the INVEST rating system rewards Intelligent Transport Systems while neither of the other systems considers this. The Envision rating system rewards Assessment of Climate Threats to the project, however, neither of the other rating systems assesses this. These sustainable practices, if implemented on a project, might help to improve the project's overall performance on one rating system, but not in the other.

Third, the variance in scores observed in all five projects from the three rating systems is as a result of some characteristics of the rating systems as well as the difference in sustainability practices measured by the rating systems. With the Envision and INVEST rating systems, inapplicable credits can be scoped out, reducing the projects chances of ending with a low score based on inapplicable credits. With the GreenLITES rating system, this was not so. As such, the normalized score usually came out low compared to the other rating systems. With respect to sustainability practices measured, Envision and INVEST had different levels of sustainability practices that could be fulfilled. With Envision, there is the improved, enhanced, superior, 
conserving and restorative levels. With INVEST, there are different points based on what percentage or level of sustainability practice was attained. With the GreenLITES system, that option was often not available.

An important trend that was identified is that in all projects, GreenLITES resulted in the lowest normalized score, followed by Envision and then INVEST. Despite having the lowest normalized score in all five projects, GreenLITES resulted in a higher award level than the other two TSRS in four of those five projects. In the remaining one project, award levels resulting from all TSRS was the same (i.e., No Award). This trend suggests that it may be easier for a project to get awarded in GreenLITES compared to the other two TSRS.

Notwithstanding all of the above, a consistency was noted in all three rating systems in the Quality of Life/Social category performance. In all three systems, with respect to four projectsD263387, D263411, D263477 and D263572, it can be said that a consistency exists in the performance of a project in the Quality of Life/Social category with all the normalized result for this category, in each project, being within $5 \%$ of the other. Thus, a project's performance in the Quality of Life/Social category on one of the rating systems may be a guide as to how it will perform on other rating systems. The INVEST rating system, also had a more even/balanced rating in the five categories considered in this study that the other rating system. 


\section{CHAPTER 5: CONCLUSIONS}

\subsection{Summary of Research}

The purpose of this study was to assess how three prominent transportation sustainability rating systems; ENVISION, INVEST and GreenLITES rate performance of transportation projects with the ultimate goal of determining if a trend or consistency exists in the way these three TSRS measure sustainability. This became important as it was noted in a study that TSRS have not been developed with a consistent "sustainability scope" ("the breadth of sustainability addressed and the prioritization within") (K. Griffiths et al., 2015; Veeravigrom et al., 2015). Thus, a project, run through more than one of these rating systems may be high performing on one rating system and low performing on another. This brought about the question of the consistency of these rating systems in measuring sustainability. Thus, there was the need to evaluate multiple TSRS to determine if a trend or consistency exists in the way the systems measure sustainability in transportation projects.

The scope of the study was limited to three transportation sustainability rating systems ENVISION, INVEST and GreenLITES. ENVISION, a third-party rating system developed by Zofnass Institute in conjunction with the American Society of Civil Engineers, INVEST, a selfassessed rating system developed by Federal Highway Administration and GreenLITES, a selfassessed rating system developed by the New York State Department of Transportation.

The steps followed to achieve the aim of this study were:

* A thorough literature review that examined the various properties and capabilities of each rating system was carried out. 
* The rating systems (Envision, INVEST and GreenLITES) were each applied to five rehabilitation projects gotten from NYSDOT.

* The results gotten from the ratings were compared and assessed based on the triple bottom line (economic, social and environmental).

\subsection{Summary of Results gotten from Ratings}

The first project rated, project D262883, had normalized scores of $13.8 \%, 28.6 \%$ and $1.4 \%$ derived the following scores 98/711, 34/119 and 4/278 gotten on the Envision, INVEST and GreenLITES rating system respectively and thus earned no award.

The second project rated, project D263387, had normalized scores of $23.4 \%, 30.4 \%$ and $14.4 \%$ derived the following scores 170/725, 41/135 and 40/278 gotten on the Envision, INVEST and GreenLITES rating system respectively and earned Bronze, Bronze and Silver awards respectively.

The third project rated, project D263411, had normalized scores of $13.1 \%, 14.1 \%$ and $5.1 \%$ derived the following scores 78/597, 19/135 and 16/278 gotten on the Envision, INVEST and GreenLITES rating system respectively and thus earned no award on the Envision and INVEST rating systems. However, it earned a Certified award on the GreenLITES system.

The fourth project rated, project D263477, had normalized scores of $19.8 \%, 23 \%$ and $15.8 \%$ derived the following scores $141 / 711,31 / 135$ and $42 / 278$ gotten on the Envision, INVEST and GreenLITES rating system respectively and thus earned a Bronze and Silver awards on the Envision and GreenLITES rating systems respectively. The project, however, earned no award on the INVEST rating system. 
The fifth project rated, project D263572, had normalized scores of 33.7\%, 38\% and 25.5\% derived the following scores 230/683, 65/171 and 71/278 gotten on the Envision, INVEST and GreenLITES rating system respectively and earned Silver, Bronze and Evergreen awards respectively.

\subsection{Concluding Remarks}

Sustainability Rating Systems are tools that have been developed in response to the need to evaluate the practical and useful performance of construction projects. This need was born from the growing desire to incorporate sustainable practices into construction activities while considering the development in terms of its economic, environmental and social benefit. While these rating tools may have been developed to fit specific contexts, it is important that a level of consistency be found in the way these rating systems rate project performance. Given this, the purpose of this study was to assess how three prominent transportation sustainability rating systems; Envision, INVEST and GreenLITES rate performance of transportation projects with the ultimate goal of determining if a consistency exists in the way these three TSRS measure sustainability.

The results gotten from running five transportation projects through the three rating systems studied in this research show that no consistency exists in the way these rating systems measure sustainability performance in transportation project as the rating systems assess and reward sustainable practices differently. Additionally, it was found that it may be easier for a project to get awarded in GreenLITES compared to the other two TSRS. Notwithstanding all of the above, a consistency was noted in all three rating systems in the Quality of Life/Social performance of projects. 
Although the stakeholders of a transportation project might decide to go with a rating system over the other because the context of the project aligns better with the context of that rating system, this however, should not be a reason why that project will not perform as well when run through other sustainability rating systems. If this be the case, then project stakeholders will begin to pick rating systems that will rate their projects well rather than really incorporating sustainability practices in their projects that are beneficial based on the triple bottom line.

While this inconsistency may presently pose a concern, it is necessary to note that these sustainability rating systems grow over time and as such the creators of these systems may improve upon whatever inconsistencies their rating systems have thus improving overall project performance.

A limitation of this study is that in certain cases the information needed about the projects to perform and confirm ratings was not completely available. Another limitation of the study was the use of a single assessor as there could be bias affecting the consistency and validity of the result. The absence of result verification is another limitation of this study.

\subsection{Future Research}

The results of this study have shown that that no consistency exists in the way these rating systems measure sustainability performance in transportation project as the rating systems assess and reward sustainable practices differently. The results also show that it may be easier for a project to get awarded in GreenLITES compared to the other two TSRS. Notwithstanding all of the above, a consistency was noted in all three rating systems in the Quality of Life/Social performance of projects. 
These results have been derived based on running five transportation projects through the three rating systems studied in this research. These ratings were however, carried out by one researcher and based on limited information provided on the NYSDOT website. To improve upon this study, additional research should be carried out on projects with more comprehensive information. Professionals and stakeholders involved in the project may also be interviewed thus providing more information and a holistic view of the projects. More assessors should also be involved in the rating of the projects so as to reduce bias that may arise from the use of a single assessor. 


\section{REFERENCES}

Anderson, J., \& Muench, S. (2013). Sustainability trends measured by the greenroads rating system. Transportation Research Record: Journal of the Transportation Research Board(2357), 24-32.

ASCE. (2017). Envision. Retrieved from https://www.asce.org/envision/

Asdrubali, F., Baldinelli, G., Bianchi, F., \& Sambuco, S. (2015). A comparison between environmental sustainability rating systems LEED and ITACA for residential buildings. Building and Environment, 86, 98-108.

Awadallah, F., Fini, E. H., \& Mellat-Parast, M. (2013). Highway and transportation implications on environmental sustainability: urban planning, construction, and operation counter measures. In ICSDEC 2012: Developing the Frontier of Sustainable Design, Engineering, and Construction (pp. 343-349).

Awasthi, A., \& Chauhan, S. S. (2011). Using AHP and Dempster-Shafer theory for evaluating sustainable transport solutions. Environmental Modelling \& Software, 26(6), 787-796.

Berardi, U. (2012). Sustainability assessment in the construction sector: rating systems and rated buildings. Sustainable Development, 20(6), 411-424.

Black, W. R. (1996). Sustainable transportation: a US perspective. Journal of transport geography, 4(3), 151-159.

Bosco, C., \& Buckingham, T. C. (2013). Applying Sustainable Practices to the Roadway Improvements of East Rosedale Street in Fort Worth, Texas. In Green Streets, Highways, and Development 2013: Advancing the Practice (pp. 388-397).

Brodie, S., Ingles, A., Colville, Z., Amekudzi, A., Peters, R. W., \& Sisiopikou, V. (2013). Review of Sustainability Rating Systems for Transportation and Neighborhood-Level Developments. Paper presented at the Second Conference on Green Streets, Highways, and Development.

Burns, T. R. (2012). The sustainability revolution: A societal paradigm shift. Sustainability, 4(6), 1118-1134.

Clevenger, C. M., Ozbek, M. E., \& Simpson, S. (2013). Review of sustainability rating systems used for infrastructure projects. Paper presented at the 49th ASC Annual International Conference Proceedings.

Clevenger, C. M., Ozbek, M. E., Simpson, S. P., \& Atadero, R. (2016). Challenges in Developing a Transportation Sustainability Rating System That Meets the Preferences of a Department of Transportation. Journal of Transportation Engineering, 142(4), 04016005. 
Creswell, J. W. (2013). Research design: Qualitative, quantitative, and mixed methods approaches: Sage publications.

Du Pisani, J. A. (2006). Sustainable Development - Historical roots of concept, Environmental Science. (3:2), $83-95$.

Fenner, R. A., \& Ryce, T. (2008, 2008). A comparative analysis of two building rating systems Part 1: Evaluation.

FHWA. (2017a). About INVEST. https://www.sustainablehighways.org/100/about.html.

FHWA. (2017b). System Planning. https://www.sustainablehighways.org/101/systemplanning.html.

FHWA. (2017c). About the System Planning Modules. https://www.sustainablehighways.org/889/about-the-system-planning-modules.html.

FHWA. (2017d). What does the System Planning Score Mean. https://www.sustainablehighways.org/897/what-does-the-system-planning-scoremean.html.

FHWA. (2017e). Project Development. https://www.sustainablehighways.org/568/projectdevelopment.html.

FHWA. (2017f). About the Project Development Module. https://www.sustainablehighways.org/900/about-the-project-development-module.html.

FHWA. (2017g). Why and When Would I Score a Project. https://www.sustainablehighways.org/903/why-and-when-would-i-score-a-project.html.

FHWA. (2017h). Who Can Use the Project Development Module. https://www.sustainablehighways.org/905/who-can-use-the-project-developmentmodule.html.

FHWA. (2017i). What Does The Project Development Score Mean. https://www.sustainablehighways.org/909/what-does-the-project-development-scoremean.html.

FHWA. (2017j). Operations and Maintenance. https://www.sustainablehighways.org/131/operations-and-maintenance.html.

FHWA. (2017k). About The Operations and Maintenance Module. https://www.sustainablehighways.org/917/about-the-operations-and-maintenancemodule.html. 
FHWA. (20171). Innovative Criteria. https://www.sustainablehighways.org/1362/innovativecriteria.html.

FHWA. (2017m). How Do I Use INVEST to Score a Project? Retrieved from https://www.sustainablehighways.org/914/how-do-i-use-invest-to-score-a-project.html

GAO. (1990). Case Study Evaluations. United States General Accounting Office. Retrieved from http://www.gao.gov/special.pubs/10_1_9.pdf

Griffiths, K., Boyle, C., \& Henning, T. (2015). Infrastructure sustainability rating tools-how they have developed and what we might expect to see in the future. IPWEA 2015: Sustainable Communities Sharing Knowldge.

Griffiths, K. A., Boyle, C., \& Henning, T. F. P. (2017). Comparative Assessment of Infrastructure Sustainability Rating Tools. Retrieved from

Hirsch, A. (2011). Summary of Transportation Sustainability Rating System Programs, . http://terralogicss.com/sustainable-transportation/summary-of-transportationsustainability-rating-system-programs.

IPCC. (2015). Climate change 2014: mitigation of climate change (Vol. 3): Cambridge University Press.

ISI. (2015). Envision Guidance Manual. https://sustainableinfrastructure.org/portal/files/GuidanceManual.pdf.

ISI. (2017a). Envision. https://sustainableinfrastructure.org/envision/.

ISI. (2017b). Envision - How it Works. https://sustainableinfrastructure.org/envision/how-itworks/.

ISI. (2017c). Envision Fact Sheet. https://sustainableinfrastructure.org/brochure/fact-sheet/.

ISI. (2017d). Project Awards. Retrieved from http://sustainableinfrastructure.org/envision/projectawards/\#3/48.22/-95.89

Kates, R. W., Parris, T. M., \& Leiserowitz, A. A. (2005). What is sustainable development? Goals, indicators, values, and practice. Environment(Washington DC), 47(3), 8-21.

Lineburg, K. (2016). Transportation Rating Systems and Social Sustainability: A Comprehensive Analysis.

McVoy, G. R., Nelson, D. A., Krekeler, P., Kolb, E., \& Gritsavage, J. S. (2010, 2010). Moving towards Sustainability: New York State Department of Transportation's GreenLITES Story. 
Nauclér, T., \& Enkvist, P.-A. (2009). Pathways to a low-carbon economy: Version 2 of the global greenhouse gas abatement cost curve. McKinsey \& Company, 192.

NYSDOT. (2014a). D262883 F. A. Project Proposal Contractor's Bid Package. New York State: NYSDOT.

NYSDOT. (2014b). Transportation Project Report: Initial Project Proposal/Final Design Report. New York: New York State Department of Transportation

NYSDOT. (2015a). D263387 F. A. Project Proposal Contractor's Bid Package. New York State: NYSDOT.

NYSDOT. (2015b). D263411 F. A. Project Proposal Contractor's Bid Package. New York: NYSDOT.

NYSDOT. (2015c). D263572 F. A Project Proposal Contractor's bid package: Highway Reconstruction on Route $5 S$ (1 mile) in the City of Utica. New York: NYSDOT.

NYSDOT. (2015d). Rotterdam Town Board Meeting. New York: NYSDOT.

NYSDOT. (2016). D263477 F. A. Project Proposal Contractor's Bid Package. New York: NYSDOT.

NYSDOT. (2017a). Transportation Project Report: Final Design Report. New York: NYSDOT.

NYSDOT. (2017b). Transportation Project Report: Stormwater Pollution Prevention Plan. New York: NYSDOT.

NYSDOT. (2017a). GreenLITES. https://www.dot.ny.gov/programs/greenlites.

NYSDOT. (2017b). Project Program. https://www.dot.ny.gov/programs/greenlites/project-design-cert.

NYSDOT. (2017c). Project Design Scorecard.

NYSDOT. (2017d). Operations Certification Program.

NYSDOT. (2017e). GreenLITES Planning-nysdot. Retrieved from https://www.dot.ny.gov/programs/greenlites/GreenLITESplanning

NYSDOT. (2018a). 390-Lyell Improvement Interchange. https://www.dot.ny.gov/390lyell. Retrieved from https://www.dot.ny.gov/3901yell

NYSDOT. (2018b). I390 INTERCHANGE IMPROVEMENTS @ I490 (STAGE 2 - LYELL RAMPS).

https://www.dot.ny.gov/portal/pls/portal/MEXIS_APP.DYN_PROJECT_DETAILS.show? p_arg_names $=p \_$pin $\& p \_$arg_values $=439030 . \quad$ Retrieved from 
https://www.dot.ny.gov/portal/pls/portal/MEXIS_APP.DYN_PROJECT_DETAILS.sho

$w$ ? $p \_$arg names $=p \_p i n \& p \_$arg $\_$values $=439030$

NYSDOT. (2018c). NY 231 Safety Improvements at Northern State Parkway Interchange. NY 231

Safety Improvements at Northern State Parkway Interchange. Retrieved from https://www.dot.ny.gov/ny231safety

NYSDOT. (2018d). Route 5S Safety Project - Broadway to Broad Street. Route 5S Safety Project

- Broadway to Broad Street. Retrieved from https://www.dot.ny.gov/route5ssafetyproject

NYSDOT. (2018e). RT. 146: HAMBURG ST. SAFETY IMPRV, TOWN OF ROTTERDAM. RT. 146: HAMBURG ST. SAFETY IMPRV, TOWN OF ROTTERDAM. Retrieved from https://www.dot.ny.gov/portal/pls/portal/MEXIS_APP.DYN_PROJECT_DETAILS.sho $\underline{\text { w?p_arg_names }=\text { p_pin\&p_arg_values }=108533}$

Shivakumar, S., Pedersen, T., Wilkins, S., \& Schuster, S. (2014). Envision: A Measure of Infrastructure Sustainability. In Pipelines 2014: From Underground to the Forefront of Innovation and Sustainability (pp. 2249-2256).

Simpson, S. (2013). A framework for assessing transportation sustainability rating systems for implementation in US State departments of transportation. Colorado State University,

Simpson, S. (2014). A Framework for Assessing Transportation Sustainability Rating Systems for Implementation in US State Departments of Transportation.

STC. (2012). STARS pilot plan application manual; V 0.2; a framework for integrating sustainability into transport plans. www.transportationcouncil.org/wpcontent/uploads/2011/12/stars-plan-1.0-Introduction.pdf.

UN-DESA. (2015). United nations conference on the human environment (Stockholm Conference). www.sustainabledevelopment.un.org/milestone/humanenvironment.

UN. (1987). Report of the World Commission on Environment and

Development: Our Common Future. . Retrieved from Retrieved from http://www.undocuments.net/our-common-future.pdf

UNEP. (2015). Declaration of the united nations conference on the human environment www.unep.org/documents. multilingual/default.asp?documentid=97articleid=503.

Veeravigrom, M., Muench, S. T., \& Kosonen, H. (2015, 2015). A global framework for sustainable roadway rating systems.

Wang, Y. L., \& Li, S. R. (2006). GREEN BUILDINGS---THE TREND OF SUSTAINABLE CONSTRUCTION. 
WKTV. (2018). NYSDOT give updates on Route 5S construction project. Retrieved from http://www.wktv.com/content/news/New-York-State-Department-of-Transportationgive-updates-on-Route-5S-construction-project-484651321.html

Yin, R. K. (2009). Case study research: Design and Methods. SAGE publications. Thousand oaks.

Yudelson, J. a. M. T. A. (2008). Book Reviews-The Green Building Revolution. Journal of Real Estate Literature 16(2): 253., 16(2), 253.

ZofnassProgram. (2016). Envision Rating System. Retrieved from https://research.gsd.harvard.edu/zofnass/menu/envision/ 